\title{
Response to disturbance and plant-animal interactions of grassland swards for chicken free-range husbandry
}

\author{
Dissertation \\ zur Erlangung des Doktorgrades \\ der Fakultät für Agrarwissenschaften \\ der Georg-August-Universität Göttingen
}

vorgelegt von

Dipl.-Biol. Univ. Laura Breitsameter geboren in München 
D 7

1. Referent: Prof. Dr. Johannes Isselstein

2. Korreferent: Prof. Dr. Christoph Leuschner

Tag der mündlichen Prüfung: 14. Februar 2013 
Dedicated to Rudolf and Marieluise Breitsameter who endowed me with the gift to perceive the beauty and marvel of the world. 
Alles ist still vor dir, du Naher! Rings umher ist Alles still! Auch das Würmchen mit Golde bedeckt, merkt auf! Ist es vielleicht nicht seelenlos? ist es unsterblich?

Friedrich Gottlieb Klopstock

Die Frühlingsfeier (1771) 


\section{Content}

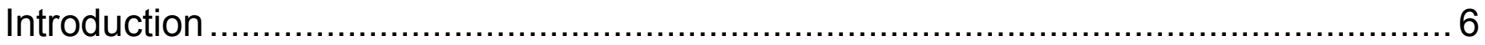

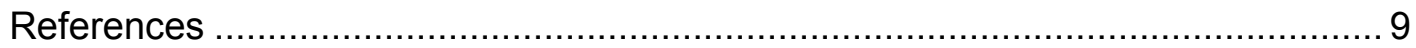

Canopy cover and herbage accumulation of fourteen grassland species when stocked

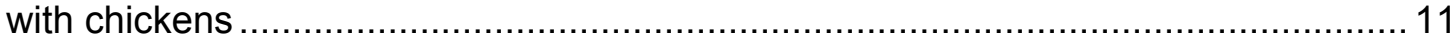

Abstract.

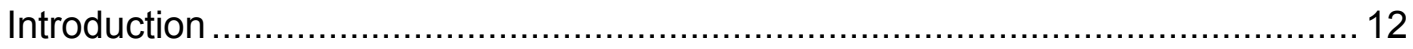

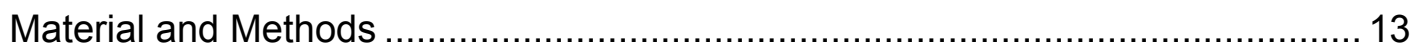

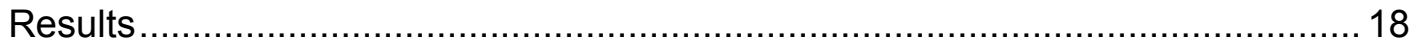

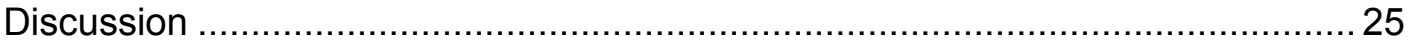

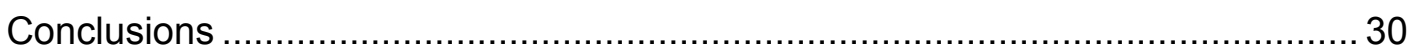

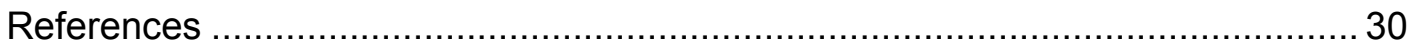

Tolerance to mechanical damage in ten herbaceous grassland plant species ............ 33

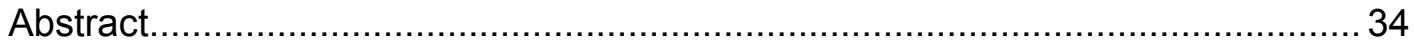

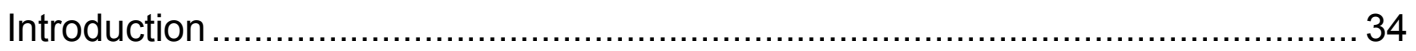

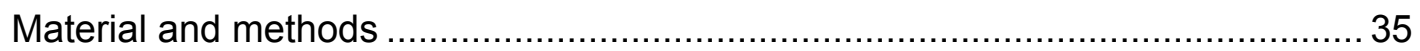

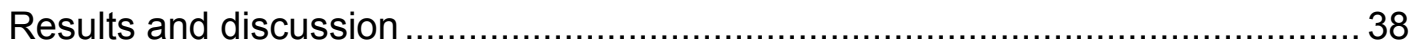

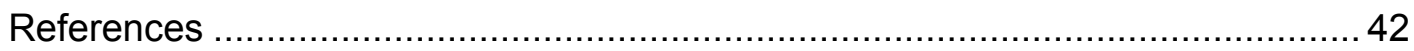

Sward botanical composition and canopy cover affect the foraging behaviour of free-

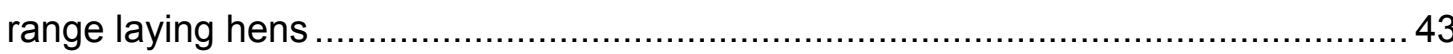

Abstract.

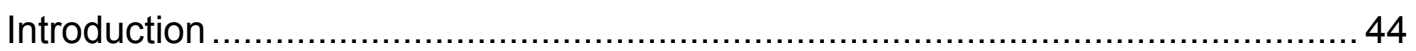

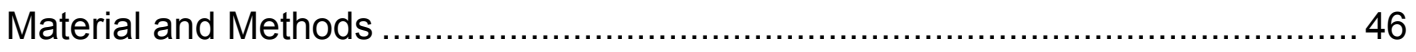

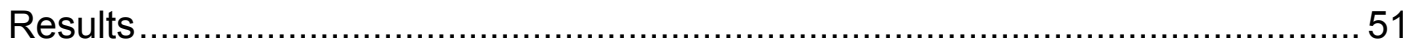

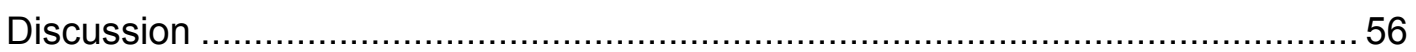

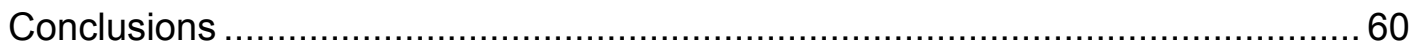

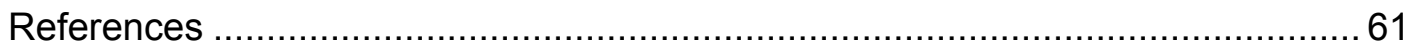

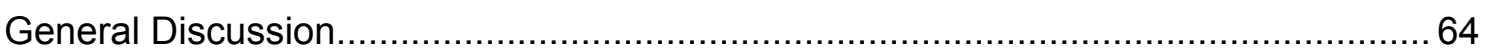

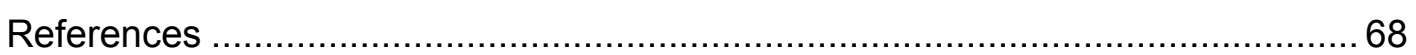

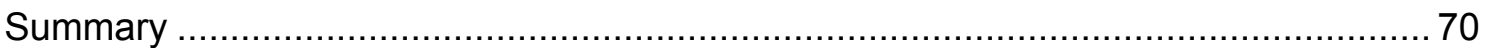

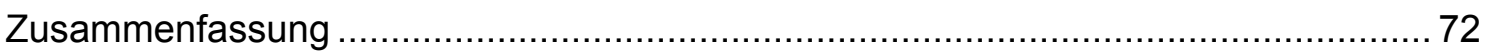

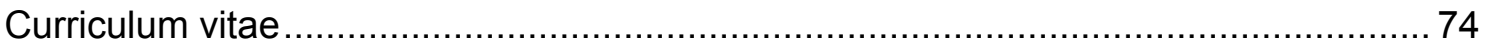

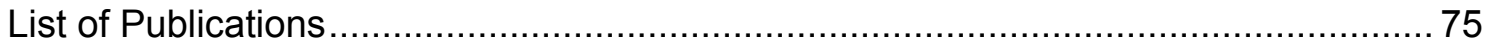

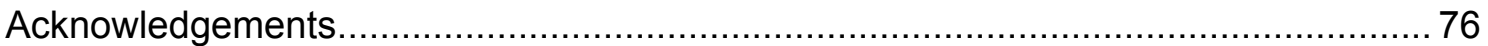

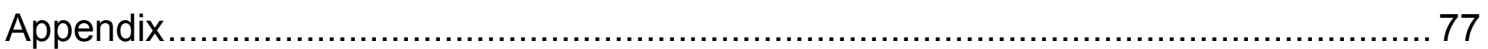


Introduction 
The production of free-range eggs has been rising in the course of the past years (European Commission 2010; Defra 2012; USDA Economic Research Service 2012), as this type of husbandry is perceived by consumers to be beneficial for animal welfare (Satimanon and Weatherspoon 2010; Bejaei et al. 2011). Yet, a number of environmental and animal health issues arise from free-range systems: The soil of the run area is exposed to a considerable input of nitrogen and phosphorus as a result of high amounts of excrement deposition (Kratz 2002; Elbe 2006; Aarnik et al. 2006). Besides, the rates of endoparasite infection are substantial in this type of husbandry system (Permin et al. 1999; Kaufmann et al. 2011).

In order to reduce the negative effects of free-range chicken husbandry, the maintenance of an intact vegetation cover in the run area is of great importance. Soil is less prone to erosion when covered by vegetation; in particular grasses which build a dense root system stabilize soil (Gyssels and Poesen 2003; De Baets et al. 2006). Plants lower the leaching of nutrients; this is particularly the case in species with high biomass accumulation and nitrogen uptake. Moreover, the sward does not only serve these environmental functions, but it also delivers a significant contribution to animal health and welfare. For instance, Shimmura et al. (2008b) have shown a reduction of feather pecking in laying hens which had access to an outdoor run covered with clover. Finally, economic advantages of free-range husbandry arise from the fact that the animals can cover a proportion of their nutritive and energy demand by intake of herbage in the outdoor run (Horsted et al. 2006), and Roth and Böhmer (2008) have recorded an improved laying performance in animals with access to pasture.

However, stocking with chickens imposes a particularly heavy strain on the sward, first and foremost because of scratching. The vegetation cover often gets degraded at stocking densities as low as one animal per $10 \mathrm{~m}^{2}$ (Hörning 2002). Established measures of run management comprise rotational stocking, either by means of mobile fences or hen-houses, or by means of the pop-holes arranged in a way to direct the chickens to different sectors of the run. Still, these measures of run management do not suffice for maintaining an intact vegetation cover at stocking durations of more than a few weeks (Fürmetz et al. 2005).

The aim of the present study was to evaluate a novel agronomic strategy as a complementary measure of run management and as a means of limiting sward degradation in outdoor chicken runs: We presume that the choice of plant species which are particularly tolerant to stocking with chickens can improve the persistence of the range vegetation. This aspect has so far received little consideration. In common practice, as recommendations on suitable plant species are scarce, farmers often utilize highly yielding forage grasses or readily available lawn mixtures for greening chicken runs. Studies evaluating different types of vegetation for chicken runs have as yet focused on structural aspects, namely on the functionality of plants for providing shade and shelter for the animals to make them use the 
range area more evenly (Dawkins et al. 2003), on positive effects of pasture on the quality of poultry products (Lopez-Bote et al. 1998; Ponte et al. 2008), and on the nutritive and metabolizable energy value of herbage (Antell and Ciszuk 2006).

In the frame of the present study, we tested the suitability of fourteen grassland plant species - nine grasses and five forbs - for the establishment of swards for free-range chicken husbandry. In a field experiment, which is presented in Chapter 1 , we evaluated the response of these plants to conditions of stocking with laying hens. We quantified the target parameters herbage accumulation, density of tillers and vegetation growing points, and sward canopy cover in order to analyse the resistance and resilience of the investigated species to stocking with chickens.

Whereas the field experiment focussed on the aboveground parts of the tested plant species, the experiment related in Chapter 2 targeted to study the response to a disturbance acting on the whole plant. A selection of the species investigated in the field experiment was subjected to a standardized damage treatment impacting simultaneously on the shoot as well as on the root. The species were chosen in a way to represent three growth form types of plants (cespitose, stoloniferous, and rhizomatous). The experiment aimed at elucidating determinants of re-growth after a disturbance affecting the whole plant in an undirected way - as it is the case in chicken scratching -, and at answering the question whether plants of different growth forms, and hence with varying biomass allocation pattern and localisation of buds and storage organs, show a different response to disturbance.

For a comprehensive study of the system, the consideration of animal behavioural interactions with the sward is essential. Chapter 3 presents an experiment which analysed the scratching, plant pecking and ground pecking behaviour of laying hens on swards of different plant species composition and of different state of degradation of the vegetation cover. The results of this experiment delivered a further criterion to the evaluation of the tested plants, namely their capacity to contribute to animal welfare. A run cover which incites a high frequency of foraging behavioural interactions with the sward potentially benefit animal welfare, because object-directed pecking can reduce the incidence of injurious and feather pecking (Huber-Eicher and Wechsler 1998; Shimmura et al. 2008a).

Based on the results of these three experiments, we aimed at making a differentiated evaluation of the suitability of the tested plant species for greening chicken outdoor runs. This approach allowed taking account of several of the multiple functions the sward serves in free-range husbandry. From the insights into the chicken pasture system thus gained, we finally attempted to deduce advice for practical application. 


\section{References}

Aarnink A.J.A., J.M.G. Hol, and A.G.C. Beurskens (2006) Ammonia emission and nutrient load in outdoor runs of laying hens. Netherlands Journal of Agricultural Science Wageningen Journal of Life Sciences 54: 223-234.

Antell S., and P. Ciszuk (2006) Forage consumption of laying hens - the crop content as an indicator of feed intake and AME content of ingested forage. Archiv für Geflügelkunde 70: 154-160.

Bejaei M., K. Wiseman, and K.M. Cheng (2011) Influences of demographic characteristics, attitudes, and preferences of consumers on table egg consumption in British Columbia, Canada. Poultry Science 90: 1088-1095.

Dawkins M.S., P.A. Cook, M.J. Whittingham, K.A. Mansell, and A.E. Harper (2003) What makes free-range broiler chickens range? In situ measurement of habitat preference. Animal Behaviour 66: 151-160.

De Baets S., J. Poesen, G. Gyssels, and A. Knapen. 2006. Effects of grass roots on the erodibility of topsoils during concentrated flow. Geomorphology 76: 54-67.

Department for Environment, Food and Rural Affairs (Defra) (2012) Joint announcement of the agricultural departments of the United Kingdom: Eggs. http://www.defra.gov.uk/statistics/foodfarm/food/eggs/ accessed July 16, 2012.

Elbe U. (2006) Freilandhaltung von Legehennen unter besonderer Berücksichtigung der Auslaufnutzung, des Stickstoff- und Phosphoreintrags in den Boden und des Nitrateintrags in das Grundwasser. Sierke. Göttingen.

European Commission. Directorate-General for Agriculture and Rural Development (2010) An analysis of the EU organic sector. Internet document. http://ec.europa.eu/agriculture/analysis/markets/organic_2010_en.pdf. Accessed July 16, 2012.

Fürmetz A., C. Keppler, U. Knierim, F. Deerberg, and J. Heß (2005) Legehennen in einem mobilen Stallsystem - Auslaufnutzung und Flächenzustand - [Laying hens in a mobile housing system - Use and condition of the free-range area]. In: Heß J., and G. Rahmann, editors, Ende der Nische, Beiträge zur 8. Wissenschaftstagung Ökologischer Landbau, Kassel University Press, Kassel, pp. 313-314.

Gyssels G., and J. Poesen (2003) The importance of plant root characteristics in controlling concentrated flow erosion rates. Earth Surface Processes and Landforms 28: 371-384.

Hörning B. (2002) Auslaufhaltung von Legehennen. Kuratorium für Technik und Bauwesen in der Landwirtschaft, Darmstadt, Germany.

Horsted K., M. Hammershøj, and J.E. Hermansen (2006) Short-term effects on productivity and egg quality in nutrient-restricted versus non-restricted organic layers with access to different forage crops. Acta Agriculturae Scandinavica Section A: Animal Science. 56: 42-54.

Huber-Eicher B., and B. Wechsler (1998) The effect of quality and availability of foraging materials on feather pecking in laying hen chicks. Animal Behaviour 55: 861-873.

Kaufmann F., G. Daş, B. Sohnrey, and M. Gauly (2011) Helminth infections in laying hens kept in organic free range systems in Germany. Livestock Science 141: 182-187.

Kratz S. (2002) Nährstoffbilanzen konventioneller und ökologischer Broilerproduktion unter besonderer Berücksichtigung der Belastung von Böden in Grünausläufen. Bundesforschungsanstalt für Landwirtschaft. Braunschweig.

Lopez-Bote C.J., R. Sanz Arias, A.I. Rey, A. Castaño, B. Isabel, and J. Thos (1998) Effect of free-range feeding on $n-3$ fatty acid and $\alpha$-tocopherol content and oxidative stability of eggs. Animal Feed Science and Technology 72: 33-40.

Permin A., M. Bisgaard, F. Frandsen, M. Pearman, J. Kold, and P. Nansen (1999) Prevalence of gastrointestinal helminths in different poultry production systems. British Poultry Science 40: 439-443.

Ponte P.I.P., C.M.C. Rosado, J.P. Crespo, D.G. Crespo, J.L. Mourão, M.A. Chaveiro-Soares, J.L.A. Brás, I. Mendes, L.T. Gama, J.A.M. Prates, L.M.A. Ferreira, and C.M.G.A. Fontes 
(2008) Pasture intake improves the performance and meat sensory attributes of freerange broilers. Poultry Science 87: 71-79.

Roth F. X., and B.M. Böhmer (2008) Feeding strategies for laying hens in housing systems with open-air runs according to organic farming principles. Archiv für Geflügelkunde 72: 121-128.

Satimanon T., and D.D. Weatherspoon (2010) Hedonic analysis of sustainable food products. IFAMR 13: $57-74$.

Shimmura T., T. Suzuki, T. Azuma, S. Hirahara, Y. Eguchi, K. Uetake, and T. Tanaka (2008a) Form but not frequency of beak use by hens is changed by housing system. Applied Animal Behaviour Science 115: 44-54.

Shimmura T., T. Suzuki, S. Hirahara, Y. Eguchi, and T. Tanaka (2008b) Pecking behaviour of laying hens in single-tiered aviaries with and without outdoor area. British Poultry Science 49: 396-401.

United States Department of Agriculture (USDA) Economic Research Service (2012) Organic Production. http://www.ers.usda.gov/data-products/organic-production.aspx accessed July 162012. 
Chapter 1

Canopy cover and herbage accumulation of fourteen grassland species when stocked with chickens 


\section{Abstract}

Maintaining an intact vegetation in the outdoor run of chickens (Gallus gallus domesticus) can be difficult due to the intense stresses such as defoliation and concentrated manure. The aim of this study was to determine the extent to which damage-tolerant plant species can improve canopy cover. In a two-year field experiment, we subjected 14 disturbance-tolerant grassland plant species (nine grasses and five forbs) to stocking with laying hens for short (one day), medium (two days) and long (three days) periods in a rotational stocking system. The species differed strongly in resistance (canopy cover; density of tillers and vegetation growing points) and resilience (biomass accumulation) to stocking. Stocking cycle, but not stocking duration had a significant effect on biomass accumulation and canopy cover in most of the species. Canopy cover decreased with repeated stocking in the majority of the tested species. In most forb species, increasing stocking duration significantly decreased density of vegetation growing points; in most grass species this factor had no significant effect on tiller density. We concluded that grasses are generally more suitable for an outdoor chicken run than forbs. The best performance was recorded in Festuca arundinacea (Schreb.) and Poa supina (Schrad.), with more than $80 \%$ canopy cover, constant tiller density and biomass accumulation of over $4.8 \mathrm{~g}$ dry matter (DM) $\mathrm{m}^{-2} \mathrm{~d}^{-1}$ after repeated three-days stocking. We conclude that use of disturbance-tolerant grassland species will improve swards in outdoor chicken runs.

\section{Introduction}

Production of free-range eggs has been rising in the course of the past years (European Commission 2010; Defra 2012; USDA Economic Research Service 2012), as this type of husbandry is perceived by consumers to be beneficial for animal welfare (Satimanon and Weatherspoon 2010; Bejaei et al. 2011). Yet, it gives rise to a number of issues, among others, considerable N, ammonia and P emissions (Edwards and Daniel 1993; Marshall et al. 1998; Kratz et al. 2004).

An intact vegetation cover is one important measure to reduce nutrient leaching from outdoor chicken runs. However, sward maintenance is difficult, because the growing conditions for plants in chicken pastures are unique and differ notably from other forms of grassland management. The animals' intensive scratching and pecking, which reduces sward height to $1 \mathrm{~cm}$ or less (Bockholt and Dittmann 2007), and the deposition of high amounts of excrement can cause rapid sward degradation. Severe sward damage occurs at stocking rates as low as one chicken per $10 \mathrm{~m}^{2}$ (Hörning 2002; Heckendorn et al. 2009). Established management practices so far do not provide a satisfactory answer to this issue. Furnishing the run area with protective structures can help to encourage chickens to use the 
total range area more evenly and, thus, to relieve the most heavily frequented zone. However, most of the flock usually remains close to the hen house (Dawkins et al. 2003; Hegelund et al. 2006; Zeltner and Hirt 2008). Rotational grazing schemes usually feature rest periods of less than the 12 weeks which Bockholt and Dittmann (2007) have shown to be necessary to revegetate gaps in the sward.

With the present study, we aimed to explore a novel approach to the preservation of vegetation cover in outdoor chicken runs. We suggest that the cultivation of plant species with particularly high tolerance to the stress exerted by chicken stocking may be an effective option in addition to existing measures of range management. So far, recommendations on plant species suitable for outdoor chicken runs are scarce; there are no cultivars explicitly bred for use in chicken pasture, and most farmers chose readily available lawn mixtures or high-yielding species commonly used for cattle pasture.

Grassland species are adapted to frequent disturbance (Cole 1995). Yet, we presume that they differ in their tolerance to chicken grazing, and that grass cultivars bred for sports turfs would generally have the highest potential for use in chicken pasture. We hypothesize that even turf species and cultivars will show a widely varying tolerance to chicken grazing, because the nature of disturbance differs from the wear exerted on the plant in a sports turf. In order to test this hypothesis we assessed the performance of 14 grassland plant species (nine grasses and five forb species) with known high tolerance to wear and intensive management (high grazing pressure, frequent cutting) when stocked with chickens. We selected three parameters to quantify their resistance (canopy cover and density of tillers/vegetation growing points) and resilience (biomass accumulation) to chicken stocking. The aim of this study was to evaluate the suitability of the tested species and cultivars in chicken pasture based on their performance as measured by these parameters.

\section{Material and Methods}

Plant species

Nine species of grasses and five forbs were used for the experiment (Table 1). Species were selected based on their performance in intensively managed grassland systems involving frequent cutting, intensive grazing, and trampling according to indicator values given in Dierschke and Briemle (2002). For turf grasses, cultivars were selected with high tolerance to deep cutting and with high suitability for use as sports turfs as indicated in the descriptive lists of turf grass cultivars (Bundessortenamt 2006). Six of the tested species were locally harvested seed (wild-types) purchased from small-scale seed companies. 
Table 1. Species tested within the present experiment and their tolerance to grassland management practices and to strain exerted by trampling and (in turf grasses) by sports use. If no cultivar information is presented, wild-type seeds purchased from local seed companies were used. Indicator values for cutting, grazing, trampling, and wear tolerance: 1: very low; 9: very high; NA: not available; -: not applicable.

\begin{tabular}{|c|c|c|c|c|}
\hline \multirow[b]{2}{*}{ Species } & \multicolumn{4}{|c|}{ Indicator values for } \\
\hline & $\begin{array}{l}\text { Cutting } \\
\text { tolerance }\end{array}$ & $\begin{array}{l}\text { Grazing } \\
\text { tolerance }\end{array}$ & $\begin{array}{l}\text { Trampling } \\
\text { tolerance† }\end{array}$ & $\begin{array}{c}\text { Turf } \\
\text { cultivars: } \\
\text { wear } \\
\text { tolerance }\end{array}$ \\
\hline \multicolumn{5}{|l|}{ Grasses } \\
\hline Agrostis stolonifera (L.) 'Barifera' & 9 & 9 & 9 & 7 \\
\hline Deschampsia cespitosa (L.) wild-type & 5 & 7 & 4 & - \\
\hline Elymus repens (L.) wild-type & 7 & 5 & 7 & - \\
\hline Festuca arundinacea (Schreb.) 'Mustang' & 7 & 6 & 7 & 7 \\
\hline Festuca rubra rubra (L.) 'Rossinante' & 9 & 7 & 6 & 7 \\
\hline $\begin{array}{l}\text { Festuca trichophylla (Ducros ex Gaudin) } \\
\text { 'Barcrown' }\end{array}$ & 9 & 7 & 6 & 8 \\
\hline Lolium perenne (L.) 'Bargold' & 8 & 8 & 8 & 9 \\
\hline Poa pratensis (L.) 'Julius' & 9 & 8 & 8 & 8 \\
\hline Poa supina (Schrad.) 'Supreme’ & NA & NA & NA & 9 \\
\hline \multicolumn{5}{|l|}{ Forbs } \\
\hline Achillea millefolium (L.) wild-type & 7 & 4 & 5 & - \\
\hline Plantago major (L.) wild-type & 5 & 9 & 9 & - \\
\hline Ranunculus repens (L.) wild-type & 8 & 7 & 7 & - \\
\hline Taraxacum officinale agg. Wild-type & 8 & 7 & 7 & - \\
\hline Trifolium repens (L.) 'Rivendel' & 8 & 8 & 8 & - \\
\hline
\end{tabular}

† Dierschke and Briemle 2002.

‡ Bundessortenamt 2006.

\section{Experimental design}

The study was conducted in 2009 and 2010, on the experimental site of the Department of Crop Sciences of Göttingen University, Göttingen, Lower Saxony, Germany (51 $32^{\prime}$ 51" $^{\prime \prime}$ North, $9^{\circ} 56^{\prime} 47^{\prime \prime}$ East). The experiment comprised a total of 45 plots with three replications of 15 plots arranged in randomized blocks. The plots were established on a field soil with the top $50 \mathrm{~cm}$ being silty clay with $\mathrm{pH} 6.7$ in block 1 and 2 and $\mathrm{pH} 7.3$ in block 3 , and $\mathrm{P}, \mathrm{K}$, and $\mathrm{Mg}$ of 14,11 , and $11 \mathrm{mg} / 100 \mathrm{~g}$ dry soil, respectively, in all of the blocks (sampled at 0 to 20 $\mathrm{cm}$ depth; $\mathrm{P}$ and $\mathrm{K}$ extracted in 1:20 soil to calcium acetate lactate; and $\mathrm{Mg}$ extracted in 1:10 soil to $0.0125 \mathrm{M} \mathrm{CaCl}_{2}$ ). Temperature and precipitation for the vegetation periods of the two years are shown in Figure 1. The species were established in August 2008 as monocultures and one mixture comprising all 14 species on plots of $2 \times 4 \mathrm{~m}$. In the monocultures, grasses were sown at a rate of 10,000 seeds $\mathrm{m}^{-2}$, forbs at 2000 seeds $\mathrm{m}^{-2}$. As A. millefolium, P. major and $R$. repens showed poor germination on the monoculture plots, these plots were re-sown 
at the initial seed rates in April 2009, and, in order to allow establishment of the respective swards, stocking did not start before mid-July 2009. In the mixture, the seed rate of each species was $1 / 14$ that of the monocultures. When stocking started, the sward of the mixed plot comprised large proportions of yield of L. perenne (approx. $50 \%$ ), F. rubra, and F. trichophylla (together approx. $30 \%$ ); F. arundinacea (<10\%), A. stolonifera, P. pratensis, T. officinale, A. millefolium, and T. repens ( $<5 \%$ ) were minor constituents of the sward; the other species occurred as individual specimens. Monocultures were maintained by manual weeding, and species not investigated in this experiment were removed from the mixed plot. All plots were split into four subplots of $2 \times 1 \mathrm{~m}$ which were exposed to stocking with four laying hens $\mathrm{m}^{-2}$ in a rotational grazing scheme for different levels of stocking duration and over two vegetation periods. The levels of stocking duration were: $5 \mathrm{~h} \mathrm{day}^{-1}$ for one (short), two (medium), and three (long) consecutive days; the control subplots were not stocked. Chickens were on the plots from 8:00 to 13:00 each day. This grazing scheme was chosen in order to assure a controlled application of the treatment, namely i) chickens have a varying activity pattern during the course of the day with one of the activity peaks being in the morning (Mahboub et al. 2004, Hegelund et al. 2005), and ii) as the chickens obtain $<10 \%$ of their energy requirement from pasture (Antell and Ciszuk 2006), a period of stay on pasture exceeding $5 \mathrm{~h}$ would have necessitated the provision of additional fodder to the animals which would have caused confounding effects, e.g. increased scratching in search of food pellets. The chosen approach allowed a precise study of the impact of distinct levels of disturbance on the individual plant species, as the chosen levels of stocking duration resulted in a graduated deterioration of the sward. The chickens used for the experiment were layers of the genotype ISA Warren aged 18 weeks at the beginning of the stocking period. In order to obtain a standardized stocking density, four chickens each were set into a cage of $80 \mathrm{x}$ $125 \times 50 \mathrm{~cm}$ on the respective subplots for the given periods. When on pasture, the chickens were kept in groups of the same four individuals throughout the year in order to minimize hierarchy encounters. For each block, all subplots of the same level of stocking duration were stocked simultaneously; subplots of different levels of stocking duration within each block were stocked successively; blocks were stocked successively in a constant order in a rotational scheme with rest periods of $27 \pm 3 \mathrm{~d}$. The plots were stocked in two cycles from late July to mid-September in 2009, and in four cycles of the same length from late May to midSeptember in 2010. Each year before the start of the stocking period, the plots were fertilized with guano and rockdust (Guano plus Gesteinsmehl, 11/6/4 + 3 N/P/K + Mg, COMPO, Münster, Germany). In 2009, $255 \mathrm{~g}$ fertilizer were applied per plot, in $2010510 \mathrm{~g}$ were applied. During the rest period of each grazing cycle, the plots were mown to $7 \mathrm{~cm}$ stubble height one week before re-stocking in order to create similar conditions of sward height, and cuttings were removed to prevent grass impaction (Christensen 1998). Additionally, the plots 
were also mown regularly when not grazed in order to maintain a dense sward: In both years, the plots were mown once post-stocking (three weeks after release from stocking) and four times (2009) or twice (2010) pre-stocking, the last cut pre-stocking in both years being $10 \mathrm{~d}$ prior to the start of grazing. In July and August 2009 and from mid-June to late September 2010, the plots were irrigated regularly with a lawn sprinkler.

When not on pasture, the chickens were kept in a roofed pen equipped with nests and perches and with sand as ground cover, and were supplied ad libitum with feed (layer pellets, Reudink Biologische Voeders B.V, Boxmeer, The Netherlands).
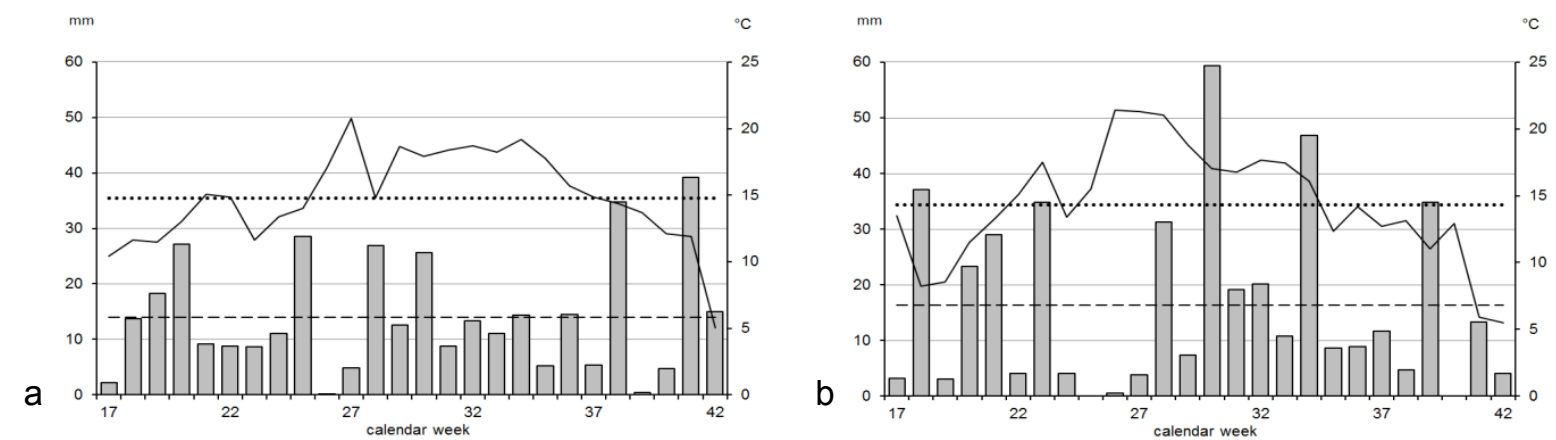

Figure 1 Weekly sum of precipitation (bars) and weekly mean air temperature (solid line) for weeks 17 to 42 , overall mean temperature (dotted line), and mean precipitation (broken line) for weeks 17 to 42 of the years 2009 (a) and 2010 (b).

\section{Sampling}

Canopy cover, density of tillers/vegetation growing points, and biomass accumulation were measured to assess the performance of the species under conditions of stocking with chickens.

Biomass accumulation was calculated from consecutive measurements of dry herbage mass within each rest period. Herbage mass was derived from compressed sward height values obtained using a rising plate meter (Castle 1976); the measured compressed sward height was converted into biomass values by means of species-specific functions which were calibrated using a double sampling procedure as described in Correll et al. (2003). Measurements of compressed sward height were made in both years in 3- to 7-d intervals during the rest period between each stocking cycle, and post-stocking after the release from the last stocking cycle in each year, as well as during $10 \mathrm{~d}$ immediately before the first stocking in 2010 at six locations within each subplot and at similar positions on the control subplot.

Tiller density in grasses and density of vegetation growing points in forbs were quantified by manual counts in the monoculture swards. Measurements were made once, three weeks 
after the last stocking in 2010. Hence, for this parameter the total effect of both years of stocking, not the effect of individual stocking cycles, was analysed. Quadrats of $10 \times 10 \mathrm{~cm}$ were sampled at two random locations within each subplot: one in the inner and one in the outer half of each subplot and at similar positions on the untreated control. The average value of the two sampled spots per subplot - being sub-samples - was used for further statistical analysis, because we did not consider intra-subplot heterogeneity of density of tillers/vegetation growing points. The numbers of tillers and vegetation growing points of individual species were not measured from the mixed sward, because we did not aim at identifying the effect of stocking on the abundance of species, and because intra-sward heterogeneity can confound measurement at the small scale applied here.

Canopy cover (percentage cover of green leaf area) was determined by digital photograph analysis, a method which has been shown to achieve high accuracy (e.g. Richardson et al. 2001). Photographs of each subplot were taken immediately pre-stocking with a digital camera (NV10, Samsung Electronics, NJ, USA) at a resolution of 1 megapixel. Four pictures of each subplot were taken. In order to ensure coverage of the complete pastured area a wood frame of $80 \times 125 \mathrm{~cm}$ with two bars crossing at the centre to form four rectangles of equal size was positioned on the grazed surface, and one photograph each was taken by holding the camera at a constant height above the centre of the rectangles. In order to obtain photographs at comparable illumination conditions, the pictures were taken during periods of clouded sky or the subplots were shaded with a portable plastic foil. Two pictures per subplot were used for further analysis. To determine canopy cover the pictures were digitally processed as follows: They were first colour-transformed using image processing software (GIMP 2, GNU Image Manipulation Program, The GIMP Development Team) by first maximizing RGB, subsequently maximizing the hue, saturation and lightness values of the colours red, blue and green, and finally maximizing the contrast of the image. The images thus transformed were analyzed using the software imageJ version $1.44 p$ (National Institutes of Health, Bethesda, MD, USA): the color channels were split and the area fraction of green pixels was determined by applying the 'analyze particle' function to the green channel slice. The average canopy cover values of the two pictures per subplot were used for further statistical analysis, because we did not consider intra-subplot heterogeneity of canopy cover.

Statistical analysis

All data were checked graphically for normal distribution and homogeneity of variance. Because of heterogeneous variance, a boxcox function (package MASS) was run for data on biomass accumulation and tiller numbers in order to determine the appropriate transformation (Box and Cox 1964; Venables and Ripley 2002). Data on density of tillers and vegetation growing points, and biomass accumulation were square root transformed; data on 
canopy cover, being percentage values, were arcsine-square root transformed. The effect of the factors plant species and stocking duration, and of their interactions on density of tillers and vegetation growing points in monoculture swards was determined by calculating a twoway split-plot analysis of variance (ANOVA). Significant intra-specific differences in means between treatments were identified applying Tukey's HSD test (95\% confidence level). For biomass accumulation and for canopy cover, initial measurements made before the first stocking in 2010 were analyzed using one-way ANOVA (stocking duration as explanatory factor) in order to test whether intra-specific differences in means among sub-plots existed as a result of stocking in 2009. As no such differences were identified in any of the species, a three-way repeated measurements split-plot ANOVA was calculated to identify the effect of the factors species, stocking duration and stocking cycle separately for each year; in addition, a two-way split-plot ANOVA was calculated for data of the individual species and years in order to elucidate species-specific significance of the factors stocking duration and stocking cycle. All data analysis was performed using the software $\mathrm{R}(\mathrm{R}$ Development Core Team 2011).

\section{Results}

Biomass accumulation

Results of three-way ANOVA showed that the factors species $(P<0.001$ in both years), stocking duration, and stocking cycle $(P<0.01$ in 2009 and $P<0.001$ in 2010 for both factors) had a significant effect on growth rates of aboveground biomass. The interaction of the factors species and stocking cycle was significant $(P<0.001)$ in both years, the interactions of species and stocking duration was significant in $2010(P<0.001)$, but not in 2009 (Table 2).

Two-way ANOVA revealed that the factors stocking duration and stocking cycle had a different effect on biomass accumulation in the individual species and years. In 2009, the effect of stocking duration was significant $(P<0.05)$ only in $P$. supina; in 2010 , it was significant in E. repens, F. arundinacea and T. repens $(P<0.05)$. Stocking cycle had significant $(P<0.01)$ effect on biomass accumulation of $A$. millefolium and $T$. officinale in 2009; in 2010, this effect was significant for all species except $A$. stolonifera, $F$. arundinacea, $P$. supina and $A$. millefolium. The interaction of the factors stocking duration and stocking cycle was only significant for biomass growth rates in $L$. perenne in $2010(P<0.05)$.

Biomass accumulation of the grazed sub-plots was higher than for the controls after several stocking cycles (Table 3). In the rest period of the third stocking cycle in 2010 , in most of the grass species it was significantly higher than in the controls; exceptions were E. repens and F. rubra. In the latter species, this was a non-significant trend; in the former 
species, biomass growth rate at long stocking was significantly lower than at short stocking from the second cycle on. In most of the forb species growth rates did not differ significantly among treatments at any time of measurement. An exception was $T$. repens, where growth rates at medium or long stocking had a strong tendency to be lower than in the other treatments; they were significantly lower than those of the control in the second cycle in 2009 and significantly lower than those at the short stocking in the third cycle in 2010. With later time in the year, biomass accumulation of all species decreased irrespective of stocking duration. After four stocking cycles at long stocking duration in 2010, F. arundinacea and $P$. supina had the highest biomass growth rates compared to the other species $(5.07$, and $4.82 \mathrm{~g} \mathrm{DM} \mathrm{m}^{-2} \mathrm{~d}^{-1}$, respectively) (Table 3).

Table 2. Results of three-way split-plot ANOVA [degrees of freedom (df); $n=3$ ] showing the effect of the factors plant species (14 monocultures, one mixture comprising all 14 species), duration of stocking with chickens (short, medium, long) and stocking cycle, and of their interactions on biomass accumulation of the grazed sub-plots immediately post-stocking and on canopy cover after rest periods of four weeks in 2009 (two stocking cycles) and in 2010 (four cycles). ${ }^{* *}$ : $P<0.001$; ${ }^{* *}$ : $0.001<P<0.01$; ns: not significant $(0.05)$.

\begin{tabular}{|c|c|c|c|c|c|c|c|c|}
\hline \multirow{3}{*}{ Source of variation } & \multicolumn{4}{|c|}{ Biomass accumulation } & \multicolumn{4}{|c|}{ Canopy cover } \\
\hline & \multicolumn{2}{|c|}{2009} & \multicolumn{2}{|c|}{2010} & \multicolumn{2}{|c|}{2009} & \multicolumn{2}{|c|}{2010} \\
\hline & $\mathrm{Df}$ & & df & & df & & $\mathrm{df}$ & \\
\hline Species (S) & 14 & $* * *$ & 14 & $* * *$ & 14 & $* * *$ & 14 & $* * *$ \\
\hline Stocking duration (D) & 2 & ** & 2 & $* * *$ & 2 & $* * *$ & 2 & ** \\
\hline Stocking cycle (C) & 1 & $* *$ & 3 & $* * *$ & 1 & ns & 3 & $* * *$ \\
\hline$S \times D$ & 28 & ns & 28 & $* * *$ & 28 & $* * *$ & 28 & $* * *$ \\
\hline$S \times C$ & 14 & $* * *$ & 42 & $* * *$ & 14 & $* * *$ & 42 & $* * *$ \\
\hline$D \times C$ & 2 & ns & 6 & ns & 2 & ns & 6 & ns \\
\hline$S \times D \times C$ & 28 & ns & 84 & ns & 28 & ns & 84 & ns \\
\hline
\end{tabular}

Density of tillers and vegetation growing points

Strong inter-specific differences in density of tillers and vegetation points were evident irrespective of stocking duration (Table 4). In grasses, mean tiller numbers per $100 \mathrm{~cm}^{2}$ were above 100 in most species, and reached values between 300 and up to 600 for A. stolonifera, F. rubra and F. trichophylla. Stocking duration did not have a significant negative effect on tiller density in grasses except for E. repens. In A. stolonifera, L. perenne and $D$. cespitosa, a clear trend of decreasing tiller density with increasing stocking duration 
was observable. In forbs, mean density of vegetation growing points was below 40 per 100 $\mathrm{cm}^{2}$ in all of the species. In $R$. repens and $T$. repens, density of vegetation growing points was significantly lower at long stocking in comparison to the ungrazed control; in T. officinale, the density of vegetation growing points at the medium stocking duration was significantly reduced in comparison to the ungrazed control (Table 4).

\section{Canopy cover}

Results of three-way ANOVA showed that the factors species and stocking duration, their interaction, and the interaction of species and stocking cycle had a significant $(P<0.001)$ effect on canopy cover. The effect of stocking cycle was significant $(P<0.001)$ in 2010 only. The interactions of the factors stocking duration and stocking cycle, and the three-way interaction were not significant for explaining canopy cover (Table 2).

Two-way ANOVA revealed that the effect of the factors stocking duration and stocking cycle, and of their interaction was of varying significance for canopy cover in the individual species. In 2009, stocking duration had a significant effect in A. stolonifera, E. repens and P. major; in 2010, it was significant in D. cespitosa, E. repens, and P. major. Stocking cycle had a significant effect on canopy cover in 2009 in A. stolonifera, D. cespitosa, F. arundinacea, L. perenne, and T. officinale; in 2010 it was significant in all species except from F. arundinacea, F. rubra, and P. pratensis. The interaction of stocking duration and stocking cycle did not have a significant effect on canopy cover in any of the species neither in 2009 nor in 2010.

Canopy cover decreased with repeated stocking most of the investigated species (Table 5). Plantago major and E. repens did not feature a completely closed canopy at any point in time during the experiment which was in the first place due to poor germination. Compared to the other species, after four stocking cycles at the long stocking duration in 2010 F. arundinacea had the highest canopy cover (94.9\%); F. trichophylla, P. supina and the mixed seed plot also reached mean values of over $80 \%$; T. repens, in contrast, showed a mean canopy cover of only $36 \%$. 
Table 3. Mean $(n=3)$ biomass accumulation [g dry matter (DM) per $\mathrm{m}^{2}$ and day, untransformed values] of the sub-plots stocked with laying hens at three levels of stocking duration (short, medium, long) and of the ungrazed control for each of the two stocking cycles in 2009, and each of the four cycles in 2010. For each species, within columns, means followed by the same superscript letter are not significantly different according to Tukey's HSD post-hoc test (0.05).

\begin{tabular}{|c|c|c|c|c|c|c|c|}
\hline \multirow[t]{4}{*}{ Species } & \multirow{4}{*}{$\begin{array}{l}\text { Stocking } \\
\text { duration }\end{array}$} & \multicolumn{6}{|c|}{ Stocking cycle } \\
\hline & & \multicolumn{2}{|c|}{2009} & \multicolumn{4}{|c|}{2010} \\
\hline & & 1 & 2 & 1 & 2 & 3 & 4 \\
\hline & & \multicolumn{6}{|c|}{ 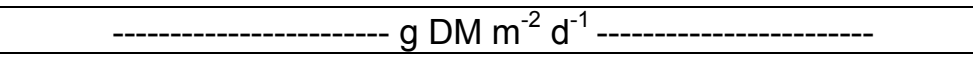 } \\
\hline \multirow{4}{*}{ A. stolonifera } & Short & 6.71 & $5.40^{\mathrm{ab}}$ & 6.95 & 4.44 & $3.51^{\mathrm{ab}}$ & 375 \\
\hline & Medium & 9.34 & $6.97^{\mathrm{ab}}$ & 7.39 & $\begin{array}{l}4.44 \\
2.31\end{array}$ & $4.97^{\mathrm{b}}$ & 5.22 \\
\hline & Long & 7.73 & $8.53^{\mathrm{b}}$ & 6.14 & 3.09 & $6.31^{\mathrm{b}}$ & 2.85 \\
\hline & Control & NA & $2.51^{a}$ & 9.30 & 1.63 & $1.21^{\mathrm{a}}$ & 1.97 \\
\hline \multicolumn{8}{|l|}{ D. cespitosa } \\
\hline & Short & 3.12 & 3.07 & 6.60 & 5.02 & $3.82^{\mathrm{b}}$ & 2.53 \\
\hline & Medium & 4.40 & 4.32 & 6.37 & 5.37 & $3.62^{b}$ & 1.78 \\
\hline & Long & 4.48 & 4.39 & 6.22 & 3.72 & $3.71^{\mathrm{b}}$ & 1.12 \\
\hline & Control & NA & 1.97 & 6.29 & 2.12 & $0.68^{\mathrm{a}}$ & 0.73 \\
\hline \multicolumn{8}{|l|}{ E. repens } \\
\hline & Short & 7.81 & 7.17 & 2.53 & $2.28^{\mathrm{b}}$ & $2.11^{\mathrm{b}}$ & $1.36^{\mathrm{b}}$ \\
\hline & Medium & 10.49 & 9.98 & 1.93 & $0.39^{\mathrm{a}}$ & $1.26^{\mathrm{b}}$ & $0.17^{\mathrm{ab}}$ \\
\hline & Long & 7.10 & 8.63 & 0.60 & $0^{\mathrm{a}}$ & $0^{a}$ & $0.00^{\mathrm{a}}$ \\
\hline & Control & NA & 8.71 & 2.58 & $1.76^{\mathrm{b}}$ & $1.19^{b}$ & $0.37^{\mathrm{ab}}$ \\
\hline \multicolumn{8}{|l|}{ F. arundinacea } \\
\hline & Short & 2.73 & 2.41 & 4.11 & 2.57 & $3.31^{\mathrm{b}}$ & 3.92 \\
\hline & Medium & 3.35 & 3.41 & 5.23 & 3.08 & $5.55^{\mathrm{b}}$ & 5.34 \\
\hline & Long & 4.17 & 3.80 & 5.45 & 3.32 & $5.60^{\mathrm{b}}$ & 5.07 \\
\hline & Control & NA & 0.90 & 4.00 & 3.06 & $0.52^{\mathrm{a}}$ & 2.25 \\
\hline \multicolumn{8}{|l|}{ F. rubra } \\
\hline & Short & 8.45 & 7.31 & 6.08 & 1.67 & 3.82 & 3.45 \\
\hline & Medium & 8.02 & 7.57 & 6.95 & 5.54 & 4.56 & 2.76 \\
\hline & Long & 8.46 & 7.35 & 6.88 & 2.43 & 3.69 & 2.29 \\
\hline & Control & NA & 3.81 & 5.48 & 2.64 & 1.19 & 2.61 \\
\hline \multicolumn{8}{|l|}{ F. trichophylla } \\
\hline 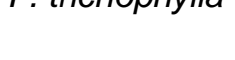 & Short & 7.07 & 9.00 & 4.27 & 1.86 & $4.01^{b}$ & $3.82^{\mathrm{b}}$ \\
\hline & Medium & 11.22 & 8.69 & 3.39 & 3.21 & $4.10^{\mathrm{b}}$ & $3.39^{b}$ \\
\hline & Long & 6.45 & 10.21 & 4.77 & 1.47 & $4.53^{b}$ & $2.58^{\mathrm{b}}$ \\
\hline & Control & NA & 6.54 & 4.39 & 0.99 & $0.39^{a}$ & $0.32^{\mathrm{a}}$ \\
\hline \multicolumn{8}{|l|}{ L. perenne } \\
\hline & Short & 2.21 & 3.39 & 5.20 & 2.02 & $3.27^{\mathrm{b}}$ & 3.16 \\
\hline & Medium & 4.35 & 4.27 & 6.45 & 3.86 & $4.16^{\mathrm{b}}$ & 1.70 \\
\hline & Long & 2.66 & 4.07 & 5.66 & 3.14 & $5.02^{\mathrm{b}}$ & 0.44 \\
\hline & Control & NA & 1.79 & 4.43 & 0.76 & $1.19^{\mathrm{a}}$ & 1.56 \\
\hline \multicolumn{8}{|l|}{ P. pratensis } \\
\hline & Short & 5.68 & 7.49 & 6.62 & 3.45 & $2.14^{\mathrm{ab}}$ & 3.43 \\
\hline & Medium & 6.56 & 9.84 & 8.78 & 4.72 & $4.71^{\mathrm{bc}}$ & 3.90 \\
\hline & Long & 5.26 & 6.67 & 6.40 & 3.24 & $5.63^{c}$ & 3.75 \\
\hline & Control & NA & 3.07 & 8.09 & 2.82 & $1.14^{\mathrm{a}}$ & 2.16 \\
\hline \multicolumn{8}{|l|}{ P. supina } \\
\hline & Short & 1.28 & 3.09 & 5.20 & 6.32 & $3.77^{\mathrm{ab}}$ & 5.01 \\
\hline & Medium & 3.26 & 3.70 & 5.93 & 3.17 & $6.77^{\mathrm{c}}$ & 5.86 \\
\hline & Long & 2.14 & 2.97 & 4.99 & 3.56 & $5.01^{b c}$ & 4.82 \\
\hline & Control & NA & 1.18 & 5.06 & 1.24 & $2.23^{\mathrm{a}}$ & 3.19 \\
\hline
\end{tabular}


(Continuation of previous page)

\begin{tabular}{|c|c|c|c|c|c|c|c|}
\hline \multirow[t]{4}{*}{ Species } & \multirow{4}{*}{$\begin{array}{l}\text { Stocking } \\
\text { duration }\end{array}$} & \multicolumn{6}{|c|}{ Stocking cycle } \\
\hline & & \multicolumn{2}{|c|}{2009} & \multicolumn{4}{|c|}{2010} \\
\hline & & 1 & 2 & 1 & 2 & 3 & 4 \\
\hline & & \multicolumn{6}{|c|}{ - } \\
\hline \multirow{5}{*}{ A. millefolium } & & & & & & & \\
\hline & Short & 6.83 & 1.12 & 3.63 & 5.63 & 4.14 & 0.98 \\
\hline & Medium & 12.04 & 1.71 & 2.93 & 3.81 & 4.02 & 1.96 \\
\hline & Long & 7.46 & 0.88 & 3.20 & 3.85 & 3.12 & 0.78 \\
\hline & Control & NA & 0.69 & 2.01 & 5.76 & 2.55 & 0.88 \\
\hline \multicolumn{8}{|l|}{ P. major } \\
\hline & Short & 6.05 & 1.17 & 1.70 & 1.41 & 3.23 & 1.18 \\
\hline & Medium & 4.10 & 0.81 & 0.21 & 1.69 & 1.90 & 1.20 \\
\hline & Long & 3.21 & 0.37 & 1.71 & 0.01 & 1.64 & 0.74 \\
\hline & Control & NA & 0.24 & 1.12 & 2.30 & 2.07 & 0.97 \\
\hline \multicolumn{8}{|l|}{ R. repens } \\
\hline & Short & 2.49 & 0.69 & 4.83 & 1.51 & 4.28 & 1.99 \\
\hline & Medium & 3.90 & 0.58 & 3.07 & 0.71 & 5.97 & 1.93 \\
\hline & Long & 1.02 & 0.63 & 1.88 & 0.34 & 3.04 & 1.59 \\
\hline & Control & NA & 0.55 & 4.72 & 1.45 & 1.23 & 1.39 \\
\hline \multicolumn{8}{|l|}{ T. officinale } \\
\hline & Short & 14.96 & 7.18 & 9.44 & $3.65^{\mathrm{ab}}$ & 5.70 & 1.60 \\
\hline & Medium & 14.29 & 7.09 & 8.12 & $6.16^{\mathrm{b}}$ & 6.25 & 2.41 \\
\hline & Long & 18.54 & 4.47 & 9.76 & $5.01^{\mathrm{ab}}$ & 6.77 & 1.95 \\
\hline & Control & NA & 5.51 & 7.40 & $1.29^{\mathrm{a}}$ & 3.29 & 2.51 \\
\hline \multicolumn{8}{|l|}{ T. repens } \\
\hline & $\begin{array}{l}\text { Short } \\
\text { Medium }\end{array}$ & $\begin{array}{c}2.91 \\
1411\end{array}$ & $\begin{array}{l}3.79^{\mathrm{ab}} \\
152^{\mathrm{a}}\end{array}$ & 9.93 & 4.04 & $5.32^{b}$ & 2.14 \\
\hline & Medium & 14.11 & $1.52^{\mathrm{a}}$ & 5.54 & 3.31 & $3.42^{\mathrm{ab}}$ & 0.67 \\
\hline & Long & 7.04 & $1.52^{\mathrm{ab}}$ & 2.13 & 0.22 & $0.39^{a}$ & 0.48 \\
\hline & Control & NA & $6.09^{b}$ & 6.68 & 3.15 & $3.44^{\mathrm{ab}}$ & 2.74 \\
\hline \multicolumn{8}{|l|}{ Mixed seed } \\
\hline & Short & 6.01 & 4.91 & 7.42 & 4.12 & 5.61 & 3.88 \\
\hline & Medium & 9.59 & 5.26 & 7.02 & 2.60 & 6.31 & 3.23 \\
\hline & Long & 4.82 & 5.22 & 7.02 & 2.66 & 5.79 & 3.61 \\
\hline & Control & NA & 5.05 & 5.89 & 0.88 & 2.10 & 2.50 \\
\hline
\end{tabular}


Table 4. Mean $(n=3)$ number of tillers in the tested grass species, and number of vegetation growing points (untransformed values) in the tested forbs per $100 \mathrm{~cm}^{2}$ in monocultures in late September 2010 after stocking with laying hens at three levels of stocking duration (short, medium, long) for two stocking cycles in 2009 and four cycles in 2010, and in the ungrazed control. Results of two-way splitplot ANOVA [degrees of freedom (df); $n=3$ ] showing the effect of the factors plant species, duration of stocking with laying hens, and of their interaction for density of tillers and vegetation growing points in monocultures. Within rows, means followed by the same superscript letter are not significantly different according to Tukey's HSD post-hoc test $(0.05) .{ }^{* * *}: P<0.001$; ns: not significant $(0.05)$.

\begin{tabular}{|c|c|c|c|c|}
\hline \multirow[t]{3}{*}{ Species } & \multicolumn{4}{|c|}{ Level of stocking duration } \\
\hline & Control & short & medium & long \\
\hline & \multicolumn{4}{|c|}{ Number of tillers/vegetation growing points } \\
\hline \multicolumn{5}{|l|}{ Grasses } \\
\hline A. stolonifera & 592.0 & 420.5 & 468.8 & 348.8 \\
\hline D. cespitosa & 111.8 & 117 & 81.7 & 74.2 \\
\hline E. repens & $26.5^{\mathrm{c}}$ & $12.8^{\mathrm{bc}}$ & $5.3^{\mathrm{ab}}$ & $0^{\mathrm{a}}$ \\
\hline F. arundinacea & 112.7 & 93.0 & 92.7 & 96.3 \\
\hline F. rubra rubra & 352.8 & 287.7 & 317.2 & 319.7 \\
\hline F. trichophylla & 477.7 & 517.0 & 397.4 & 437.8 \\
\hline L. perenne & 195.5 & 152.7 & 139.0 & 120.7 \\
\hline P. pratensis & 141.5 & 131 & 144.8 & 132.5 \\
\hline P. supina & 242.0 & 227.5 & 202.7 & 231.2 \\
\hline \multicolumn{5}{|l|}{ Forbs } \\
\hline A. millefolium & 11.3 & 16.5 & 12.2 & 8.5 \\
\hline P. major & 5.3 & 6.1 & 3.8 & 1.5 \\
\hline R. repens & $25.2^{\mathrm{b}}$ & $19.5^{\mathrm{ab}}$ & $12.7^{\mathrm{ab}}$ & $9.8^{\mathrm{a}}$ \\
\hline T. officinale & $11.3^{\mathrm{b}}$ & $5.9^{\mathrm{ab}}$ & $4.8^{\mathrm{a}}$ & $5.3^{\mathrm{ab}}$ \\
\hline T. repens & $39.8^{\mathrm{b}}$ & $31.2^{\mathrm{b}}$ & $19.2^{\mathrm{ab}}$ & $9.7^{\mathrm{a}}$ \\
\hline \multicolumn{5}{|l|}{ ANOVA table } \\
\hline Source of variance & df & & & \\
\hline Species (S) & 13 & $* * *$ & & \\
\hline Stocking duration (D) & 3 & $* * *$ & & \\
\hline$S \times D$ & 39 & ns & & \\
\hline
\end{tabular}


Table 5. Mean canopy cover (percentage of green foliage; $\%$, untransformed values, $n=3$ ) of the subplots stocked with laying hens at three levels of stocking duration (short, medium, long) after rest periods of four weeks following each of the two stocking cycles in 2009 and each of the four cycles in 2010. For each species, within columns, means followed by the same superscript letter are not significantly different according to Tukey's HSD post-hoc test (0.05).

\begin{tabular}{|c|c|c|c|c|c|c|c|}
\hline \multirow[t]{4}{*}{ Species } & \multirow{4}{*}{$\begin{array}{l}\text { Stocking } \\
\text { duration }\end{array}$} & \multicolumn{6}{|c|}{ Stocking cycle } \\
\hline & & \multicolumn{2}{|c|}{2009} & \multicolumn{4}{|c|}{2010} \\
\hline & & 1 & 2 & 1 & 2 & 3 & 4 \\
\hline & & \multicolumn{6}{|c|}{------------------------ \% ------------------------ } \\
\hline A. stolonifera & Short & 82.9 & $69.7^{a}$ & 65.5 & 70.4 & 89.6 & 63.5 \\
\hline & $\begin{array}{l}\text { Short } \\
\text { Medium }\end{array}$ & $\begin{array}{l}82.9 \\
91.7\end{array}$ & $\begin{array}{l}69.7^{\mathrm{ab}} \\
84.7^{\mathrm{ab}}\end{array}$ & $\begin{array}{l}05.5 \\
68.7\end{array}$ & $\begin{array}{l}10.4 \\
82.4\end{array}$ & $\begin{array}{l}09.0 \\
93.5\end{array}$ & $\begin{array}{l}03.5 \\
57.6\end{array}$ \\
\hline & Long & 93.9 & $88.2^{\mathrm{b}}$ & 84.6 & 82.3 & 96.6 & 48.7 \\
\hline \multicolumn{8}{|l|}{ D. cespitosa } \\
\hline & Short & 90.5 & 85.3 & 92.6 & 86.1 & 82.4 & 71.1 \\
\hline & Medium & 92.5 & 86.8 & 87.7 & 88.0 & 79.9 & 57.8 \\
\hline & Long & 92.5 & 83.7 & 87.8 & 83.6 & 76.6 & 59.8 \\
\hline \multicolumn{8}{|l|}{ E. repens } \\
\hline & Short & 63.8 & 58.8 & 48.6 & 50.9 & 49.4 & 43.9 \\
\hline & Medium & 81.5 & 68.6 & 43.4 & 35.8 & 51.4 & 32.2 \\
\hline & Long & 80.8 & 81.6 & 26.7 & 20.5 & 19.2 & 18.7 \\
\hline \multicolumn{8}{|c|}{ F. arundinacea } \\
\hline & Short & 89.3 & 81.3 & 86.1 & 79.3 & 90.1 & 90.9 \\
\hline & Medium & 87.9 & 81.9 & 84.2 & 88.0 & 90.1 & 91.0 \\
\hline & Long & 89.6 & 84.5 & 81.6 & 84.7 & 91.6 & 94.9 \\
\hline \multicolumn{8}{|l|}{ F. rubra } \\
\hline & Short & 91.3 & 89.8 & 84.7 & 77.0 & 87.1 & 76.0 \\
\hline & Medium & 95.8 & 86.9 & 83.3 & 82.3 & 90.1 & 72.9 \\
\hline & Long & 93.4 & 90.6 & 82.0 & 76.7 & 89.9 & 79.7 \\
\hline \multicolumn{8}{|l|}{ F. trichophylla } \\
\hline & Short & 96.0 & 94.7 & 90.8 & 90.5 & 97.2 & 89.1 \\
\hline & Medium & 96.5 & 92.9 & 86.2 & 82.9 & 97.0 & 90.7 \\
\hline & Long & 94.3 & 90.3 & 86.9 & 89.1 & 92.8 & 78.7 \\
\hline \multicolumn{8}{|l|}{ L. perenne } \\
\hline & $\begin{array}{l}\text { Short } \\
\text { Medium }\end{array}$ & $\begin{array}{l}82.7 \\
91.8\end{array}$ & $\begin{array}{l}75.2 \\
82.2\end{array}$ & $\begin{array}{l}84.9 \\
80.7\end{array}$ & $\begin{array}{l}80.6 \\
91.0\end{array}$ & $\begin{array}{l}91.0^{\mathrm{a}} \\
93.6^{\mathrm{b}}\end{array}$ & $\begin{array}{l}81.8 \\
57.6\end{array}$ \\
\hline & Long & 90.5 & $\begin{array}{l}02.2 \\
86.0\end{array}$ & $\begin{array}{l}00.1 \\
87.8\end{array}$ & 91.3 & $94.4^{\mathrm{b}}$ & 56.7 \\
\hline \multicolumn{8}{|l|}{ P. pratensis } \\
\hline & Short & 71.6 & 61.1 & 85.4 & 74.4 & 73.9 & 70.7 \\
\hline & Medium & 72.3 & 65.9 & 71.9 & 86.6 & 80.0 & 74.7 \\
\hline & Long & 70.7 & 67.6 & 79.8 & 82.3 & 86.0 & 84.4 \\
\hline \multicolumn{8}{|l|}{ P. supina } \\
\hline & Medium & $\begin{array}{l}09.2 \\
93.5\end{array}$ & $\begin{array}{l}83.4 \\
87.9\end{array}$ & $\begin{array}{l}86.8 \\
95.1\end{array}$ & $\begin{array}{l}90.5 \\
98.5\end{array}$ & $\begin{array}{l}98.0 \\
98.2\end{array}$ & $\begin{array}{l}89.9 \\
82.7\end{array}$ \\
\hline & Long & 86.9 & 88.2 & 95.4 & 96.5 & 98.2 & 89.4 \\
\hline
\end{tabular}

(continued next page) 
(Continuation of previous page)

\begin{tabular}{|c|c|c|c|c|c|c|c|}
\hline \multirow[t]{4}{*}{ Species } & \multirow{4}{*}{$\begin{array}{l}\text { Stocking } \\
\text { duration }\end{array}$} & \multicolumn{6}{|c|}{ Stocking cycle } \\
\hline & & \multicolumn{2}{|c|}{2009} & \multicolumn{4}{|c|}{2010} \\
\hline & & 1 & 2 & 1 & 2 & 3 & 4 \\
\hline & & & ------. & - & ------- & - & \\
\hline \multicolumn{8}{|l|}{ A. millefolium } \\
\hline & Short & 58.4 & 75.2 & 74.3 & 85.4 & 67.2 & 55.0 \\
\hline & Medium & 70.3 & 79.3 & 78.7 & 88.2 & 86.4 & 50.2 \\
\hline & Long & 66.7 & 80.5 & 75.6 & 91.1 & 74.4 & 40.3 \\
\hline \multicolumn{8}{|l|}{ P. major } \\
\hline & Short & 51.3 & 50.8 & 54.0 & $69.3^{\mathrm{b}}$ & 65.4 & 52.4 \\
\hline & Medium & 21.5 & 44.3 & 25.3 & $42.8^{a}$ & 47.3 & 35.1 \\
\hline & Long & 50.8 & 61.1 & 42.8 & $55.1^{\mathrm{ab}}$ & 47.0 & 35.3 \\
\hline \multicolumn{8}{|l|}{ R. repens } \\
\hline & Short & 61.2 & 77.3 & 68.6 & $94.8^{\mathrm{b}}$ & 95.0 & 79.5 \\
\hline & Medium & 75.6 & 82.3 & 77.0 & $97.8^{\mathrm{b}}$ & 94.9 & 61.6 \\
\hline & Long & 80.2 & 79.1 & 70.3 & $86.2^{\mathrm{a}}$ & 90.1 & 56.4 \\
\hline \multicolumn{8}{|l|}{ T. officinale } \\
\hline & Short & 72.3 & 86.3 & 80.8 & 87.8 & 72.6 & 48.7 \\
\hline & Medium & 82.2 & 94.2 & 81.2 & 94.5 & 65.5 & 47.5 \\
\hline & Long & 67.0 & 91.1 & 78.6 & 95.6 & 65.2 & 62.0 \\
\hline \multicolumn{8}{|l|}{ T. repens } \\
\hline & Short & 92.6 & 96.2 & 85.9 & 95.8 & $96.5^{b}$ & 64.5 \\
\hline & Medium & 93.6 & 90.5 & 77.3 & 95.3 & $87.9^{\mathrm{ab}}$ & 40.6 \\
\hline & Long & 89.1 & 80.4 & 64.1 & 50.4 & $63.2^{a}$ & 36.5 \\
\hline \multicolumn{8}{|l|}{ Mixed seed } \\
\hline & Short & 90.6 & 91.9 & 83.6 & 93.5 & 93.2 & 82.4 \\
\hline & Medium & 88.8 & 90.8 & 91.3 & 97.0 & 94.0 & 75.9 \\
\hline & Long & 94.9 & 90.8 & 87.1 & 94.6 & 95.2 & 83.0 \\
\hline
\end{tabular}

\section{Discussion}

Confirming our hypothesis, our data show that the species differed strongly with regard to their tolerance to stocking with chickens. These differences became more pronounced with repeated and prolonged stocking, as is evident from the significant effects of the species $\mathrm{x}$ stocking cycle and the species $x$ stocking duration interactions for biomass allocation and canopy cover. In order to answer our initial research question and to evaluate the eligibility of the tested species for establishing durable swards for outdoor runs, we need to consider their performance concerning the individual target parameters and their resistance and resilience to stocking with chickens.

Response of target parameters to stocking with chickens

Chicken grazing simultaneously leads to positive and negative effects on each of the three measured target parameters. The enhancing effects are, firstly, the deposition of excrements, which act as a fertilizer. The subplots received $\mathrm{N}$ and $\mathrm{P}$ from the feed provided 
in the hen house. In our experiment, we calculated inputs of $N$ and $P$ of $1.8,3.7$ and $5.5 \mathrm{~g} \mathrm{~m}^{-2}$ and of $0.3,0.7$ and $1.0 \mathrm{~g} \mathrm{~m}^{-2}$, respectively, per stocking cycle for the short, medium and long stocking duration presuming a uniform excretion over the course of one day of $170 \mathrm{~g}$ of fresh excrements per animal with an $N$ and $P$ content of $1.3 \%$ and $0.24 \%$ based on values reported in Bessei and Damme (1998) and Aarnink et al. (2006). A non-quantified proportion of the deposited excrements, however, was removed when mowing the plots one week prior to re-stocking. Secondly, the biomass removal from the sward caused by grazing can be assumed to have resulted in an increase in aboveground biomass growth rates (Oesterheld 1992). The amount of biomass removed was not quantified within this experiment, but other studies have shown herbage uptake to be 10 to $30 \mathrm{~g}$ per animal per day in pastured laying hens provided ad libitum with complete feed (Antell and Ciszuk 2006; Horsted and Hermansen 2007; Rivera-Ferre et al. 2007 for broilers). On the other hand, the birds' scratching which is a feature particular to chicken grazing causes a significant disturbance of the sward, which results in a depression of re-growth. This is expected to be particularly severe if it involves damaging of the root (Breitsameter et al. 2012). Finally, the deposition of chicken excrements may be detrimental to sward growth in a similar way as shown for cattle and pig slurry in Wightman et al. (1997).

The tested species had featured strong differences in density of tillers and vegetation growing points and in growth rates of aboveground biomass pre-stocking and hence independently of stocking. This is due to species-specific growth habits, and differences in $\mathrm{N}$ uptake and utilization strategies (Levang-Brilz and Biondini 2002). We therefore focused on alterations in target parameter values caused by stocking. Altogether, we expected highly performing species to maintain high canopy cover and constant density of tillers/vegetation growing points, and to feature post-stocking biomass growth rates which are higher than those of the control (fertilizer effect), and which are in long-duration stocking higher than or at least as high as those in short-duration stocking (prevalence of fertilizer effect over damaging effects of stocking). In order to rank the overall performance of the tested species, we based evaluation on their resistance and resilience to stocking with chickens.

\section{Evaluation of the tested species}

The chosen target parameters are indicators of resistance and resilience of the investigated plant species to stocking with chicken. Biomass accumulation is a measure of resilience, because it indicates the promptness of restitution of sward biomass after release from stocking. Roovers et al. (2004) measured sward resilience by considering the recovery of vegetation ground cover after a period of one to two years after release from disturbance. Recovery of canopy cover from stocking, however, was not relevant in the present 
experiment, because rest periods - following management practices of rotational grazing in farms - only comprised four weeks, which does not allow a significant revegetation in grass swards (Bockholt and Dittmann 2007). Instead, we classified canopy cover at the end of the rest period of each stocking cycle, and density of tillers and vegetation growing points at the end of the grazing season in 2010 as measures of resistance similar to Cole (1995). Tillering also strongly responds to light and is repressed by generative growth. However, as the swards were mown to $7 \mathrm{~cm}$ during the rest periods of each stocking cycle grasses were kept at non-limited light conditions and at vegetative growth. Therefore, we presume that alterations in tiller numbers were predominantly governed by the disturbance caused by stocking, and not by a thinning of the sward due to competition for light or by generative growth.

Resilience of vegetation after disturbance does not only depend on the plants' inherent resilience capacity, but also on a number of environmental factors. As elucidated in Bernhardt-Römermann et al. (2011), adequate levels of precipitation and radiation need to be given for recovery of vegetation from disturbance. A recovery period of too short duration may not allow the realization of the inherent potential resilience either. In view of these considerations and given the conditions regularly found in laying hens free-range husbandry systems (stocking cycles with short rest periods; potentially low precipitation during summers without supplemental irrigation of pastures), we rate resistance to stocking with chickens as a characteristic more relevant than resilience when evaluating the species' overall suitability. Therefore, we considered the stability of canopy cover and density of tillers and vegetation growing points as the evaluation criteria of prevalent importance. Aboveground biomass growth rates served as complementary information on plant fitness and were therefore used as a secondary evaluation criterion. Biomass accumulation additionally gave an approximation of the amount of soil nutrients which can be bound in the form of plant biomass. We did not, however, consider standing dry herbage mass, because it was not the objective of this study to evaluate the capacity of the investigated species to provide a substantial amount of supplementary fodder to the chickens. For this reason the nutritive value of the tested species also was not used as an evaluation criterion, although this aspect deserves consideration in further studies.

According to these criteria, we deduce from our data that among tested species $F$. arundinacea and $P$. supina, which showed constant and high canopy cover, and high tiller density, as well as comparatively high biomass growth rates after repeated stocking at long stocking duration (no significant effect or positive effect of stocking duration and stocking cycle on the target parameters), displayed the highest tolerance to the applied disturbance. Festuca rubra and F. trichophylla also featured good performance in terms of canopy cover and constant tiller density, however, their biomass growth rates were only approximately half 
that of $F$. arundinacea. In contrast to these species, L. perenne, which is known for its high performance in other management systems, suffered extensive gaps in canopy cover and showed a strong decrease in biomass growth rate at long stocking. Eligibility of this species for establishing chicken swards therefore appears to be limited. In those species which had their complete aboveground biomass removed in several cycles at the long stocking duration (R. repens, $T$. officinale, $T$. repens, data not shown) recovery can be assumed to cause a substantial expenditure of stored resources. Even though some of them possess storage in belowground compartments (tap root, rhizome), repeated stocking with short rest periods potentially results in reduced fitness in these species. In T. repens a low tolerance to stocking with chickens was evident from both strongly reduced biomass accumulation and canopy cover at long stocking after merely a few cycles. Generally, grasses featured a better overall performance than forbs under conditions of stocking with laying hens. The mixed sward, in contrast, displayed a comparatively good performance both concerning canopy cover and biomass growth rates. This is remarkable due to the fact that $L$. perenne, which yielded mediocre results as a monoculture, contributed the largest yield proportion to this sward type. We consider it an interesting question for further research to clarify how mixtures can benefit durability of swards for chicken runs and to investigate the factors contributing to their good performance.

\section{Traits conferring resistance}

As we have explained above, the most important feature warranting high performance under the disturbance regime considered in our study is resistance to the damaging effects caused by chicken grazing. For an application of the results shown here beyond the species pool we have tested, an understanding of the primary traits that confer resistance is of importance. In our study we found important differences in resistance to stocking with laying hens between grasses on the one hand and forbs on the other, but also among the grass species and among the species with either creeping or cespitose growth. In order to identify predictors of resistance, we need to consider the specific pressures exerted on vegetation in chicken pastures. Scratching, which is the feature distinguishing chicken grazing most distinctly from ruminant grazing and other practices of grassland management, is presumably the heaviest impact plants are facing in this type of pasture. Therefore, the characteristics conferring good performance to turf grass cultivars in wear tests may also serve as a basis for explaining high resistance to chicken grazing: cell wall composition and high leaf tensile strength (Shearman and Beard 1975a and 1975b; Dowgiewicz et al. 2011). We did not conduct chemical analysis of cell wall constituents for the present study, but we determined neutral detergent fibre (NDF) using near infrared spectroscopy (Kesting et al. 2009). We generally found the 
correlation of canopy cover and NDF to be comparatively weak $\left(R^{2}=0.03, P<0.001\right.$ for pooled data of the second, third and fourth cycle in 2010), but to get stronger with repeated stocking $\left(R^{2}=0.25, P<0.001\right.$ for the forth cycle in 2010; data not shown). Stem flexibility, which was shown to be correlated with trampling tolerance by Sun and Liddle (1993), and leaf elasticity (Brosnan et al. 2005) may further benefit scratching tolerance under chicken grazing. The latter parameter may explain the observed differences between $F$. arundinacea, which showed high resistance and proved to be comparatively flexible when leaves or stems were bent, and $D$. cespitosa, which featured a lower resistance and whose leaves were relatively stiff and tended to break when bent. The correlation of higher tiller density with better wear tolerance which is reported in other studies (Trenholm et al. 2000; Dowgiewicz et al. 2011) was not supported by our data. In stoloniferous plants, morphology may give a further clue to understanding resistance. In $P$. supina, stolons tended to form a tightly interwoven and thus relatively stable mat; in contrast, in $A$. stolonifera stolons were more loosely aligned in the sward which may have caused a lower overall stability. Moreover, we repeatedly observed long stolons having been torn off the plants which, if not removed from the plots, caused shading damage as they covered yet intact portions of the sward.

Finally, a study by Breitsameter et al. (2012), which is presented in Chapter 2 of this thesis, has confirmed that damage to the roots is especially detrimental to production of aboveground biomass. The extent to which root damage occurs in chicken pasture has not been quantified so far. Yet, we consider it deserves assessment in order to determine the importance of root traits (e.g. distribution of root biomass across layers of soil depth, lignification of root tissue) for plant resistance in this type of pasture system. This may also be helpful for understanding the varying resistance to chicken grazing of the canopy cover on different soil types (Sossidou et al. 2008), and it may additionally clarify the potential of technical solutions aiming at the prevention of sward damage via the stabilization of the upper soil.

This study did not evaluate the capacity of the investigated species to provide a substantial amount of supplementary fodder to the animals and therefore the nutritive value of the tested species was not used as an evaluation criterion. Yet, we deem this aspect deserves consideration in further studies. We further estimate the interaction of the animals with different sward types to be of major importance for a comprehensive evaluation of the suitability of different plants for greening chicken outdoor runs. 


\section{Conclusions}

From the present data, we conclude that grassland plant species which show high tolerance towards intensive grassland management practices and mechanical damage differ strongly in their performance under conditions of stocking with chicken, and that these differences get more pronounced with repeated stocking. Grasses generally feature a better overall performance in chicken pastures. According to the parameters we measured, among the tested species $F$. arundinacea and $P$. supina are most suitable for greening chicken outdoor runs. Our data indicate that the choice of plant species showing a high resistance to the disturbance caused by this type of grazing system, can - in addition to established measures of pasture management - provide a means of creating a durable greening of the outdoor run.

\section{References}

Aarnink A.J.A., J.M.G. Hol, and A.G.C. Beurskens (2006) Ammonia emission and nutrient load in outdoor runs of laying hens. Netherlands Journal of Agricultural Sciences Wageningen Journal of Life Sciences 54: 223-234.

Antell S., and P. Ciszuk (2006) Forage consumption of laying hens - the crop content as an indicator of feed intake and AME content of ingested forage. Archiv für Geflügelkunde 70: 154-160.

Bejaei M., K. Wiseman, and K.M. Cheng (2011) Influences of demographic characteristics, attitudes, and preferences of consumers on table egg consumption in British Columbia, Canada. Poultry Science 90: 1088-1095.

Bernhardt-Römermann M., A. Gray, A.J. Vanbergen, L. Bergès, A. Bohner, R.W. Brooker et al. (2011) Functional traits and local environment predict vegetation responses to disturbance: a pan-European multi-site experiment. Journal of Ecology 99: 777-787.

Bessei W., and K. Damme (1998) Neue Verfahren für die Legehennenhaltung. Kuratorium für Technik und Bauwesen in der Landwirtschaft, KTBL-Schrift 378. Landwirtschaftsverlag, Münster-Hiltrup, Germany.

Bockholt R., and L. Dittmann (2007) Ein Experiment zur Prüfung verschiedener Gräser als Hühnerweide. In: Wrage N., and J. Isselstein, editors, Neue Funktionen des Grünlands: Ökosystem, Energie, Erholung. Mitteilungen der Arbeitsgemeinschaft Grünland und Futterbau, Vol. 8, pp. 32-36.

Box G.E.P., and D.R. Cox (1964) An analysis of transformations. Journal of the Royal Statistical Society. Series B (Methodological) 26: 211-252.

Breitsameter L., K. Küchenmeister, F. Küchenmeister, and J. Isselstein (2012) Tolerance to mechanical damage in ten herbaceous grassland plant species. Plant, Soil and Environment 58: 334-339.

Brosnan J.T., J.S. Ebdon, and W.M. Dest (2005) Characteristics in diverse wear tolerant genotypes of Kentucky Bluegrass. Crop Science 45: 1917-1926.

Bundessortenamt (Ed.) (2006) Beschreibende Sortenliste Rasengräser. Bundessortenamt, Hannover, Germany.

Castle M.E. (1976) A simple disc instrument for estimating herbage yield. Grass and Forage Science 31: 37-40.

Christensen N.H. (1998) Alleviation of grass impaction in a flock of free-range hens. Veterinary Record 143: 397.

Cole D.N. (1995) Experimental trampling of vegetation. II. Predictors of resistance and resilience. Journal of Applied Ecology 32: 215-224. 
Correll O., J. Isselstein, and V. Pavlu (2003) Studying spatial and temporal dynamics of sward structure at low stocking densities: the use of an extended rising-plate-meter method. Grass and Forage Science 58: 450-454.

Dawkins M.S., P.A. Cook, M.J. Whittingham, K.A. Mansell, and A.E. Harper (2003) What makes free-range broiler chickens range? In situ measurement of habitat preference. Animal Behaviour 66: 151-160.

Department for Environment, Food and Rural Affiars (Defra) (2012) Joint announcement of the agricultural departments of the United Kingdom: Eggs. http://www.defra.gov.uk/statistics/foodfarm/food/eggs/ accessed July 16, 2012.

Dierschke H., and G Briemle (2002) Kulturgrasland. Wiesen, Weiden und verwandte Staudenfluren. Ulmer, Stuttgart.

Dowgiewicz J., J.S. Ebdon, M. DaCosta, and W.D. Dest (2011) Wear tolerance mechanisms in Agrostis species and cultivars. Crop Science 51: 1232-1243.

Edwards D.R., and T.C. Daniel (1993) Effects of poultry litter application rate and rainfall intensity on quality of runoff from fescuegrass plots. Journal of Environmental Quality 22: 361-365.

European Commission. Directorate-General for Agriculture and Rural Development (2010) An analysis of the EU organic sector. Internet document. Accessed July 16, 2012.

Heckendorn F., D.A. Häring, Z. Amsler, and V. Maurer (2009) Do stocking rate and a simple run management practice influence the infection of laying hens with gastrointestinal helminths? Veterinary Parasitology 159: 60-68.

Hegelund L., J.T. Sørensen, J.B. Kjaer, and I.S. Kristensen (2005) Use of the range area in organic egg production systems: effect of climatic factors, flock size, age and artificial cover. British Poultry Science 46: 1-8.

Hegelund L., J.T. Sørensen, and J.E. Hermansen (2006) Welfare and productivity of laying hens in commercial organic egg production systems in Denmark. Netherlands Journal of Agricultural Sciences - Wageningen Journal of Life Sciences 54: 147-155.

Hörning B. (2002) Auslaufhaltung von Legehennen. Kuratorium für Technik und Bauwesen in der Landwirtschaft (KTBL), Darmstadt, Germany.

Horsted K., J.E. Hermansen, H. Ranvig (2007) Crop content in nutrient-restricted versus nonrestricted organic laying hens with access to different forage vegetations. British Poultry Science 48: 177-184.

Jodan D., I. Stuhec, W. Bessei (2011) Effect of whole wheat and feed pellets distribution in the litter on broilers' activity and performance. Archiv für Geflügelkunde 75:98-103.

Kesting S., N. Wrage, and J. Isselstein. 2009. Herbage mass and nutritive value of herbage of extensively managed temperate grasslands along a gradient of shrub encroachment. Grass and Forage Science 64: 246-254.

Kratz S., J. Rogasik, and E. Schnug (2004) Changes in soil nitrogen and phosphorus under different broiler production systems. Journal of Environmental Quality 33: 1662-1674.

Levang-Brilz N., and M.E. Biondini (2002) Growth rate, root development and nutrient uptake of 55 plant species from the Great Plains Grasslands, USA. Plant Ecology 165: 117-144.

Mahboub H.D.H., J. Müller, and E. von Borell (2004) Outdoor use, tonic immobility, heterophil/lymphocyte ratio and feather condition in free-range laying hens of different genotype. British Poultry Science 45: 738-744.

Marshall S.B., C.W. Wood, L.C. Braun, M.L. Cabrera, M.D. Mullen, and E.A. Guertal (1998) Ammonia volatilization from tall fescue pastures fertilized with broiler litter. Journal of Environmental Quality 27: 1125-1129.

Oesterheld M. (1992) Effect of defoliation intensity on aboveground and belowground relative growth rates. Oecologia 92: 313-316.

R Development Core Team (2011) R. A language and environment for statistical computing. R Foundation for Statistical Computing, Vienna, Austria.

Richardson M.D., D.E. Karcher, and L.C. Purcell (2001) Quantifying turfgrass cover using digital image analysis. Crop Science 41: 1884-1888.

Rivera-Ferre M.G., E.A. Lantinga, and R.P. Kwakkel (2007) Herbage intake and use of outdoor area by organic broilers: effect of vegetation type and shelter addition. 
Netherlands Journal of Agricultural Sciences - Wageningen Journal of Life Sciences 54: 279-291.

Roovers P., K. Verheyen, M. Hermy, H. Gulinck, and J.P. Bakker (2004) Experimental trampling and vegetation recovery in some forest and heathland communities. Applied Vegetation Science 7: 111-118.

Satimanon T., and D.D. Weatherspoon (2010) Hedonic analysis of sustainable food products. IFAMR 13: $57-74$.

Shearman R.C., and J.B. Beard (1975a) Turfgrass wear tolerance mechanisms. II. Effects of cell wall constituents on turfgrass wear tolerance. Agronomy Journal 67: 211-215.

Shearman R.C., and J.B. Beard (1975b) Turfgrass wear tolerance mechanisms. III. Physiological, morphological, and anatomical characteristics associated with turfgrass wear tolerance. Agronomy Journal 67: 215-218.

Sossidou E.N., S.P. Rose, S.S.P. Silva, N.W. Hall, A. Tserveni-Goussi, and V. Christodoulou (2008) Different soil media for free-range laying hens. British Poultry Science 49: 390395.

Sun D., and M.J. Liddle (1993) Trampling resistance, stem flexibility and leaf strength in nine Australian grasses and herbs. Biological Conservation 65: 35-41.

Trenholm L.E., R.N. Carrow, and R.R. Duncan (2000) Mechanisms of wear tolerance in seashore paspaltum and bermudagrass. Crop Science 40:1350-1357.

United States Department of Agriculture (USDA) Economic Research Service (2012) Organic Production. http://www.ers.usda.gov/data-products/organic-production.aspx accessed July 162012.

Venables W. N., and B. D. Ripley (2002) Modern applied statistics with S. Springer. New York.

Wightman P.S., M.F. Franklin, and D. Younie (1997) The effect of sward height on response of mini-swards of perennial ryegrass/white clover to slurry application. Grass and Forage Science 52: 42-51.

Zeltner E., and H. Hirt (2008) Factors involved in the improvement of the use of hen runs. Applied Animal Behaviour Science 114: 395-408. 
Chapter 2

Tolerance to mechanical damage in ten herbaceous grassland plant species 


\section{Abstract}

The establishment of plants with high damage tolerance may provide a means for soil protection on sites exposed to strong disturbance. In a pot experiment, we investigated the tolerance to mechanical strain of ten grassland plant species representing three growth form groups (cespitose: Festuca arundinacea, Lolium perenne, Taraxacum officinale; rhizomatous: Achillea millefolium, Elymus repens, Poa pratensis; stoloniferous: Agrostis stolonifera, Festuca rubra rubra, Poa supina, Trifolium repens). We hypothesised that growth form and pre-disturbance biomass allocation to the root serve as predictors of damage tolerance. With a tool imitating the action of cleated football boots or scratching chicken, we applied three standardized levels (moderate, medium, strong) of a torsional force which exceeded the shear strength of the sward and impacted on shoots and roots. Post-treatment shoot biomass in relation to shoot biomass of the non-treated control plants served as a measure of damage tolerance. Species, but not growth form groups, differed significantly in damage tolerance, with $F$. arundinacea and $P$. pratensis showing the best performance. Shoot re-growth was strongly correlated with relative post-treatment root biomass across all species and treatment levels $\left(R^{2}=0.25, P<0.001\right)$, but not with pre-treatment root biomass. We conclude that root resistance to mechanical damage is the prevalent determinant of tolerance to disturbance.

\section{Introduction}

Bare soil areas, which commonly arise as an unwanted consequence of overstraining of the vegetation cover at highly frequented sites, cause various environmental problems (Morgan 2005). In grassland sites which are subject to continuous mechanical disturbance, e.g. resulting from free-range chicken or horse husbandry or intensive leisure sports use, the maintenance of an intact vegetation cover remains a challenge to be tackled. The choice of plant species with strong tolerance to mechanical damage for the establishment of durable swards may be an answer to this issue.

Physical disturbance generally impacts on plants by tear-off or wounding of leaf, shoot or root tissue or by combinations of these. In agricultural contexts, studies on tolerance to disturbance in plants mainly focus on recovery from loss of biomass related to harvesting, e.g. mowing or grazing in grasslands (Ferraro and Oesterheld 2002), and on root or shoot herbivory by pest organisms (Maron 1998). In horse or chicken pasture or on sports grounds, however, different types of damaging impacts simultaneously and in an undirected way act upon the plant by wounding or tearing off leaves, parts of the shoot, and root tissue. So far, 
studies elucidating the tolerance of herbaceous plants to these combined damage regimes are rare.

Within the present study, we aim at filling this gap of knowledge. We investigated the response of ten grassland plant species to comprehensive mechanical strain by simulating disturbance arising e.g. from the action of scratching chicken or of soccer boots. Within a greenhouse experiment, we subjected potted plants to three standardized levels of mechanical damage (moderate, medium and strong) impacting on shoot and root simultaneously; non-treated plants served as a control. We used the ratio of post-treatment shoot biomass in relation to shoot biomass of the non-treated control as a measure of damage tolerance. We based species selection on high performance within intensive cutting and grazing systems. Despite their relative homogeneity in terms of tolerance towards the latter types of disturbance, we firstly hypothesized the species to differ markedly in tolerance to comprehensive mechanical disturbance exerted on both shoot and root. We expected post-treatment shoot re-growth to depend on traits related to pre-treatment biomass allocation to the roots, to storage organs and to the location of clonal growth organs (Iwasa and Kubo 1997; Klimešová and Klimeš 2007). We assumed tolerance to mechanical damage to be high in plants with strong biomass allocation to the root, with buds of clonal growth organs concentrated close to or underneath the soil surface and with storage primarily located in the tussock or root. Therefore, we chose the tested species in a way to represent three vegetative growth form groups differing in these traits: cespitose, rhizomatous, and stoloniferous plants. Based on this, we secondly hypothesized the overall damage tolerance to be high in cespitose and rhizomatous plants. The general aim of this study was to describe characteristics common to herbaceous plants with high tolerance to mechanical damage in order to facilitate the choice of species suitable for greening sites that are subject to heavy disturbance.

\section{Material and methods}

Plant species

Ten species (cultivars, or wild-type seeds if no cultivar information is given) of herbaceous grassland plants were used for the experiment: three cespitose species (Festuca arundinacea Mustang; Lolium perenne Bargold; Taraxacum officinale agg.), three rhizomatous species (Achillea millefolium; Elymus repens; Poa pratensis Julius), and four stoloniferous species (Agrostis stolonifera Barifera; Festuca rubra rubra Rossinante; Poa supina Supreme; Trifolium repens Rivendel). Wild-tpye seeds were purchased from a domestic seed company. Species were selected based on their high tolerance to frequent 
and deep cutting, intensive grazing and cattle trampling according to indicator values given in Dierschke et al. (2002) and in the descriptive lists of turf grass cultivars (Bundessortenamt 2006).

\section{Damage treatment}

The plants were subjected to three levels of a damage treatment (moderate, medium, strong; control: no treatment) which simulated the action of disturbance inflicted on the sward e.g. by scratching chicken or by cleated soccer boots. In order to apply a standardized treatment, a special tool had been constructed. It consisted of a wooden disc of $12 \mathrm{~cm}$ diameter attached to a handle with the disc being penetrated by 12 screws protruding the bottom by approx. 4 $\mathrm{cm}$. The removable handle allowed loading the disc with weights of $10 \mathrm{~kg}$. For treatment application, the tool was set onto the pot so that the screws would reach into the ground. The pot was fixed, and by means of rotation of the handle the spiked disc was moved within the sward. The level of treatment was produced by the degree of rotation: $90^{\circ}$ for moderate, $180^{\circ}$ for medium, and $270^{\circ}$ for strong damage. By exerting a torsional force to the sward, the treatment simultaneously acted upon the plants by tearing off portions of varying extent of both the shoots and the roots.

The construction and operating mode of the damage tool combines some characteristics of instruments commonly used for testing shear resistance in turf (imitation of cleats reaching several $\mathrm{cm}$ into the ground, torsional force exerted to the sward). The treatment application in our setup, however, differs from the protocol used in shear strength measurement. In the latter, the measured target is the threshold value of force needed to break the shear resistance of the sward. In our experimental protocol, in contrast, the rotational force is set to values well above the threshold of shear resistance at all of the three treatment levels, with the intention of exerting a distinct disturbance to the whole plant. Therefore, we also chose the diameter of the tool to be larger than e. g. in a field vane tester, which, particularly in those parts of the sward located close to the edge of the spiked disk, further augmented the effectiveness of its application.

\section{Setup and data sampling}

The experiment was established in October 2008. It consisted of 10 (species) x 4 (treatment levels) $\times 3$ (replications) $=120$ pots placed in a randomized block setup. The plants were grown as monocultures in pots of $13 \times 13 \times 13 \mathrm{~cm}$ and with common potting soil from compost as substrate: $\mathrm{P} / \mathrm{K} / \mathrm{Mg} 44 / 119 / 26 \mathrm{mg} / 100 \mathrm{~g}$ dry matter ( $\mathrm{P}$ and $\mathrm{K}$ extracted in 1:20 soil to calcium acetate lactate; $\mathrm{Mg}$ extracted in $1: 10$ soil to $0.0125 \mathrm{M} \mathrm{CaCl}_{2}$ ), $\mathrm{C} / \mathrm{N}$ ratio 14.8 , 
$\mathrm{pH}$ 7.3. 10 specimens in grasses and 2 specimens in forbs per pot were cultivated in the greenhouse with 16 hours of light from sodium vapour lamps additional to daylight, and at temperatures of 11 to $18^{\circ} \mathrm{C}$ at night and 18 to $24^{\circ} \mathrm{C}$ at day time.

During an establishment phase, the plants were cut three times (92, 126 and 155 days after sowing) to $3 \mathrm{~cm}$ stubble height. Four days after the third time of clipping, the damage treatment was imposed. 14 days later, it was repeated with each pot receiving the same treatment level as in the first application, yet without a preceding harvest. Another 14 days later, a final harvest of the aboveground biomass was carried out by cutting to $3 \mathrm{~cm}$ stubble height. The complete belowground biomass was obtained by removing the stubbles and washing the roots clean of soil particles, and dry weights were determined. Throughout the course of the experiment, all pots were kept sufficiently watered and, to ensure a non-limiting nutrient status, they were supplied with six applications of $1.5 \mathrm{~g}$ of a $15 / 10 / 15+2 \mathrm{NPK}+\mathrm{Mg}$ fertilizer per pot.

\section{Data analysis}

All data were tested for normal distribution and transformed if necessary. Data on shoot biomass were square root transformed for analysis; data on root dry weights were logtransformed. Relative post-treatment shoot re-growth and relative post-treatment root biomass were calculated for each species and treatment level as percentage values of the post-treatment shoot or root biomass of the treated plants in relation to those of the respective control plants, and arcsine-square root transformed for analysis. A two-way ANOVA was performed to analyse treatment and species effects on shoot and root biomass. Intra-specific differences between biomass of treated and control plants were determined using Tukey HSD post-hoc test (95\% confidence interval). Explanatory power of the factors growth form group and treatment on post-treatment shoot re-growth was also determined by means of a two-way ANOVA. We tested correlations of relative post-treatment shoot regrowth with both pre-treatment root biomass and relative post-treatment root biomass using linear models. For the former analysis, post-treatment root biomass of the control plant was used as an approximation for pre-treatment root biomass based on the assumption that root growth of the control plants would be minimal under the experimental conditions applied, i.e. at good water and nutrient supply, a long establishment phase pre-treatment, and a shoot biomass harvest immediately pre-treatment (Caloin et al. 1990). For the latter analysis, relative biomass of the roots as determined at the final harvest date was utilized as an approximation of relative root biomass immediately post-treatment, as we assumed root growth to be minimal during the two weeks following treatment application (van der Meijden 
2000). All statistical analyses were executed using of the software $R$, version 2.13 .2 ( $R$ Development Core Team 2011).

\section{Results and discussion}

Post-treatment shoot and root biomass in individual species

The factors plant species and treatment level were significantly explanatory for posttreatment shoot and root biomass $(P<0.001$ for both factors). The interaction of the two factors was significant for shoot $(P<0.001)$, but not for root biomass. In relation to the controls, we observed a reduction in shoot biomass which was paralleled by a reduction in root biomass in all plants having received the treatment. The species differed concerning the minimum treatment level at which significant reductions of shoot biomass relative to the control were determined. The decrease in root biomass relative to the control was significant only in P. pratensis, $T$. officinale, $T$. repens, A. millefolium, and $E$ repens (Table 6 ).

According to these data, F. arundinacea, which did not show statistically significant decreases neither in shoot nor in root biomass at any of the three treatment levels applied, and $P$. pratensis, with an average decrease in shoot biomass of only about $30 \%$ at the strong level of treatment, proved to have the highest damage tolerance of the examined species.

Damage tolerance of growth form groups

The factor treatment had significant explanatory power for relative post-treatment shoot regrowth of the examined plants $(P<0.001)$. Growth form group (cespitose, stoloniferous, rhizomatous), however, had less explanatory power for this parameter $(P<0.05)$. Only at the moderate level of damage did relative shoot re-growth differ significantly between the three groups; rhizomatous plants displayed significantly higher values than stoloniferous plants; the values of cespitose plants were intermediate. The interaction of the factors treatment and growth form group in explaining relative shoot re-growth was not significant.

Correlations between relative post-treatment shoot re-growth and root variables

Relative post-treatment root biomass, but not pre-treatment root biomass was a significant explanatory variable of relative post-treatment shoot re-growth at each of the three treatment levels applied (Table 7). The correlation of these two parameters also proved to be significant across the complete range of species and the three treatment levels (Figure 2). Our hypothesis that pre-treatment allocation of biomass to the roots and the location of storage and clonal growth organs - as reflected in the three growth form groups considered 
here (cespitose, rhizomatous, stoloniferous) - serve as predictors of overall damage tolerance, however, was not supported. In comparison to stoloniferous plants, cespitose and rhizomatous plants exhibit stronger prevalence of the root and the tussock as storage organs, and their buds are concentrated closer to or underneath the soil surface. Therefore, we had expected these latter two groups to have a higher damage tolerance than stoloniferous plants. Yet, only at the moderate level of treatment did rhizomatous plant show significantly higher re-growth than stoloniferous plants. Obviously, other traits than those used to define the growth form groups are relevant for the explanation of post-treatment shoot re-growth. Our data indicated a significant correlation of relative post-treatment shoot re-growth and relative post-treatment root biomass across the whole range of examined species and the three treatment levels applied. Pre-treatment root biomass, however, did not serve as a predictor of shoot re-growth, which is in concordance with Chapin et al. (1990) who also point out that storage may not always be accessible for recovery after disturbance. Based on these findings, we conclude that the extent to which the root is reduced as a consequence of the damage event (by tear-off of root tissue) is an important predictor of post-treatment shoot re-growth. This is in concordance with previous studies which have shown that the loss of root tissue has an over-proportionally more severe effect on plant fitness than the removal of aboveground biomass (Humphries 1958; Schmid et al. 1990; Reichman und Smith 1991).

A limitation of the applied experimental protocol is the fact that it only provided a measure of overall damage tolerance for the tested plants. As biomass of intact root and shoot tissue could not be assessed immediately post-treatment, a differentiation between damage resistance on the one hand - resulting in high values of relative root and shoot biomass at the final harvest due to a limited impact of the treatment - and resilience on the other hand resulting in high values of relative root and shoot biomass at the final harvest due to fast regrowth post-treatment - is not possible in the present approach. However, as explained above, under the applied experimental conditions we expect harvested root biomass to represent a fair approximation of biomass of intact roots immediately post-treatment.

Another aspect deserving consideration is the fact that a number of species examined here display significant intraspecific variation, and cultivars can, therefore, be expected to show high variation in damage tolerance. The species $L$. perenne, for instance, comprises forage cultivars as well as cultivars for sports turf, and even among the latter, damage tolerance varies notably (Bundessortenamt 2006). Still, we assume the strong correlation of relative post-treatment shoot re-growth and relative post-treatment root biomass which we 
discovered across the whole range of all the tested species also to be valid across different cultivars of one species. Intraspecific variation may, however, alter the ranking of overall damage tolerance among the tested species.

Altogether, the results of our experiment indicate that plants with high resistance to root damage (e.g. given by root architecture or lignification) may have a high overall tolerance to comprehensive mechanical damage. In order to evaluate the prospective practical application of the results shown, trials on the performance of the investigated species under field conditions as presented in Breitsameter et al. (2010) are of major importance.

Table 6. Post-treatment shoot and root biomasses of the examined species representing three growth form groups at three levels of damage treatment (moderate - mod.; medium - med.; strong - strg.) and in non-treated control. For each species and for shoot or root biomass, respectively, within rows, means followed by the same superscript letter are not significantly different according to Tukey's HSD post-hoc test (0.05).

\begin{tabular}{|c|c|c|c|c|c|c|c|c|}
\hline \multirow[b]{3}{*}{ Species } & \multicolumn{4}{|c|}{ Shoot biomass ( $\mathrm{g}$ dry mass pot $^{-1}$ ) } & \multicolumn{4}{|c|}{ root biomass ( $\mathrm{g}$ dry mass pot $^{-1}$ ) } \\
\hline & \multicolumn{8}{|c|}{ Level of treatment } \\
\hline & none & mod. & med. & strg. & none & mod. & med. & strg. \\
\hline \multicolumn{9}{|l|}{ Cespitose } \\
\hline F. arundinacea & 6.4 & 5.9 & 4.6 & 3.1 & 12.1 & 13.0 & 10.6 & 8.4 \\
\hline L. perenne & $7.3^{\mathrm{b}}$ & $5.4^{\mathrm{ab}}$ & $4.1^{\mathrm{a}}$ & $3.6^{\mathrm{a}}$ & 19.2 & 8.4 & 7.0 & 6.8 \\
\hline T. officinale & $10.1^{\mathrm{b}}$ & $9.5^{\mathrm{b}}$ & $3.5^{\mathrm{a}}$ & $4.7^{\mathrm{a}}$ & 36.4 & 29.6 & 18.5 & 19.5 \\
\hline \multicolumn{9}{|l|}{ Rhizomatous } \\
\hline A. millefolium & $6.5^{\mathrm{b}}$ & $5.0^{\mathrm{ab}}$ & $1.8^{\mathrm{a}}$ & $1.7^{\mathrm{a}}$ & 4.76 & 4.1 & 1.6 & 1.2 \\
\hline E. repens & $5.9^{\mathrm{b}}$ & $5.0^{\mathrm{b}}$ & $4.1^{\mathrm{b}}$ & $1.0^{\mathrm{a}}$ & $19.4^{\mathrm{b}}$ & $10.9^{\mathrm{ab}}$ & $13.1^{\mathrm{ab}}$ & $6.9^{\mathrm{a}}$ \\
\hline F. rubra rubra & $7.1^{\mathrm{b}}$ & $5.0^{\mathrm{ab}}$ & $2.9^{\mathrm{a}}$ & $3.0^{\mathrm{a}}$ & 9.9 & 4.2 & 3.0 & 4.3 \\
\hline P. pratensis & $5.0^{c}$ & $4.7^{\mathrm{bc}}$ & $3.0^{\mathrm{a}}$ & $3.4^{\mathrm{ab}}$ & $6.3^{\mathrm{b}}$ & $4.8^{\mathrm{ab}}$ & $3.4^{\mathrm{a}}$ & $3.1^{\mathrm{a}}$ \\
\hline \multicolumn{9}{|l|}{ Stoloniferous } \\
\hline A. stolonifera & $7.2^{b}$ & $4.1^{\mathrm{ab}}$ & $2.3^{\mathrm{a}}$ & $2.1^{\mathrm{a}}$ & 5.5 & 3.0 & 2.7 & 2.4 \\
\hline P. supina & $5.9^{b}$ & $2.9^{\mathrm{a}}$ & $2.1^{\mathrm{a}}$ & $2.8^{\mathrm{a}}$ & 2.6 & 1.6 & 1.9 & 1.8 \\
\hline T. repens & $9.4^{\mathrm{b}}$ & $5.6^{\mathrm{ab}}$ & $3.3^{\mathrm{a}}$ & $2.7^{\mathrm{a}}$ & $2.5^{\mathrm{b}}$ & $2.4^{\mathrm{ab}}$ & $1.3^{\mathrm{ab}}$ & $0.2^{\mathrm{a}}$ \\
\hline
\end{tabular}


Table 7. Results of regression analysis ( $R^{2}$ and $p$ values of linear models) with pre-treatment root biomass (BM) and relative post-treatment root biomass (proportion of the root biomass of the treated plant in relation to that of the non-treated control) as explanatory variables of relative post-treatment shoot re-growth (proportion of the harvested aboveground biomass of the treated plant in relation to that of the non-treated control) at three levels of damage treatment (moderate, medium, strong)

\begin{tabular}{lccccccccc}
\hline & \multicolumn{2}{c}{ Moderate } & \multicolumn{2}{c}{ Level of treatment } & \multicolumn{2}{c}{ medium } & \multicolumn{2}{c}{ strong } & \multicolumn{2}{c}{ all data } \\
\cline { 2 - 10 } & $p$ & $R^{2}$ & $p$ & $R^{2}$ & $p$ & $R^{2}$ & $p$ & $R^{2}$ \\
\cline { 2 - 10 } & 0.08 & 0.086 & 0.08 & 0.073 & 0.8 & -0.033 & 0.1 & 0.016 \\
\hline $\begin{array}{l}\text { Root BM } \\
\text { pre-treatment }\end{array}$ & $<0.001$ & 0.48 & $<0.05$ & 0.15 & $<0.01$ & 0.24 & $<0.001$ & 0.25 \\
$\begin{array}{l}\text { Rel. root BM } \\
\text { post-treatment }\end{array}$ & & & & & & & & & \\
\hline
\end{tabular}

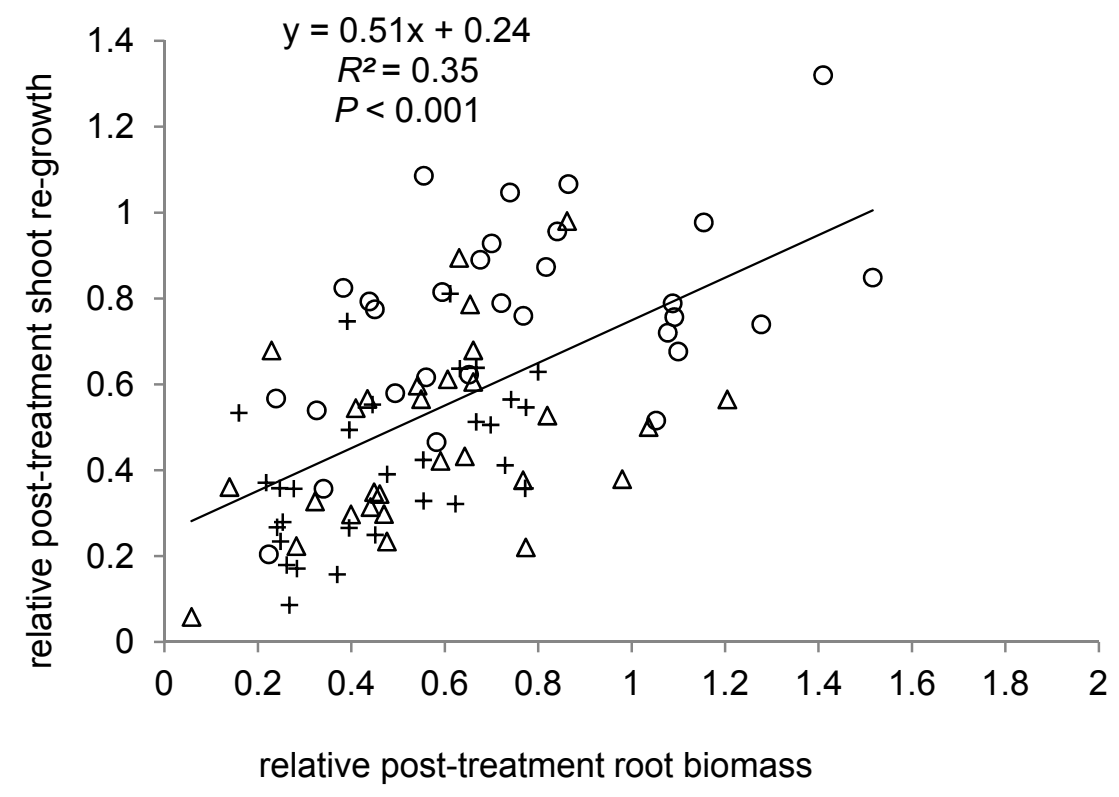

Figure 2. Correlation of relative post-treatment shoot re-growth (proportion of the harvested aboveground biomass of the treated plant in relation to that of the non-treated control) and relative post-treatment root biomass (proportion of the root biomass of the treated plant in relation to that of the non-treated control) across the whole range of species examined and for the three levels of treatment applied. Level of damage treatment: o moderate, $\Delta$ medium, + strong. 


\section{References}

Breitsameter L., N. Wrage, and J. Isselstein (2010) The quest for persistent green in outdoor chicken runs - an investigation on fourteen grassland species. Grassland Science in Europe 15: 916-918.

Bundessortenamt (Ed.) (2006) Beschreibende Sortenliste Rasengräser. Bundessortenamt. Hannover.

Caloin M., B. Clément, and S. Herrmann (1990) Regrowth kinetics of Dactylis glomerata following defoliation. Annals of Botany 66: 397-405.

Chapin F.S., E.D. Schulze, and H.A. Mooney (1990) The ecology and economics of storage in plants. Annual Review of Ecology and Systematics 21: 423-447.

Dierschke H., and G. Briemle (2002) Kulturgrasland. Wiesen, Weiden und verwandte Staudenfluren. Ulmer, Stuttgart.

Ferraro D.O., and M. Oesterheld (2002) Effect of defoliation on grass growth. A quantitative review. Oikos 98: 125-133.

Humphries E.C. (1958) Effect of removal of a part of the root system on the subsequent growth of the root and shoot. Annals of Botany 22: 251-257.

Iwasa Y., Kubo T. (1997) Optimal size of storage for recovery after unpredictable disturbances. Evolutionary Ecology 11: 41-65.

Klimešová J., and L. Klimeš (2007) Bud banks and their role in vegetative regeneration - A literature review and proposal for simple classification and assessment. Perspectives in Plant Ecology, Evolution and Systematics 8: 115-129.

Maron J.L. (1998) Insect herbivory above- and belowground: individual and joint effects on plant fitness. Ecology 79: 1281-1293.

Morgan R.P.C. (2005) Soil erosion and conservation. Blackwell Publishing, Malden.

R Development Core Team (2011) R. A language and environment for statistical computing. R Foundation for Statistical Computing, Vienna.

Reichman O.J., and S.C: Smith (1991) Responses to simulated leaf and root herbivory by a biennial, Tragopogon dubius. Ecology 72: 116-124.

Schmid B., S.L. Miao, and F.A. Bazzaz (1990) Effects of simulated root herbivory and fertilizer application on growth and biomass allocation in the clonal perennial Solidago canadensis. Oecologia 84: 9-15.

van der Meijden E., N. de Boer, and C. van der Veen-Van Wijk (2000) Pattern of storage and regrowth in ragwort. Evolutionary Ecology 14: 439-455. 
Chapter 3

Sward botanical composition and canopy cover affect the foraging behaviour of free-range laying hens 


\section{Abstract}

In organic and free-range chicken husbandry, the animals must have access to an outdoor run. The vegetation cover of the run can act as a foraging enrichment. In a two-year experiment, we investigated the influence of sward botanical composition (sward type) and of sward degradation - represented by stocking duration and canopy cover of green vegetation - on the foraging behaviour of chickens. Laying hens of the genotype ISA Warren were pastured on 15 sward types: on 14 monocultures of grassland plant species (nine grasses and five forbs) and one mixed sward comprising all these 14 species for three levels of stocking duration ( $1 \mathrm{~d}, 2 \mathrm{~d}$ and $3 \mathrm{~d}$ ). The behavioural traits pecking plants, ground pecking and scratching were recorded by scan sampling. Sward type $(P<0.01)$, stocking duration and the sward type $x$ stocking duration interaction $(P<0.001)$ had a significant effect on all three behavioural traits and the total of sward-directed pecking (plant and ground pecking together). With prolonged stocking, the frequency of ground pecking significantly increased, whereas that of scratching, plant pecking and of total sward-directed pecking significantly decreased. The tested sward types differed strongly with respect to degradation resulting from fixed levels of stocking duration. Percentage ground cover of green foliage proved to be a determinant of some traits of foraging behaviour. Plant pecking and total sward-directed pecking behaviour decreased with decreasing canopy cover of green foliage in a number of sward types. We conclude from these results that the tested sward types differed in providing a pecking incentive for the chickens and that increasing sward degradation reduced the value of the sward as a stimulus for pecking. This may be relevant for animal health and welfare, because in environments displaying few pecking stimuli, feather and injurious pecking may result from re-directed foraging-related pecking.

\section{Introduction}

Providing animals with access to an outdoor run is a fundamental constituent of organic chicken husbandry and a prerequisite for the production of eggs labelled as 'free-range'. It is important that the run area is covered with green vegetation since, amongst other benefits, vegetation cover reduces both soil erosion and nutrient leaching which results from the significant amounts of manure deposited on the run area (Kratz et al. 2004; De Baets et al. 2006). Furthermore, the provision of an outdoor run covered with plants has been shown to have beneficial effects on animal health and welfare. Shimmura et al. (2008) have recorded a reduced incidence of feather and injurious pecking when laying hens had access to a range covered with clover, and Mahboub et al. (2004) observed a better plumage condition with increasing time spent on grassland. Lambton et al. (2010) and Bestman and Wagenaar (2003) have found a reduced incidence of feather pecking in flocks with a good use of the run area, which the latter attributed primarily to a reduction of stress levels due to lower 
animal densities. The vegetation cover of the outdoor run can also be viewed as a type of enrichment (Jones 2002). Previous studies have accumulated evidence that environmental and foraging enrichment reduces injurious and feather pecking (Sherwin et al. 1999; McAdie et al. 2005). This can be explained by the fact that chickens spend approximately the same time budgets on pecking in barren as in enriched environments; in barren environments, however, due to a reduction of time spent on foraging-related pecking behaviour (e.g. litter, ground or food pecking) the animals more frequently re-direct pecking towards their conspecifics (Blokhuis 1989; Steenfeldt et al. 2007). Reduced feather pecking may also result from intake of forage from pasture. Fibre-rich or low-energy diet has been found to reduce cannibalism and mortality (Hartini et al. 2002; van Krimpen et al. 2009), which may be caused by an increased time spent on feed intake (van Krimpen et al. 2008; Jordan et al. 2010).

Considering these benefits of the vegetation cover for animal health and welfare, surprisingly few studies have investigated the relevance of the quality and the botanical composition of the sward on chicken behaviour. Studies evaluating different types of vegetation for chicken runs have so far focused on various other aspects. For example, the functionality of plants providing shade and shelter has been taken into account for the design of structures that would make a larger proportion of the flock use the outdoor run and spread more evenly over the total area (Dawkins et al. 2003; Zeltner and Hirt 2008). Besides, the effects on quality of poultry products resulting from herbage intake (Ponte et al. 2008; Horsted et al. 2010; Anderson 2011), and the nutritive and metabolizable energy value provided by herbage (Antell and Ciszuk 2006; Horsted and Hermansen 2007) have been the main subject of research on the choice of plants for greening outdoor chicken runs.

The pecking behaviour of chickens is guided by the colour, texture and structure of the object or feed (Jones et al. 2000). Nutritional requirements have been shown to explain the choice and the amount of feed intake in layers (Horsted et al. 2006). For ground pecking and scratching behaviour, Petherick and Duncan (1989) have found significant differences in substrate choice when chickens were provided with substrates of different particle size and structure. As different species of plants come in a variety of shapes and sizes and differ with regard to their chemical composition, it may be that the pecking and scratching behaviour of chickens varies in response to the botanical composition of the pasture sward, and also in response to the percentage canopy cover of green foliage. In addition, although this aspect has as yet not been investigated, we assumed that chickens may also adapt their pecking behaviour in response to the freshness and palatability of the pasture; it has been shown that ruminants avoid patches of pasture contaminated with faeces (e.g. Cooper et al. 2000; Fleurance et al. 2007; Smith et al. 2009). Therefore, we hypothesized that sward degradation 
as caused by prolonged period of grazing reduces the foraging behavioural activity of laying hens.

The target of the present study was to analyse the effect of plant species composition (sward type) and of sward quality in terms of state of degradation on the foraging behaviour of chickens. In a field experiment, laying hens were taken to pasture at three standardised levels of stocking duration on monoculture swards of fourteen different herbaceous plant species and one mixed sward. The frequency of the behaviours scratching, pecking plants, and ground pecking was recorded, and the effect of sward type, stocking duration and state of sward degradation on these variables was analysed. We aimed to identify properties of the run cover which trigger high activity levels in terms of behavioural interaction with the sward. The results were intended to deliver a basis for the improvement of design and management of outdoor runs for laying hens.

\section{Material and Methods}

In a field experiment, laying hens were taken to pasture at three standardised levels of stocking duration on monoculture swards of fourteen different plant species and one mixed sward. The frequency of the behaviours scratching, pecking plants, and ground pecking was recorded, and the effect of sward plant species composition (sward type) and state of sward degradation on them was analysed. Sward degradation was in the first place represented by the factor stocking duration with the underlying assumption that prolonged stocking would result in an increasing deposition of excrements and an increasing destruction of the canopy by scratching. The standardised levels of stocking duration applied, however, resulted in degradation of varying extent in the investigated sward types. In forbs, the largest part of the vegetation was eliminated at the long stocking duration, whereas in several grass species, the same stocking duration resulted in minor sward gaps. Due to this fact, we additionally analysed the correlation between ground cover of green foliage and the frequency of scratching, ground pecking and pecking plants.

\section{Subjects, housing and pasture}

The study was conducted in 2009 and 2010. In both years, sixty non-beak trimmed laying hens (ISA Warren) were used for the experiment; different flocks were used in the two years. The animals were purchased in July 2009 and in May 2010 at the age of 18 weeks from one organic farm. In both years, the animals were randomly assigned to 15 groups of four animals and individually marked with coloured rings.

When not on pasture, the animals were kept as one group of 60 animals in a roofed outdoors pen of $3 \times 15 \mathrm{~m}$ and a height of $4 \mathrm{~m}$ equipped with perches and nests and with sand as ground cover. The pen had solid walls at two sides (one on the short, and one on 
the long side); the other two sides were made of wire mesh fence covering the complete height of the pen. One half of the pen area $(3 \times 7.5 \mathrm{~m}$, solid walls at two sides), where the nests, perches, feeders and the water fountain were located, was roofed with light green plastic foil; the other half of the pen was roofed with wire mesh. Temperature in the pen was at ambient air temperature. The animals were provided ad libitum with layers' complete fodder (Reudink Biologische Voeders B.V, Boxmeer, The Netherlands) in the pen.

\section{Experimental design}

The study was conducted on an experimental site of the Department of Crop Sciences of

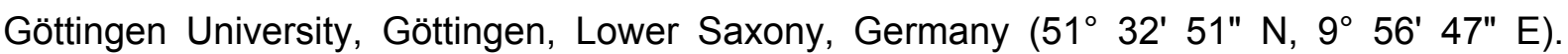
Fourteen species of grassland plants were used to establish the 15 sward types for the experiment. The main criterion for their choice was their known high tolerance to intensive management, i.e. to frequent grazing, cutting and trampling (Dierschke and Briemle 2002). We expected that these traits would confer a high persistence of the sward under conditions of stocking with chickens. In most of the grass species, turfgrass cultivars bred for frequent and low cutting (e.g. in sports turfs) were chosen (Bundessortenamt 2006). The following plant species were used: grasses: Agrostis stolonifera L. 'Barifera', Deschampsia cespitosa L. (wild-type), Elymus repens L. (wild-type), Festuca arundinacea Schreb. 'Mustang', F. rubra rubra L. 'Rossinante', F. trichophylla Ducros ex Gaudin 'Barcrown', Lolium perenne L. 'Bargold', Poa pratensis L. 'Julius', P. supina Schrad. 'Supreme'; forbs: Achillea millefolium L. (wild-type), Plantago major L. (wild-type), Ranunculus repens L. (wild-type), Taraxacum officinale agg. (wild-type), Trifolium repens L. 'Rivendel'. The swards were sown and established as monocultures and as one mixture comprising all the fourteen species in summer 2008. When stocking started, the sward of the mixed plot comprised large proportions of yield of L. perenne (approx. $50 \%$ ), F. rubra, and F. trichophylla (together approx. 30\%); F. arundinacea (<10\%), A. stolonifera, P. pratensis, T. officinale, A. millefolium, and $T$. repens $(<5 \%)$ were minor constituents of the sward; the other species occurred as individual specimens. The design comprised a total of 45 main plots: the 15 different sward types (whole-plot level factor) were arranged in three randomised blocks as replications.

Laying hens were taken to pasture on the plots from 8:00 $\mathrm{h}$ to $13: 00 \mathrm{~h}$ each Monday to Friday in the summer months of both years. This time of the day was chosen as the stocking period in order to take account of the fact that chickens use the run most frequently during the morning hours (Mahboub et al. 2004; Hegelund et al. 2005). Three separate sections (subplots) of each main plot were stocked at different levels of stocking duration: four animals per $\mathrm{m}^{2}$ for five hours per day for one (short), two (medium), and three (long) consecutive days. Subplots were stocked at the same level of stocking duration throughout 
the experiment. The animals were pastured in a rotational grazing scheme: Per block, all subplots of the same level of stocking duration were stocked simultaneously; subplots of different levels of stocking duration within each block were stocked successively; blocks were stocked successively in a constant order (Figure 3). Hence, between two stocking events, the subplots were not stocked for approximately 25 days (one stocking cycle: one time of stocking plus consecutive rest period). One week before re-stocking, the plots were mown to $7 \mathrm{~cm}$ stubble height. Altogether, in 2009 , two stocking cycles were run from late July to midSeptember; in 2010 four cycles were run from late May to mid-September. In 2009, the date of start of grazing resulted from the fact that due to poor germination, some of the swards needed re-sowing in spring 2009; in order to allow for proper sward establishment, stocking was not commenced before summer.

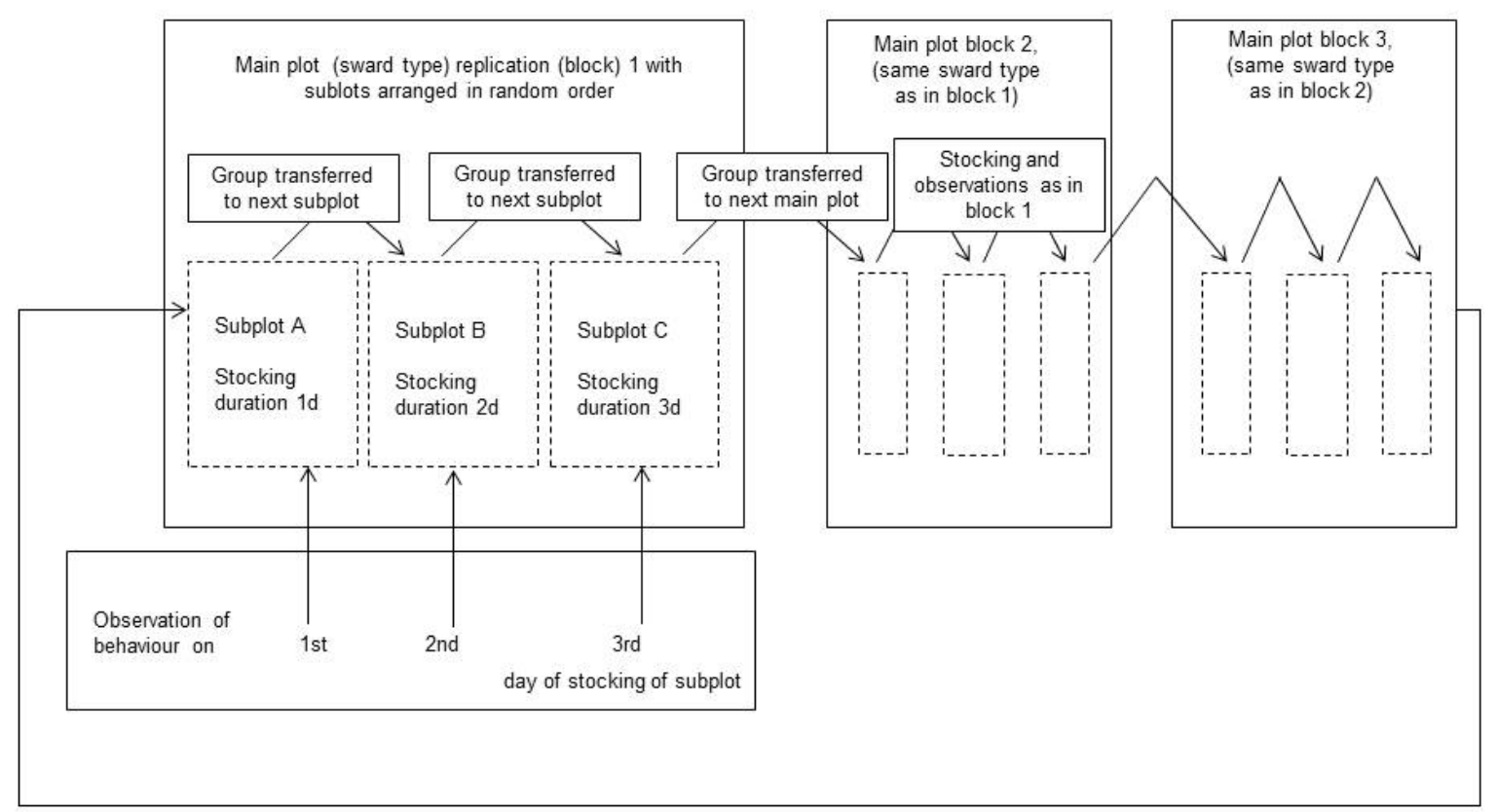

Re-stocking of block 1 after approx. $25 \mathrm{~d}$ (one stocking cycle)

Figure 3 Schematic illustration of the experimental design, stocking scheme and dates of behavioural data sampling

In order to obtain a standardized stocking density, each group of four animals was set in a mesh wire cage of $80 \times 125 \times 50 \mathrm{~cm}$ on the respective subplot. The small group and plot size allowed an accurate recording of behaviour as the observer was able to stand at close distance to the animals without disturbing them. When on pasture, the animals were kept in groups of the same four individuals throughout the year in order to minimize encounters 
between unfamiliar birds. Each group was taken to pasture on the same sward type for a whole grazing season (year) in order to reduce confounding effects caused by frequent change of diet. For transfer, the animals were handled by trained staff: each morning they were set into chicken crates in the pen, carried to the respective plots which were located at a distance of approx. $50 \mathrm{~m}$ and set into the cages on the plots; at noon, they were transferred back to the pen in the same way. From the beginning of the experiment, the animals were very calm, generally showed indifferent reaction to the presence of humans in the pen, and appeared to be habituated to daily handling within short time.

\section{Sampling}

Behavioural data were recorded by scan sampling during the second stocking cycle in 2009 and during the fourth stocking cycle in 2010, which is from mid-August to mid-September in both years. These two periods were chosen for the following reasons: (i) as the animals had not had any previous experience of grazing, the first stocking cycle of both years was considered as a habituation phase, and therefore no behavioural data were collected during this period, and (ii) we expected sward canopy cover to decrease with increasing number of stocking events; as we intended to use state of sward degradation as an explanatory variable for behaviour, we chose those stocking cycles which would provide the largest possible range of values of this variable. Behavioural data were sampled on each last day of a group's stay on a subplot. Hence, for the subplots stocked for three consecutive days, data were sampled on the third day, for the subplots stocked for two consecutive days, data were sampled on the second day, and for the subplots stocked for one day, data were sampled on that day (Figure 3). Data were obtained during a period from 8:00 h to 10:30 h. Sampling was performed in the following way: The observer approached a randomly chosen group and stood at close distance to the group, which allowed a precise sampling, e.g. an accurate discrimination of pecking plants or bare soil. The animals did not show any reaction to the presence of the observer. The observer focussed one animal and counted to five seconds. The behaviour displayed at this second was recorded. Then the observer changed his focus to the next animal to obtain the next data point in the same way, and so on. Keeping a constant order of the animals observed, this sampling procedure was repeated for each group of animals until five data points had been obtained from each of the animals, and hence twenty data points had been collected per group. Then the observer changed to the next group. Per observation day, data were collected six times in this way from each group of animals. Hence, a total of 120 data points were collected per day of observation and group of animals. The following interactions of the animals with the vegetation and the ground were recorded as a count: scratching, pecking plants (beak touching green plant (leaf), stem or plant parts detached of sward), and ground pecking (beak touching soil). When the animal 
was in a ground-directed pecking movement at the second of recording of a data point, this movement was followed to determine either plant or ground pecking. Other behaviour were recorded as counts, but not analysed.

Canopy cover (ground cover of green vegetation) as a measure of state of sward degradation was determined by means of digital photograph analysis, a method which has been shown to achieve high accuracy (e.g. Richardson et al., 2001). Photographs of the complete grazed surface of each subplot were taken immediately pre-stocking, and immediately post-stocking at the last day of stocking of a subplot in each stocking cycle. Photographs were taken with a digital camera (NV10, Samsung Electronics, NJ, USA) at a resolution of 1 megapixel. In order to ensure coverage of the complete pastured area a wood frame of $80 \times 125 \mathrm{~cm}$ with two bars crossing at the centre to form four rectangles of equal size was positioned on the grazed surface, and one photograph of each was taken by holding the camera at a constant height above the centre of the rectangle. In order to obtain photographs at comparable conditions of illumination, the pictures were taken during periods of clouded sky or the subplots were shaded with a portable plastic foil. Two pictures per subplot were selected the canopy cover values of which were pooled for statistical analysis. To determine canopy cover in terms of percentage ground cover of green foliage area the pictures were digitally processed as follows: They were first colour-transformed using the software GIMP 2 (GNU Image Manipulation Program, The GIMP Development Team) by maximizing $R G B$, subsequently maximizing the hue, saturation and lightness values of the colours red, blue and green, and finally maximizing the contrast of the image. The images thus transformed were analysed using the software image J version $1.44 p$ (National Institutes of Health, Bethesda, MD, USA): the colour channels were split and the area fraction of green pixels was determined by applying the 'analyse particle' function to the green channel slice. The applied method hence differentiated between "green" and "non-green" sward areas. The latter comprised dead biomass, bare soil areas, patches of manure and vegetation covered by mud. This approach was chosen, because it was the aim of this study to identify the effect of ground cover of green (i.e., living, and presumably palatable) vegetation. When mentioning the term "canopy cover" in the following, we refer to the percentage ground cover of green foliage.

\section{Statistical analysis}

Statistical data analysis was conducted using the software $R$, version 2.14 ( $R$ Development Core Team, 2011). We determined the effects of the factors sward type and stocking duration and of their interaction on behaviour (given as count data of incidence of the behavioural traits scratching, plant pecking, ground pecking and the sum of plant and ground pecking) by calculating generalized mixed models with a poisson distribution and a 
random term incorporating the nested effects of year, group of animals, main plot, and subplot within the experimental design using the glmer() function of the Ime4 package. The models were validated by graphical inspection of residues. The significance of the fixed effects for each trait of behaviour was determined by model comparison using the anova() function.

The effect of sward type, stocking duration, stocking cycle (repeated stocking), and of their interactions for percentage cover of green foliage was analysed for data from the two years separately by calculating a three-factorial split-plot ANOVA. The experimental design and the repeated measurements were incorporated by a corresponding hierarchical error structure. Data on canopy cover - being percentage values - were arcsine-square root transformed for analysis.

We determined the effect of canopy cover of green foliage on the frequency of scratching, pecking plants, ground pecking and of total sward-directed pecking by linear regression. As canopy cover of the subplots in many cases decreased considerably in the course of the daily stocking period, it was impossible to attribute precise values of canopy cover to each value of the behavioural data sampled during a $3.5 \mathrm{~h}$-observation period. For this reason, we calculated approximation values: The average canopy cover of a subplot at the start of the observation period (the mean over the three replications) was used as an approximation of the canopy cover at the respective level of stocking duration. Hence, for the short stocking duration, the mean canopy cover of the respective subplots immediately pre-stocking was used; for the medium and long stocking duration, the means of the post-stocking values of the short and medium stocking duration, respectively, were used. Linear regression was based on the mean canopy cover values over the short, medium and long stocking duration per species and stocking cycle and, for the behavioural data, in the same way the means of the respective data of the corresponding observation periods per species and stocking cycle were utilised.

\section{Results}

Effects of sward type and stocking duration on behaviour

The factors sward type, stocking duration and their interaction had a significant effect on the scratching and pecking behaviour of the laying hens.

In average over the total of observations, scratching accounted for approximately $3 \%$ of the behaviour of the laying hens. With prolonged stocking, the frequency of scratching significantly declined $(P<0.001)$. The factors sward type $(P=0.003)$ and the sward type $\mathrm{x}$ stocking duration interaction $(P<0.001)$ had a significant effect on the frequency of scratching. At the short stocking duration, scratching was most frequent in T.repens, 
L. perenne and the mixed sward, and least frequent in $R$. repens, F. rubra and $F$. trichophylla swards (Table 8).

Ground pecking also accounted for a proportion of $3 \%$ of the behaviour of the laying hens during the total of the observation periods. With prolonged stocking, the frequency of ground pecking significantly increased $(P<0.001)$ (Table 8$)$. The factors sward type and the sward type $x$ stocking duration interaction had significant effect on the frequency of ground pecking $(P<0.001)$.

Plant pecking accounted for approximately $29 \%$ of the total of the behaviour of the laying hens in average over the complete data set. With prolonged stocking (factor stocking duration), the frequency of plant pecking was significantly reduced $(P<0.001)$. The factors sward type $(P=0.001)$ and the sward type $x$ stocking duration interaction $(P<0.001)$ had a significant effect on plant pecking behaviour. At the short stocking duration, plant pecking was most frequent in T. repens, P. major, A. stolonifera, and P. pratensis and the mixed sward ( $>39 \%$ of the total of behaviour data recorded during this level of stocking duration) and least frequent in $F$. arundinacea and F. trichophylla swards ( $<24 \%$ of the total of behaviour data recorded during short stocking) (Table 8).

Total sward-directed pecking (plant and ground pecking together) showed a similar response to the factors sward type, stocking duration and their interaction as plant pecking. The frequency of total sward-directed pecking decreased significantly with increasing stocking duration $(P<0.001)$. In some of the tested swards, particularly in forbs swards, the frequency of total sward-directed pecking was reduced by one third or more at 3-day stocking compared to 1-day stocking (Table 8). 
Table 8. Frequency of the behaviours pecking plants, ground pecking and scratching as percentage of all behavioural data sampled during the observation periods (\%, untransformed values) at three levels of stocking duration on monoculture swards of fourteen plant species and one mixed sward. Means ( $n=6)$ over the second stocking cycle in 2009 and the forth stocking cycle in 2010 and three replications per stocking duration level.

\begin{tabular}{|c|c|c|c|c|c|c|c|c|c|}
\hline & \multicolumn{3}{|c|}{ Pecking plants } & \multicolumn{3}{|c|}{ ground pecking } & \multicolumn{3}{|c|}{ scratching } \\
\hline & \multicolumn{9}{|c|}{ Stocking duration } \\
\hline & Short & medium & long & short & medium & long & short & medium & long \\
\hline Grasses & & & & & - \% -- & - & ----י- & - & - \\
\hline A. stolonifera & 39.7 & 35.0 & 25.3 & 3.2 & 2.1 & 4.5 & 5.8 & 4.9 & 5.0 \\
\hline D. cespitosa & 29.7 & 28.2 & 22.5 & 1.7 & 0.7 & 5.6 & 4.7 & 2.5 & 2.4 \\
\hline E. repens & 33.7 & 30.0 & 22.3 & 1.9 & 6.7 & 9.1 & 2.9 & 2.8 & 2.1 \\
\hline F. arundinacea & 23.1 & 20.4 & 19.9 & 1.8 & 1.2 & 2.6 & 4.9 & 0.6 & 3.0 \\
\hline F. rubra & 32.9 & 31.8 & 28.1 & 0.7 & 1.0 & 3.5 & 1.1 & 1.7 & 2.2 \\
\hline F. trichophylla & 23.2 & 23.9 & 21.9 & 1.3 & 1.5 & 6.5 & 2.4 & 1.4 & 1.8 \\
\hline L. perenne & 35.2 & 34.0 & 24.4 & 3.5 & 2.5 & 6.6 & 7.9 & 5.0 & 4.1 \\
\hline P. pratensis & 40.3 & 31.0 & 31.2 & 0.7 & 1.3 & 4.6 & 2.9 & 2.4 & 2.9 \\
\hline P. supina & 38.0 & 35.1 & 30.4 & 1.1 & 1.1 & 0.9 & 3.5 & 3.3 & 1.8 \\
\hline \multicolumn{10}{|l|}{ Forbs } \\
\hline A. millefolium & 35.2 & 28.0 & 12.8 & 1.8 & 2.4 & 7.5 & 4.7 & 2.9 & 2.9 \\
\hline P. major & 41.8 & 13.1 & 10.0 & 2.0 & 8.2 & 5.4 & 3.1 & 0.7 & 0.6 \\
\hline R. repens & 35.7 & 23.9 & 18.1 & 3.2 & 6.0 & 3.5 & 0.7 & 1.0 & 4.9 \\
\hline T. officinale & 37.2 & 31.3 & 14.4 & 3.5 & 5.6 & 13.2 & 4.9 & 3.3 & 4.6 \\
\hline T. repens & 39.3 & 44.9 & 31.9 & 0.3 & 1.1 & 5.6 & 8.9 & 5.6 & 3.8 \\
\hline Mixed plot & 40.5 & 36.0 & 25.3 & 2.6 & 1.0 & 4.7 & 6.4 & 4.6 & 4.0 \\
\hline
\end{tabular}




\section{Effect of stocking on vegetation canopy cover}

ANOVA revealed that the factors sward type, stocking duration and stocking cycle (repeated stocking) had significant effect on sward canopy cover in both years. In both years, the sward type $x$ stocking cycle interaction, and additionally in 2010 sward type $x$ stocking duration interaction were significant for canopy cover (Table 9).

Stocking reduced canopy cover in all of the tested species (Table 10). This had varying extent in the different swards. After three days of stocking, cover of green foliage of the forb and E. repens swards frequently was $<20 \%$, whereas in F. arundinacea swards, canopy cover mostly was $>60 \%$.

Effect of canopy cover of green foliage on behaviour

There was no correlation of scratching behaviour with canopy cover. In contrast, our data revealed correlations of canopy cover with the frequency of the sampled traits of pecking behaviour. There was a significant negative correlation of ground pecking and canopy cover $\left(R^{2}=0.52 ; P<0.001\right)$ (Figure 4$)$. The frequency of plant pecking was positively correlated with canopy cover; however, this correlation was not significant for the whole data set. The determination of this correlation was strong at canopy cover values $<75 \%\left(R^{2}=0.71\right.$, $P<0.001)$. At canopy cover values of $>75 \%$ plant pecking and canopy cover were not significantly correlated. This was attributable to certain sward types, particularly to F. arundinacea and F. trichophylla in which low values of pecking frequency were observed despite of high percentage canopy cover of green foliage. (Table 8 and Table 10). For the total of sward-directed pecking behaviours, the correlation with canopy cover showed a similar pattern as for plant pecking. It was significant at canopy cover values $<75 \%$ $\left(R^{2}=0.55, P<0.001\right)$, but not significant for the complete data set. 
Table 9. Results of three-factorial ANOVA showing the effect of the factors sward type (14 monocultures, one mixed sward), stocking duration (short, medium, long) and stocking cycle ( $n=2$ in $2009, n=4$ in 2010) on the percentage ground cover of green foliage of the grazed swards immediately post-stocking. ${ }^{* * *}: P<0.001$; ns: not significant $(0.05)$.

\begin{tabular}{|c|c|c|c|c|c|}
\hline \multicolumn{3}{|c|}{2009} & \multicolumn{3}{|c|}{2010} \\
\hline & $\mathrm{df}$ & & & $d f$ & \\
\hline Sward type (S) & 14 & $* * *$ & Sward type (S) & 14 & $* * *$ \\
\hline Stocking duration (D) & 2 & $* * *$ & Stocking duration (D) & 2 & $* * *$ \\
\hline Stocking cycle (C) & 1 & $* * *$ & Stocking cycle (C) & 3 & $* * *$ \\
\hline$S \times D$ & 28 & ns & $S \times D$ & 28 & $* * *$ \\
\hline$S \times C$ & 14 & $* * *$ & $S \times C$ & 42 & $* * *$ \\
\hline$D \times C$ & 2 & ns & $D \times C$ & 6 & ns \\
\hline$S \times D \times C$ & 28 & ns & $S \times D \times C$ & 84 & ns \\
\hline
\end{tabular}

Table 10. Ground cover of green foliage [\%] immediately post-stocking in fifteen sward types and at three levels of duration of stocking with laying hens. Mean $(n=6)$ values, in brackets $1^{\text {st }}$ and $3^{\text {rd }}$ quartile, of the second stocking cycle in 2009 and the fourth cycle in 2010.

Sward type

Grasses

A. stolonifera

D. cespitosa

E. repens

$F$. arundinacea

F. rubra

F. trichophylla

L. perenne

P. pratensis

$P$. supina

Forbs
23.7 (13.1 / 36.3)

$22.2(10.0 / 35.4)$

35.0 (26.3 / 42.7)

$20.5(14.6 / 26.3)$

37.6 (23.1 / 42.7)

$$
\begin{gathered}
22.6(17.3 / 28.9) \\
6.3(1.8 / 8.6) \\
15.1(4.2 / 22.5) \\
9.5(5.7 / 14.5) \\
19.4(7.3 / 31.5)
\end{gathered}
$$

40.9 (33.2 / 51.2) 39.8 (15.9/58.5)

19.3 (4.3/ 33.3) 70.5 (65.1/ 74.4) 56.8 (46.9 / 64.2) $63.9(59.7 / 67.4)$ $42.0(23.3 / 57.1)$ 44.9 (32.6 / 57.3) $66.1(56.8 / 81.8)$
$28.9(6.1 / 47.7)$ $32.4(7.6 / 57.8)$ $13.1(0 / 24.9)$ $62.4(54.2 / 71.5)$ 56.8 (44.6 / 68.5) $52.4(40.9 / 59.8)$ 33.3 (9.7 / 51.9) 35.4 (19.8/52.0) 54.4 (48.0 / 63.3)

Mixed sward

61.0 (48.5 / 71.3)

38.7 (19.3 / 59.2)

$8.5(0.5 / 17.5)$

$6.3(0.4 / 6.2)$

$6.0(0 / 6.2)$

$4.6(0.5 / 7.4)$

$10.8(0 / 20.4)$ 


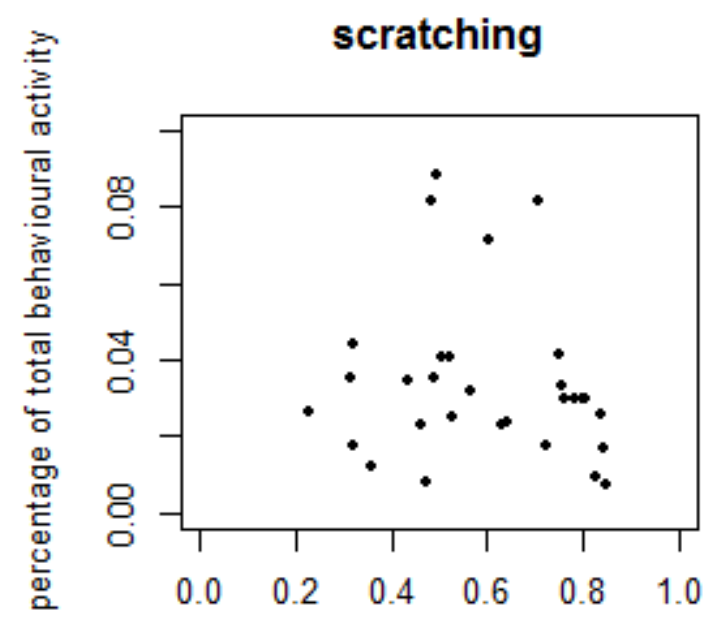

percentage canopy cover

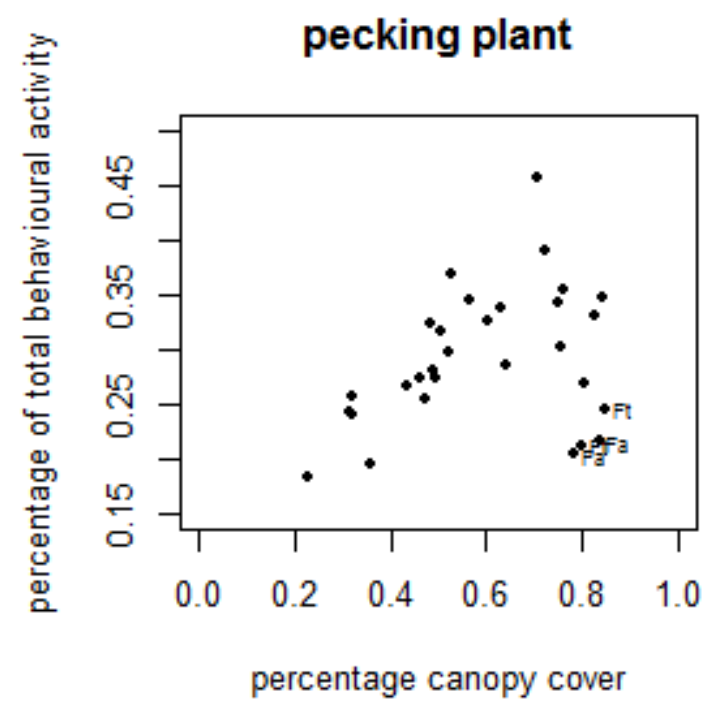

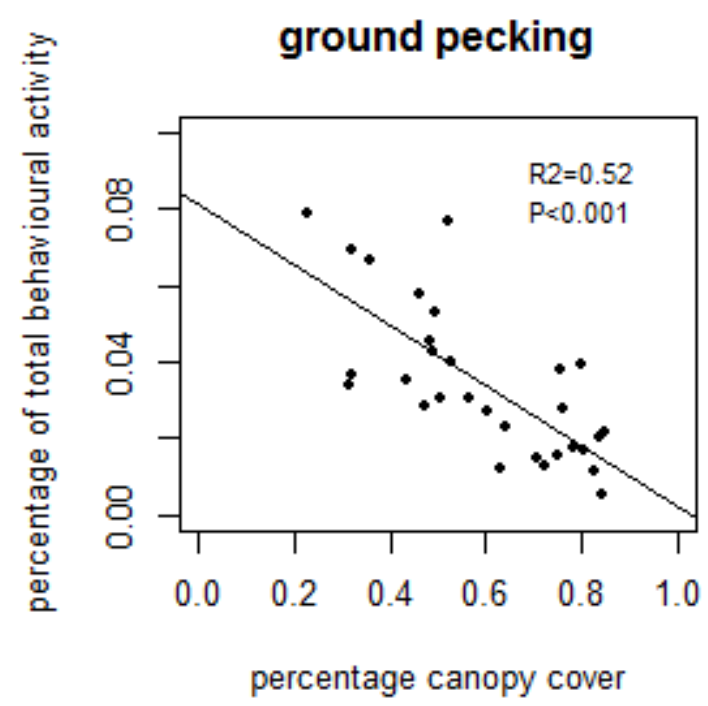

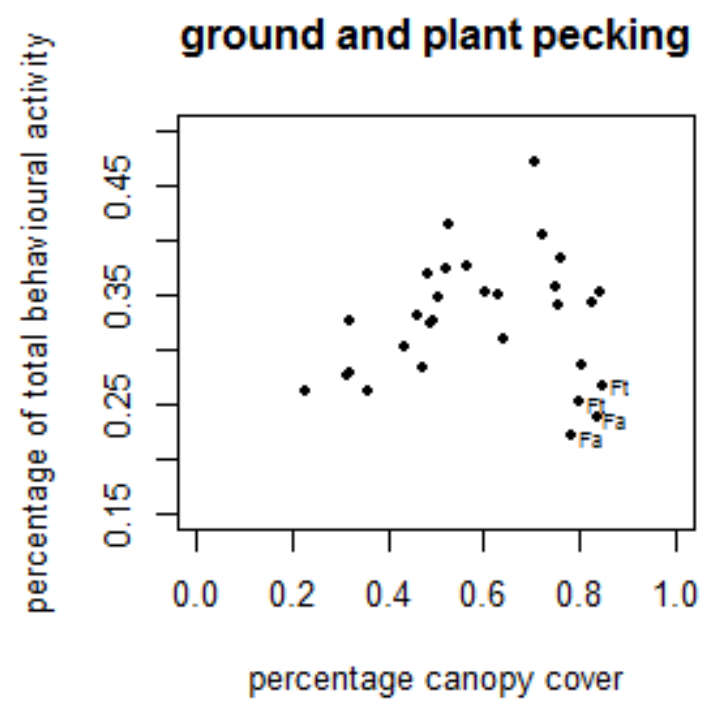

Figure 4. Correlations between percentage canopy cover of green vegetation and the frequency of the behaviours scratching, ground pecking, pecking plants, and of pecking plants and ground pecking together. Each data point represents the average value of three levels of stocking duration and of three pasture plots per sward type and year. Fa: Festuca arundinacea; Ft: Festuca trichophylla. Data of the second stocking cycle in 2009 and of the fourth stocking cycle in 2010.

\section{Discussion}

The present experiment was conducted in order to analyse the effects of sward botanical composition (sward type) and state of sward degradation caused by stocking - represented by stocking duration and canopy cover of green foliage - on the foraging behaviour of pastured laying hens. The behavioural traits pecking plants, ground pecking and scratching were recorded. The results confirm our hypothesis that both sward type and the state of sward degradation affect the foraging behaviour of pastured laying hens. 
The data obtained from observations at the short (1d-) stocking duration allow statements about behavioural interactions of the animals with the vegetation cover of fresh pasture or at a state of comparatively minor sward degradation.

Our data point out significant differences in the frequency of scratching on the tested swards at the short stocking duration. Scratching was observed most frequently on the $T$. repens sward. In contrast, F. rubra and F. trichophylla were among the sward types where scratching was least frequent. This may be due to the structure of vegetation of the respective plots. The mentioned Festuca species form a very dense sward of $>350$ tillers per $100 \mathrm{~cm}^{2}$ with hair-shaped leaves and a relatively plain surface. Opposed to this, T. repens features a comparatively loose and highly structured sward composed of stems and leaves of different size and at varying height throughout the canopy. Other studies have given some indication of particle size and texture of the litter to be an important incentive for scratching (Petherick and Duncan 1989). We assume that this preference for certain substrate structures also explains variations in the frequency of scratching on swards of different botanical composition.

Our data revealed significant differences in the frequency of plant pecking among the tested sward types. We observed that plant pecking was comparatively infrequent in the F. arundinacea, F. trichophylla and D. cespitosa swards. In contrast, the chickens appeared to display a pecking preference for forbs and grasses with comparatively soft leaves. A previous study by Horsted et al. (2006) has also reported observable foraging preferences for chicory over herbage of a grass/clover sward in concentrate-feed layers, but large variations in the amounts of dry matter removed from the plots did not reveal significant differences in intake between these two types of forage. Our sampling method did not allow a quantification of the amount of herbage actually ingested, but we assume the frequency of plant pecking to be correlated with intake. The animals hence appear to have complemented their diet of complete layers' pellets with variable amounts of herbage from pasture. A robust quantification of feeding preferences, however, will necessitate other methodological approaches, e.g. the analysis of crop content or of faeces (Antell and Ciszuk 2006; Horsted et al. 2007).

Prolonged stocking and sward degradation had a significant effect on foraging behaviour of the laying hens. Ground pecking increased with increasing stocking duration. This was presumably due to the mere fact that with prolonged stocking more gaps in the sward were present, which is supported by the photographic data of the swards. For scratching, which decreased with prolonged stocking, this explanation may also apply if the incentive for the chickens to this behaviour is to create bare soil areas which provide the animals with access 
to soil particles and invertebrates. However, we need to point out that the number of counts of scratching, as well as of ground pecking, was comparatively low, and there was generally a high variation in the frequency of all the recorded behavioural traits within sward types and observation periods, which may limit the robustness of the interpretation of observations of these two traits of behaviour.

Prolonged stocking and sward degradation significantly decreased the frequency of plant pecking. Notably, the frequency of the total of sward-directed pecking (plant and ground pecking together) also decreased with increasing sward degradation. Apparently, the reduced frequency of plant pecking was not balanced by an increased frequency of ground pecking.

There was a strong effect of sward botanical composition on the relationship between the frequency of the recorded behavioural traits and prolonged stocking. This is underpinned by the significant sward type $\mathrm{x}$ stocking duration interaction for all the recorded behaviours. We initially used the factor stocking duration as an approximation of the state of sward degradation with the premise of sward degradation getting stronger with prolonged stocking. However, the photographic data of the plots showed that sward degradation resulting from a fixed level of stocking duration did not have the same extent in all of the sward types. In $F$. arundinacea and $P$. supina swards, merely limited effects of prolonged stocking were visible in terms of sward gaps, and canopy cover of green foliage was $>50 \%$ throughout the experiment. In contrast, other grass sward types displayed signs of degradation in the form of stolons or tillers torn-off the canopy, presumably as a result of scratching; this was particularly the case in A. stolonifera, L. perenne, and the mixed sward. In E. repens and most of the forbs swards, the vegetation cover was close to completely removed after prolonged stocking as an effect of the chickens' herbage intake, and the low resistance of the comparatively soft foliage of the forb plants to scratching and trampling. These differences in resistance to stocking were also reflected by the significant effects on canopy cover of the factor sward type and the sward type $x$ stocking duration interaction. Differences in the resistance of various grassland plants to stocking with chickens were investigated and are related in greater detail in Chapter 1 of this thesis, and may be explained among others by the fibre content of the leaves, as well as stem and leaf flexibility (e.g. Shearman and Beard 1975a and 1975b; Sun and Liddle 1993; Brosnan et al. 2005; Dowgiewicz et al. 2011).

Our results indicate that percentage ground cover of green vegetation is an important determinant of the frequency of sward-directed pecking. During the observation periods of this experiment, at a canopy cover of approximately $70 \%$ the chickens in general spent more than $35 \%$ of their total behavioural on sward-directed pecking, and the largest proportion of 
it on plant pecking. A decrease of canopy cover was correlated with a decrease of the frequency of plant pecking; ground pecking showed the opposite pattern and significantly increased with decreasing canopy cover. A decrease by $50 \%$ of canopy cover of green foliage resulted in a decline of total sward-directed pecking by one third. Altogether, however, there appeared to be a strong effect of sward botanical composition on this relationship. In swards consisting of plants which generally seemed to provide little pecking incentive (e.g. F. arundinacea and F. trichophylla), sward-directed pecking activity was low despite of high canopy cover.

We recognize that our experimental design did not explicitly include "canopy cover of vegetation" as an explanatory variable and test a range of set levels of canopy cover for each sward type. We deem it an interesting question for further research to investigate the effect of different levels of sward canopy cover on chicken behaviour. This will help to establish in more robust way the relationship between behavioural traits of pastured laying hens and the state of the sward. We estimate this to be important aspect, because, in addition to providing forage, the vegetation cover of the outdoor run can be viewed as a type of enrichment (Jones 2002). In environments providing numerous pecking incentives the chickens are likely to spend a large proportion of their behaviour involving use of the beak on foraging-related pecking behaviour (e.g. litter, ground or food pecking) and are less likely to re-direct pecking towards their conspecifics (Blokhuis 1989; Steenfeldt et al. 2007; Shimmura et al. 2008). The provision of incentive for scratching by the sward, in contrast, may be of minor importance in this context; however, up to date there are merely a few studies on this aspect: e.g., in Bubier (1996) ground scratching had the same frequency in enriched as in non-enriched environments, and in Huber-Eicher and Wechsler (1998) the limitation of scratching facilities, as opposed to the deprivation of pecking facilities, did not alter the incidence of feather pecking.

In the present study, we did not analyse the effect of sward properties on feather or injurious pecking. For the groups of chickens we used in our experiment, we generally did not notice any incidence of feather or injurious pecking behaviour, and the plumage of all of the animals featured no damage at all. Despite the fact that we did not record any indicators of animal welfare in this experiment, due to the evidence of an association between increased ranging and a better plumage condition which other studies have found, we think that our findings may be relevant for the design of swards for laying hens outdoor runs. The choice of plant species that feature a high resistance to the adverse impacts of stocking with chickens, in particular to scratching, and which simultaneously provide attractive stimuli for pecking behaviour may hence offer a method of run management to foster animal welfare. 
Among the plant species tested for this study, $P$. supina appears to have a high capacity to fulfil both criteria; it was among those species receiving the highest frequency of pecking, and it featured a stable canopy cover even after repeated long-duration stocking. Our results also underpin the importance of further, established practices of run management, like rotational grazing with adequate rest periods, which support the preservation of an intact vegetation cover.

Further, specifically targeted experiments are needed to establish in more robust form the relevance of the sward for providing an effective enrichment that benefits animal welfare. Several other aspects deserve consideration in this respect; for instance the fact that, depending on the size of the flock, only part of the animals use the run (Hegelund et al. 2005). The observation that most animals also appear to spend merely a few hours per day on the run (Mahboub et al. 2004), however, would presumably not impair the effectiveness of the run sward as an enrichment, based on the finding of McAdie et al. (2005) who have shown that the presentation of an enrichment for only a few hours per day reduced feather pecking to the same extent as did its permanent display. Altogether, we consider the contribution of the run vegetation to animal welfare to be an important area for further research.

\section{Conclusions}

The results of this study show that the botanical composition and the state of degradation of the sward of the outdoor run have significant effects on the foraging behaviour of pastured laying hens. Plant species, freshness of sward and ground cover of green vegetation are important determinants of the incentive value of the sward for pecking. Forbs, and grasses with soft leaves were preferred for pecking. Progressive sward degradation and a decrease of canopy cover of green foliage were correlated with a decrease of the frequency of swarddirected pecking. This may be relevant for animal health and welfare as in environments providing few pecking stimuli, there is the risk of pecking to be re-directed to conspecifics and hence for injurious or feather pecking to arise. Different plant species feature a widely varying degree of resistance to stocking with chickens. The choice of plant species which have a high value as a pecking incentive and which additionally provide a stable ground cover can therefore contribute to animal welfare due to the evidence of an association between increased ranging and a better plumage condition which other studies have found. In addition, established measures of run management, like rotational grazing which allows for the vegetation to recover from stocking and provides frequent access to fresh pasture, are important for fostering animal welfare in free-range chicken husbandry. 


\section{References}

Anderson K.E. (2011) Comparison of fatty acid, cholesterol, and vitamin A and E composition in eggs from hens housed in conventional cage and range production facilities. Poultry Science 90: 1600-1608.

Antell S., and P. Ciszuk (2006) Forage consumption of laying hens - the crop content as an indicator of feed intake and AME content of ingested forage. Archiv für Geflügelkunde 70: 154-160.

Bestman M.W.P., and J.P. Wagenaar (2003) Farm level factors associated with feather pecking in organic laying hens. Livestock Production Science 80: 133-140.

Blokhuis H.J. (1989) The effect of a sudden change in floor type on pecking behaviour in chicks. Applied Animal Behaviour Science 22: 65-73.

Brosnan J.T., J.S. Ebdon, and W.M. Dest (2005) Characteristics in diverse wear tolerant genotypes of Kentucky Bluegrass. Crop Science 45: 1917-1926.

Bubier N.E. (1996) The behavioural priorities of laying hens: the effects of two methods of environment enrichment on time budgets. Behavioural Processes 37: 239-249.

Bundessortenamt (Ed.) (2006) Beschreibende Sortenliste Rasengräser. Bundessortenamt, Hannover, Germany.

Cooper J., I.J. Gordon, and A.W. Pike (2000) Strategies for the avoidance of faeces by grazing sheep. Applied Animal Behaviour Science 69: 15-33.

Dawkins M.S., P.A. Cook, M.J. Whittingham, K.A. Mansell, and A.E. Harper (2003) What makes free-range broiler chickens range? In situ measurement of habitat preference. Animal Behaviour 66: 151-160.

De Baets S., J. Poesen, G. Gyssels, and A. Knapen (2006) Effects of grass roots on the erodibility of topspoils during concentrated flow. Geomorphology 76, 54-67.

Dierschke, H., Briemle, G. (2002) Kulturgrasland. Wiesen, Weiden und verwandte Staudenfluren. Ulmer, Stuttgart.

Dowgiewicz J., J.S. Ebdon, M. DaCosta, and W.D. Dest (2011) Wear tolerance mechanisms in Agrostis species and cultivars. Crop Science 51: 1232-1243.

Fleurance G., P. Duncan, H. Fritz, J. Cabaret, J. Cortet, and I.J. Gordon (2007) Selection of feeding sites by horses at pasture: Testing the anti-parasite theory. Applied Animal Behaviour Science 108: 288-301.

Hartini S., M. Choct, G. Hinch, A. Kocher, and J.V. Nolan (2002) Effects of light intensity during rearing and beak trimming and dietary fibre sources on mortality, egg production, and performance of ISA brown laying hens. Journal of Applied Poultry Research 11, 104-110.

Hegelund L., J.T. Sørensen, J.B. Kjaer, and I.S. Kristensen (2005) Use of the range area in organic egg production systems: effect of climatic factors, flock size, age and artificial cover. British Poultry Science 46: 1-8.

Horsted K., M. Hammershøj, and J.E. Hermansen (2006) Short-term effects on productivity and egg quality in nutrient-restricted versus non-restricted organic layers with access to different forage crops. Acta Agriculturae Scandinavica Section A: Animal Science. 56: 42-54.

Horsted K., J.E. Hermansen, and H. Hansen (2007) Botanical composition of herbage intake of free-range laying hens determined by micro-histological analysis of faeces. Archiv für Geflügelkunde 71: 145-151.

Horsted K., M. Hammershøj, and B.H. Allesen-Holm (2010) Effect of grass-clover forage and whole-wheat feeding on the sensory quality of eggs. Journal of the Science of Food and Agriculture 90: 343-348

Horsted K., and J.E. Hermansen (2007) Whole wheat versus mixed layer diet as supplementary feed to layers foraging a sequence of different forage crops. Animal 1: 575-585.

Huber-Eicher B., and B Wechsler (1998) The effect of quality and availability of foraging materials on feather pecking in laying hen chicks. Animal Behaviour 55: 861-873. 
Jones R.B. (2002) Role of Comparative Psychology in the Development of Effective Environmental Enrichment Strategies to Improve Poultry Welfare. International Journal of Comparative Psychology 15: 77-106.

Jones R.B., N.L. Carmichael, and E. Rayner (2000) Pecking preferences and predispositions in domestic chicks: implications for the development of environmental enrichment devices. Applied Animal Behaviour Science 69: 291-312.

Jordan D., M.U. Faruk, P. Lescoat, M.N. Ali, I. Štuhec, W. Bessei, and C. Leterrier (2010) The influence of sequential feeding on behaviour, feed intake and feather condition in laying hens. Applied Animal Behaviour Science 127: 115-124.

Kratz S., J. Rogasik, and E. Schnug (2004) Changes in soil nitrogen and phosphorus under different broiler production systems. Journal of Environmental Quality 33: 1662-1674.

Lambton S.L., T.G. Knowles, C. Yorke, C.J. Nicol (2010) The risk factors affecting the development of gentle and severe feather pecking in loose housed laying hens. Applied Animal Behaviour Science 123: 32-42.

Mahboub H.D.H., J. Müller, and E. von Borell (2004) Outdoor use, tonic immobility, heterophil/lymphocyte ratio and feather condition in free-range laying hens of different genotype. British Poultry Science 45: 738-744.

McAdie T.M., L.J. Keeling, H.J. Blokhuis, and R.B. Jones (2005) Reduction in feather pecking and improvement of feather condition with the presentation of a string device to chickens. Applied Animal Behaviour Science 93: 67-80.

Petherick J.C., and I.J.H. Duncan (1989) Behaviour of young domestic fowl directed towards different substrates. British Poultry Science 30: 229-238.

Ponte P.I.P., C.M.C. Rosado, J.P. Crespo, D.G. Crespo, J.L. Mourão, M.A. Chaveiro-Soares, J.L.A. Brás, I. Mendes, L.T. Gama, J.A.M. Prates, L.M.A. Ferreira, and C.M.G.A. Fontes (2008) Pasture intake improves the performance and meat sensory attributes of freerange broilers. Poultry Science 87: 71-79.

R Development Core Team (2011) R. A language and environment for statistical computing. $R$ Foundation for Statistical Computing, Vienna, Austria.

Richardson M.D., D.E. Karcher, and L.C. Purcell (2001) Quantifying turfgrass cover using digital image analysis. Crop Science 41: 1884-1888.

Shearman R.C., and J.B. Beard (1975a) Turfgrass wear tolerance mechanisms. II. Effects of cell wall constituents on turfgrass wear tolerance. Agronomy Journal 67: 211-215.

Shearman R.C., and J.B. Beard (1975b) Turfgrass wear tolerance mechanisms. III. Physiological, morphological, and anatomical characteristics associated with turfgrass wear tolerance. Agronomy Journal 67: 215-218.

Sherwin C.M., P.D. Lewis, and G.C. Perry (1999) The effects of environmental enrichment and intermittent lighting on the behaviour and welfare of male domestic turkeys. Applied Animal Behaviour Science 62: 319-333.

Shimmura T., T. Suzuki, T. Azuma, S. Hirahara, Y. Eguchi, K. Uetake, and T. Tanaka (2008) Form but not frequency of beak use by hens is changed by housing system. Applied Animal Behaviour Science 115: 44-54.

Smith L.A., P.C.L. White, G. Marion, and M.R. Hutchings (2009) Livestock grazing behavior and inter- versus intraspecific disease risk via the fecal-oral route. Behavioural Ecology 20: $426-432$.

Steenfeldt S., J.B. Kjaer, and R.M. Engberg (2007) Effect of feeding silages or carrots as supplements to laying Henson production performance, nutrient digestibility, gut structure, gut microflora and feather pecking behaviour. British Poultry Science 48: 454468.

Sun D., and M.J. Liddle (1993) Trampling resistance, stem flexibility and leaf strength in nine Australian grasses and herbs. Biological Conservation 65: 35-41.

van Krimpen M.M., R.P. Kwakkel, C.M.C. van der Peet-Schwering, L.A. den Hartog, and M.W.A. Verstegen (2008) Low dietary energy concentration, high nonstarch polysaccharide concentration, and coarse particle sizes of nonstarch polysaccharides affect the behavior of feather-pecking-prone laying hens. Poultry Science 87: 485-496.

van Krimpen M.M., R.P. Kwakkel, C.M.C. van der Peet-Schwering, L.A. den Hartog, and M.W.A. Verstegen (2009) Effects of nutrient dilution and nonstarch polysaccharide 
concentration in rearing and laying diets on eating behavior and feather damage of rearing and laying hens. Poultry Science 88: 759-773.

Zeltner E., and H. Hirt. (2008) Factors involved in the improvement of the use of hen runs. Applied Animal Behaviour Science 114: 395-408. 
General Discussion 
The aim of the present study was to evaluate the suitability of fourteen grassland plant species for establishing swards for outdoor chicken runs. To this purpose, two field experiments and a supplemental greenhouse experiment were conducted, which allowed to examine this pasture system from several perspectives. The responses to stocking with laying hens concerning growth and productivity of the plants, and the influence of sward botanical composition and state of sward degradation on animal behaviour were analysed. The study addressed the following questions which will receive further discussion within this section:

- What are the most important animal-plant interactions in the chicken pasture system?

- Which plant species are particularly suitable for greening outdoor chicken runs, and what are their relevant characteristics?

- What can be learnt from this study for practical application?

Animal-plant interactions in chicken pasture

Like in other forms of pasture, in chicken grazing systems plants are exposed to frequent disturbance by defoliation. Some features, however, are particular to chicken grazing. Herbage can be pecked down to a stubble height of less than $1 \mathrm{~cm}$, which is lower than in sheep or horse grazing (Bockholt and Dittmann 2007; Catorci et al. 2012). Another aspect differentiating chicken grazing distinctly from other types of livestock grazing is scratching, which is a central part of chicken foraging behaviour. According to our data, the birds spent more than one third of their total activity in the morning hours on behavioural interaction with the sward, and approximately $29 \%$ and $3 \%$, respectively, on plant pecking and scratching. Our data have revealed that, as a consequence of these behaviours, and of trampling and the deposition of excrements, during fifteen hours of stocking with four laying hens per square metre, ground cover of green vegetation can be reduced by over $50 \%$, and in some plant species, especially in forbs, aboveground biomass had frequently been close to completely or completely removed by the end of the stocking period. Plants are thus facing a considerable strain as a consequence of the foraging behaviour of the chickens.

In return, behavioural data have shown that sward botanical composition and canopy cover of green vegetation strongly influence the foraging behaviour of the chickens. On the one hand, the animals distinctly responded to incentives arising from specific properties of the plants constituting the sward. Our data have shown that the factor sward type (plant species) significantly influenced scratching, and that chickens scratched least frequently on F. trichophylla swards, whereas scratching was most frequent on T. repens swards. The structure of the canopy may explain these differences (Petherick and Duncan 1989). The 
latter plant species also appeared to be among the sward types preferred by the chickens for pecking. Although the methods applied in the present experiment did not allow a quantification of the amount of herbage ingested, it is likely that those species that were pecked more frequently than others were also exposed to a greater extent of defoliation. Species which strongly trigger foraging behaviour are therefore more heavily exposed to the damaging effects of chicken grazing. On the other hand, our data have given evidence that the overall frequency of traits of foraging behaviour and that of plant pecking in particular decreased with proceeding sward degradation and the reduction of canopy cover of green foliage.

Properties of plant species suitable for greening outdoor runs

Vegetation ground cover can be considered as an environmental enrichment for the chickens (Jones 2002). Considering studies like the work by Huber-Eicher and Wechsler (1998) which have shown that foraging enrichment stimulates the animals to interact with the objects on display instead of directing pecks to conspecifics, it is therefore possible that the risk of the animals to develop feather or injurious pecking increases with proceeding sward degradation. Plant species which build a persistent canopy cover and which give strong incentive for foraging behaviour hence support the functionality of the sward for animal welfare by providing a stable environmental enrichment. Furthermore, the maintenance of a closed canopy cover in outdoor chicken runs is desirable for reasons of soil and water protection, i.e. for erosion control and the limitation of leaching of the high nutrient loads resulting from excrement deposition (Elbe et al. 2005; De Baets et al. 2006).

In order to understand the persistence of plant species under conditions of stocking with chicken we need to take account of the plant traits conferring tolerance to disturbance (Mclntyre et al. 1999). Plant species which are adapted to environmental conditions prevailing in managed grasslands feature a high resilience to frequent defoliation, e.g. via an adapted resource acquisition and biomass allocation (Nassiri and Elgersma 2002), or they have evolved avoidance strategies, e.g. by the location of their buds close to the soil surface (Cullen et al. 2006; Evju et al. 2009). The disturbance exerted on plants when stocked with chickens generally does not allow for these strategies of avoidance, because scratching causes a more comprehensive damage to the plant than ruminant bites, as it also reaches below the soil surface. Environmental and management conditions in chicken free-range husbandry additionally may not allow for the resilience capacity of the vegetation to be realised, for instance in rotational stocking systems with short rest periods, when plots are restocked irrespective of the re-growth state of herbage, or during arid periods if no supplemental irrigation is provided. 
Therefore we regarded a strong capacity of resistance to the damaging effects of chicken grazing as the most important characteristic of the tested plants. The maintenance of a good canopy cover and of a constant density of tillers or vegetation growing points at prolonged stocking were considered as the prevalent criteria for eligible species. Constant high growth rates of aboveground biomass, which would enable the binding of a relevant proportion of the nutrient input from excrements, and which would provide large quantities of herbage to supplement chicken alimentation, were used as a complementary criterion. Hence, the particular disturbance exerted on the sward when stocked with chickens necessitated different evaluation criteria than those usually applied for pasture plant species. Instead, our results showed that a number of properties which explain good performance of turf grasses in wear tests were found in the species featuring a strong resistance to stocking with chicken, e.g. a high fibre content of the cell wall, and high stem and leaf flexibility (Brosnan et al. 2005; Dowgiewicz et al. 2011).

A comprehensive evaluation of the tested plant species requires the consideration of the multiple functions of the sward in the outdoor run. The species Festuca arundinacea and Poa supina clearly featured the highest resistance towards stocking with chickens. The tested Festuca species, however, appeared to be comparatively unattractive for foraging. The animals merely spent little more than $20 \%$ of their complete activity pecking F. arundinacea or F. trichophylla swards, in comparison to close to or over $30 \%$ in most of other sward types. Festuca species therefore may not contribute to animal health and welfare, and to animal nutrition as well as the other tested plants.

The methods applied in the present experiment did not allow a quantification of the herbage intake of the animals, and we did not analyse the nutritive values of herbage from the different sward types. The capacity of the tested plant species to provide forage to the chickens hence necessitates separate investigation. In our opinion this point deserves further research, as the provision of supplemental forage by the outdoor run can be a relevant contribution to the optimisation of organic chicken husbandry systems: firstly, with respect to economic aspects - via the reduction of costs for feed - and secondly, concerning their environmental impact - via a better adaptation of feed nutrient supply to the animals' demand (Walker and Gordon 2003; Horsted and Hermansen 2007; Almeida et al. 2012).

Another focus of future research may be to address the question whether or not, and to which extent reductions in nutrient leaching can be affected by the plants we suggest for greening outdoor runs.

Lessons learnt for practical application

Our data have shown that the tested plant species differ significantly concerning their resistance to disturbance caused by stocking with chickens. The foraging behaviour of the 
animals was also significantly influenced by the botanical composition of the sward. We derive from these results that the choice of the plant species for greening outdoor chicken runs has considerable relevance for the realisation of the multiple functions of the sward, and can therefore be recommended as an effective novel method of run management.

Still, we deem it important to emphasize that the choice of suitable plant species for greening outdoor chicken runs alone does not suffice for maintaining an intact vegetation cover. Further, established practices of run management are indispensable; these include rotational grazing which allows adequate rest periods for the sward to recover, and a design of the run area with protective structures which encourage the animals to evenly frequent the whole of the run area (Zeltner and Hirt 2008).

Another novel way of protecting the vegetation of the chicken run may focus on the root and crown space of the sward. The results of our greenhouse experiment have shown that damage to the root is particularly detrimental to post-disturbance growth of the plants. Although we have not quantified this parameter in the field experiment, scratching presumably causes considerable damage to the crown and to a lesser extent also to the root of grasses. Therefore, the mechanical stabilisation of the upper soil layer and the meristem zone may potentially provide a further measure to protect the vegetation cover. Additionally, the treatment of the run with a grassland harrow in regular intervals, in order to disperse excrements covering the most heavily frequented areas of the sward after a prolonged stocking period may facilitate vegetation re-growth. We suggest that the efficiency of these latter two novel management options should be evaluated in field trials.

We conclude from the results of the present study that the management of the botanical composition of the sward has a relevant influence on several of the multiple functions of the outdoor run: It affects the environmental impact of free-range husbandry by mediating improved soil protection, and it fosters the contribution to animal health and welfare of the run. Therefore, we perceive that there is significant potential for further research concerning the optimisation of chicken free-range husbandry systems via an adequate design and management of the sward in outdoor runs.

\section{References}

Almeida G.F. de, L.K. Hinrichsen, K. Horsted, S.M. Thamsborg, and J.E. Hermansen (2012) Feed intake and activity level of two broiler genotypes foraging different types of vegetation in the finishing period. Poultry Science 91: 2105-2113.

Bockholt R., and L. Dittmann (2007) Ein Experiment zur Prüfung verschiedener Gräser als Hühnerweide. In: Wrage, N., and J. Isselstein, editors, Neue Funktionen des Grünlands: Ökosystem, Energie, Erholung. Mitteilungen der Arbeitsgemeinschaft Grünland und Futterbau, Vol. 8, pp. 32-36.

Brosnan J.T., J.S. Ebdon, and W.M. Dest (2005) Characteristics in diverse wear tolerant genotypes of Kentucky Bluegrass. Crop Science 45: 1917-1926. 
Catorci A., R. Gatti, and S. Cesaretti (2012) Effect of sheep and horse grazing on species and functional composition of sub-Mediterranean grasslands. Applied Vegetation Science 15: 459-469.

Cullen B.R., D.F. Chapman, and P.E. Quigley (2006) Comparative defoliation tolerance of temperate perennial grasses. Grass and Forage Science 61: 405-412

De Baets S., J. Poesen, G. Gyssels, and A. Knapen (2006) Effects of grass roots on the erodibility of topspoils during concentrated flow. Geomorphology 76, 54-67.

Dowgiewicz J., J.S. Ebdon, M. DaCosta, and W.D. Dest (2011) Wear tolerance mechanisms in Agrostis species and cultivars. Crop Science 51: 1232-1243.

Elbe U., A. Roß, G. Steffens, H. Van den Weghe, and C. Winckler (2005) Ökologische Legehennenhaltung in großen Herden: Spezifische Auslaufnutzung und Nährstoffeintrag. In: Heß, J., and G. Rahmann, editors, Ende der Nische, Beiträge zur 8. Wissenschaftstagung Ökologischer Landbau, kassel university press $\mathrm{GmbH}$, Kassel, pp. 307-310.

Evju M., G. Austrheim, R. Halvorsen, and A. Mysterud (2009) Grazing responses in herbs in relation to herbivore selectivity and plant traits in an alpine ecosystem. Oecologia 161: 77-85

Horsted K., and J.E. Hermansen (2007) Whole wheat versus mixed layer diet as supplementary feed to layers foraging a sequence of different forage crops. Animal 1: 575-585.

Huber-Eicher B., and B. Wechsler (1998) The effect of quality and availability of foraging materials on feather pecking in laying hen chicks. Animal Behaviour 55: 861-873.

Jones R.B. (2002) Role of comparative psychology in the development of effective environmental enrichment strategies to improve poultry welfare. International Journal of Comparative Psychology 15: 77-106.

Mclntyre S., S. Lavorel, J. Landsberg, and T.D.A. Forbes (1999) Disturbance response in vegetation - towards a global perspective on functional traits. Journal of Vegetation Science 10: 621-630.

Nassiri M., and A. Elgersma (2002) Effects of nitrogen on leaves, dry matter allocation and regrowth dynamics in Trifolium repens L. and Lolium perenne L. in pure and mixed swards. Plant and Soil 246: 107-121.

Petherick J.C., and I.J.H. Duncan (1989) Behaviour of young domestic fowl directed towards different substrates. British Poultry Science 30: 229-238.

Walker A., and S. Gordon (2003) Intake of nutrients from the pasture. Proceedings of the Nutrition Society 62: 253-256.

Zeltner E., and H. Hirt (2008) Factors involved in the improvement of the use of hen runs. Applied Animal Behaviour Science 114: 395-408. 


\section{Summary}

The aim of the present study was to evaluate the suitability of fourteen grassland plant species for establishing swards for free-range chicken husbandry. Nine grasses and five forbs which are known for their good performance in intensively managed grasslands and for their high tolerance towards frequent grazing and cutting, and to trampling were used.

In a field experiment, we tested the tolerance of these plants to stocking with chickens. We hypothesized that the performance of the individual species would vary strongly, because the disturbance affected by chickens is particularly heavy and differs distinctly from the conditions commonly found in other systems of grassland management. Monoculture swards of the fourteen tested species, and one mixture comprising all of these species were subjected to rotational stocking with chicken at three levels of stocking duration. The effect of plant species, stocking duration, and stocking cycle on the canopy cover, density of tillers or vegetation growing points, and growth rates of aboveground biomass were analysed. From the former two target parameters, resistance of the plant species to stocking with chicken was derived; from the latter, resilience was estimated. Our data confirmed the assumption that the tested species differ strongly with respect to their resistance and resilience to stocking with chicken, and indicated that grasses are generally more suitable than forbs for greening an outdoor chicken run. The species Festuca arundinacea and Poa supina featured the best performance, with a canopy cover of over $80 \%$ and constant tiller densities, and with a stable and comparatively high biomass accumulation of over $4.8 \mathrm{~g}$ dry matter $\mathrm{m}^{-2} \mathrm{~d}^{-1}$ after repeated long-duration stocking.

By means of a supplemental pot experiment under greenhouse conditions we aimed at elucidating whether traits related to plant growth form give an explanation for tolerance to the disturbance affected by stocking with chicken. We hypothesized that pre-disturbance biomass allocation, and the location of storage and clonal growth organs would be important determinants of damage tolerance. We expected that tolerance would be high in plants with these organs concentrated in a tussock or located close to or underneath the soil surface, and with high allocation to storage organs in root or tussock. A selection of the species used in the field experiment which represented three growth forms (cespitose, stoloniferous, and rhizomatous) were subjected to three levels of a standardized damage treatment impacting simultaneously on shoot and root. Our results showed that plant species, but not growth form groups differed significantly in damage tolerance, and that $F$. arundinacea and Poa pratensis showed the best performance. Shoot re-growth was strongly correlated with relative posttreatment root biomass, i.e. with the ratio of root biomass of the treated plants in relation to that of the non-treated control across all species and treatment levels, but not with pre- 
treatment root biomass. Root resistance to mechanical damage therefore appears to be the prevalent determinant of tolerance to the applied type of disturbance.

In a field experiment we thirdly investigated the impact of sward botanical composition (sward type) and sward degradation on the foraging behaviour of chickens. Monoculture swards of nine grasses and five forbs and a mixture of these fourteen species, which had also been used for the first experiment, were stocked with chickens at three levels of stocking duration. The frequency of the animals' plant pecking, ground pecking and scratching behaviour were recorded. Our results showed that sward type and sward degradation had a significant effect on the foraging behaviour of the chickens. Prolonged stocking significantly reduced the canopy cover of green vegetation; however, the tested sward types strongly differed with regard to the degradation caused by standardised levels of stocking duration. Our data revealed that the frequency of total sward-directed pecking (plant and ground pecking together) declined with prolonged stocking and with decreasing canopy cover in most of the sward types. This result may be relevant for considerations on animal health and welfare, because in environments which offer little incentive for object-directed pecking, there is the risk of pecking to be re-directed towards conspecifics and hence for feather and injurious pecking to occur. We derive from our results that the choice of plant species for sward establishment is a strong determinant of the animals' behavioural interactions with the sward. Species like $P$. supina which feature a high resistance to the damaging effects of stocking with chickens and which at the same time provide high incentive for foraging behaviour, particularly for plant pecking, benefit the contribution of the outdoor run to animal health and welfare.

In synopsis of these three experiments, our results have shown that the choice of plant species for greening outdoor chicken runs is a relevant factor for the realisation of multifunctional swards for outdoor chicken runs. Plants which feature a high canopy cover and biomass accumulation under conditions of prolonged long-duration stocking enhance the potential of the sward for soil and water protection in view of the high amounts of excrement deposition in the run area. A sward composition which additionally highly triggers swarddirected pecking behaviour in the chicken can foster animal health and welfare. Among the plants we tested within the present study $P$. supina altogether featured the best results with regard to these criteria; F. arundinacea showed a high resistance to stocking with chickens, but was comparatively less attractive for pecking than the other species. We conclude that the choice of plant species is a promising complementary measure of run management in addition to established practices like rotational grazing with rest periods of sufficient duration and to providing incentive for the animals to evenly use the total of the run area. 


\section{Zusammenfassung}

Das Ziel der vorliegenden Arbeit war es, die Eignung von vierzehn Pflanzenarten des Wirtschaftsgrünlands für die Etablierung von Grasnarben für die Hühnerfreilandhaltung zu untersuchen. Neun Gräser und fünf Kräuter, deren hohe Leistungsfähigkeit aus intensiv bewirtschafteten Systemen, und deren gute Schnitt-, Weide- und Trittverträglichkeit bekannt sind, wurden vergleichend bewertet.

In einem Feldexperiment wurde die Verträglichkeit der Pflanzen gegenüber Beweidung mit Hühnern untersucht. Die Hypothese lautete, dass sich die Leistungsfähigkeit der Arten deutlich unterscheiden würde, da die Störung, die durch Beweidung mit Hühnern erzeugt wird, stärker und von anderer Natur ist als in anderen Bewirtschaftungssystemen. Monokulturen und eine Mischsaat der vierzehn Arten wurden einer Umtriebsbeweidung mit Legehennen in drei Stufen der Weidedauer unterzogen. Die Wirkung der Faktoren Pflanzenart, Weidedauer und Umtrieb auf Bodendeckung, Dichte der Triebe und Vegetationspunkte, und Wachstum der oberirdischen Biomasse wurde analysiert. Aus ersteren Zielgrößen wurde die Resistenz der Grasnarbe gegenüber der Beweidung abgeleitet, aus der dritten ihre Resilienz. Die Hypothese, dass sich die untersuchten Arten stark im Hinblick auf ihre Resistenz und Resilienz gegenüber Beweidung mit Hühnern unterscheiden würden, wurde bestätigt. Unsere Ergebnisse deuteten darauf hin, dass Gräser prinzipiell besser für die Bepflanzung von Auslaufflächen geeignet sind als Kräuter. Die Arten Festuca arundinacea und Poa supina zeigten mit einer Bodendeckung von über $80 \%$, einer konstanten Triebdichte und einer gleich bleibenden, vergleichsweise hohen Wachstumsrate von mehr als $4,8 \mathrm{~g}$ Trockenmasse $\mathrm{m}^{-2} \mathrm{~d}^{-1}$ die beste Leistungsfähigkeit bei wiederholter Beweidung und langer Weidedauer.

In einem ergänzenden Gefäßversuch im Gewächshaus wurde untersucht, welche mit der Wuchsform in Zusammenhang stehenden Eigenschaften die Toleranz der Pflanzen gegenüber Beweidung mit Hühnern erklären. Die Hypothese bestand darin, dass die Biomasseallokation vor der Störung und die Lage von Speicherorganen und Knospen für klonales Wachstum die Schädigungstoleranz bestimmen würden; sie würde bei Arten hoch sein, bei denen diese Organe konzentriert an der Sprossbasis und unterhalb von oder nahe der Erdoberfläche liegen. Eine Auswahl der im Freilandversuch verwendeten Pflanzenarten, die drei Wuchsformen repräsentierte (Arten ohne Ausläufer; Arten mit Stolonen; Arten mit Rhizomen) wurde einer standardisierten mechanischen Schädigung in drei Intensitäten ausgesetzt, welche zugleich auf Spross und Wurzel wirkte. Die Ergebnisse dieses Versuchs zeigten, dass die Pflanzenart, nicht aber die Wuchsform die Toleranz gegenüber Schädigung bestimmten. Die höchste Toleranz wurde bei F. arundinacea und Poa pratensis festgestellt. Der Wiederaufwuchs oberirdischer Biomasse war über alle Arten und Intensitäten der Behandlung hinweg stark mit der relativen Wurzelbiomasse (der Wurzelbiomasse der 
behandelten Pflanze im Verhältnis zu der der Kontrollpflanze) korreliert, allerdings nicht mit der Wurzelbiomasse vor der Behandlung. Die Resistenz der Wurzel gegenüber mechanischer Schädigung ist daher offenbar eine wesentliche Determinante der Toleranz gegenüber der untersuchten Störung.

Schließlich wurde der Einfluss von botanischer Zusammensetzung und Degradierung der Grasnarbe auf das Nahrungssuchverhalten der Hühner untersucht. In dem oben erläuterten Feldexperiment war die Häufigkeit der Verhaltensweisen Picken an Pflanzen, Picken am Boden und Scharren aufgezeichnet worden. Aus den Daten ging hervor, dass Pflanzenart und Degradierung der Grasnarbe das Nahrungssuchverhalten der Hühner signifikant beeinflussten. Eine steigende Weidedauer reduzierte die Bodendeckung grüner Vegetation signifikant; allerdings unterschieden sich die untersuchten Pflanzenarten deutlich im Hinblick auf das Ausmaß der Degradierung, die durch standardisierte Beweidungsdauer erzeugt wurde. Bei steigender Weidedauer und sinkender Bodendeckung grüner Vegetation war bei den meisten Pflanzenarten eine Abnahme der Häufigkeit des auf die Grasnarbe gerichteten Pickverhaltens (Picken an Boden und Pflanzenteilen summiert) nachweisbar. Dieses Ergebnis wird als bedeutsam für das Tierwohl erachtet, da in Umwelten, die wenig Anreiz zu Picken an Objekten bieten, die Gefahr besteht, dass die Tiere vermehrt Federpicken zeigen. Wir leiten aus diesen Ergebnissen ab, dass die Wahl von Pflanzenarten wie P. supina, die sowohl eine hohe Resistenz gegenüber der durch Beweidung verursachten Störung aufweisen, als auch einen starken Anreiz zu Nahrungssuchverhalten, und insbesondere zu Picken liefern, als Begrünung den Beitrag der Auslauffläche zu Tierwohl und -gesundheit fördern können.

Zusammenfassend haben unsere Experimente gezeigt, dass die Wahl der Pflanzenart zur Auslaufbegrünung ein wichtiger Faktor zur Gewährleistung der Multifunktionalität der Grasnarbe ist. Pflanzen, die bei langer Beweidung eine stabile Bodendeckung und starkes Wachstum aufweisen, können einen höheren Anteil der im Auslauf anfallenden Nährstoffmengen binden und tragen somit zum Schutz von Boden und Wasser bei. Eine Grasnarbe, die zusätzlich das Nahrungssuchverhalten anregt, begünstigt Tierwohl und gesundheit. Von den untersuchten Arten zeigte $P$. supina insgesamt das beste Ergebnis in Bezug auf diese Kriterien; F. arundinacea zeichnete sich zwar durch eine hohe Resistenz gegenüber der Störung durch die Beweidung aus, allerdings schien diese Art weniger stark bepickt zu werden. Wir schließen daraus, dass die Wahl der Pflanzenart für die Auslaufbegrünung als eine wichtige Methode des Auslaufmanagements betrachtet werden kann, die etablierte Methoden der Auslaufpflege, wie Umtriebsbeweidung mit ausreichenden Beweidungspausen und eine Gestaltung des Auslaufs, welche die Tiere zur Nutzung der gesamten Fläche animiert, ergänzen sollte. 


\section{Curriculum vitae}

Laura Breitsameter (Dipl.-Biol. Univ.)

born 1st October 1981 in Munich

e-mail: Ibreits@agr.uni-goettingen.de

\section{Academic Career}

2009-2012 PhD student of Agricultural Sciences at Georg-August-Universität Göttingen Department of Crop Sciences, Grassland Science

Research focus: Tolerance of grassland plant species to mechanical damage and drought

2010-2012: Scholar of the Dorothea-Schlözer-Programme of Georg-AugustUniversität Göttingen

2009: Research Associate within the project „Suitability of damage-tolerant plants for greening poultry outdoor runs" (Eignung belastungsfester Pflanzenarten für die Etablierung von Grasnarben für die GeflügelAußenhaltung) funded by the German Federal Office for Agriculture and Food, Federal Programme for Organic Farming (BLE, 06OE202)

2008 Georg-August-Universität Göttingen

Department of Crop Sciences, Agroecology

Scholar within the Haeckel-1b-Cluster of Excellence „Functional Biodiversity Research“, Grassland Management Experiment (GrassMan)

Higher Education

$\begin{array}{ll}\text { 10/2007-03/2008 } & \begin{array}{l}\text { Technische Universität Dresden } \\ \text { Post-graduate course Environmental Planning and Protection }\end{array} \\ \text { 10/2001-09/2007 } & \begin{array}{l}\text { Technische Universität München } \\ \text { Studies of Biology (degree: Diplom) }\end{array} \\ 02 / 2004-12 / 2004 & \text { University of Canterbury, Christchurch/New Zealand }\end{array}$

\section{Extracurricular and voluntary civic activities}

07/2010-12/2012 Equal opportunities officer at the Faculty of Agricultural Sciences, Georg-August-Universität Göttingen

$1999-2010$

Voluntary civic work for Naturschutzjugend im NABU

Göttingen, 19 December 2012 


\section{List of Publications}

as to December 2012

\section{Peer-reviewed journal articles}

Breitsameter L., Küchenmeister K., Küchenmeister F., Isselstein J., 2012: Tolerance to mechanical damage in ten herbaceous grassland plant species. Plant, Soil and Environment 58, 334-339.

\section{Conference proceedings}

Breitsameter L., Dücker R., Jasper J., Isselstein J, 2012. Impact of sward properties on the predictability of forage quality and yield in grassland using remote sensing. Grassland Science in Europe 17, 346-348.

Breitsameter L., Wrage N., Isselstein J., 2012: Regeneration nach Trockenstress und morphologische Anpassung an Wassermangel bei fünf Arten von Futtergräsern. Mitteilungen der Arbeitsgemeinschaft Grünland und Futterbau 13, 198-203.

Breitsameter L., Wrage N., Isselstein J., 2011: Untersuchung der Eignung heimischer Grünlandarten für die Bepflanzung von Legehennen-Auslaufflächen. Beiträge zur 11. Wissenschaftstagung Ökologischer Landbau, 30-33.

Breitsameter L., Wrage N., Isselstein J., 2010: The quest for persistent green in chicken outdoor runs - an investigation on fourteen grassland species. Grassland Science in Europe 15, 916-918.

Küchenmeister K., Breitsameter L., Küchenmeister F., Wrage N., Isselstein J., 2009: Pflanzenarten für Hühnerfreilandausläufe - Wachstum und Eignung. Mitteilungen der Arbeitsgemeinschaft Grünland und Futterbau 10, 219-223.

\section{Further publications}

„Welche Pflanzen für den Auslauf?“ DGS Magazin 22/2012, S. 36-40

„Dauerhalft grün halten“ Landwirtschaftliches Wochenblatt Westfalen/Lippe 31/2012, S. 27

\section{Talks}

Breitsameter L., Isselstein J.: Eignung belastungsfester Pflanzenarten für die Begrünung von GeflügelAuslaufflächen. Eingeladener Vortrag auf der Bioland-Geflügeltagung, Magdeburg, 22 February 2012

Breitsameter L., Isselstein J.: Eignung belastungsfester Pflanzenarten für die Etablierung von Grasnarben in der Legehennen-Freilandhaltung. Biopark e. V., Güstrow, 3 March 2011

Breitsameter L., Wrage N., Isselstein J.: Untersuchung der Eignung heimischer Grünlandarten für die Bepflanzung von Legehennen-Auslaufflächen. Wissenschaftstagung Ökologischer Landbau, Gießen, 17 March 2011

\section{Posters}

Breitsameter L., Wrage N., Isselstein J.: Morphological adaptations to water deficiency and recovery from drought stress in eight native grass species. Adaptation of perennial plants to episodic drought: impact on ecosystems. International Workshop, Göttingen 6-8 October 2010

Breitsameter L., Leppelsack H.-J.: An intensively managed agricultural landscape as habitat of an endangered bird species - woodlark (Lullula arborea) populations in a hop plantations area of Upper Bavaria. Student Conference on Conservation Science, University of Cambridge, Department of Zoology, 22-24. March 2011 


\section{Acknowledgements}

This project was funded by the German Federal Office for Agriculture and Food (BLE), Federal Programme for Organic Farming (BÖL 06OE202). My PhD studies were financially supported by the Dorothea-Schlözer-Programme of the University of Göttingen.

I would like to thank Prof. Dr. Johannes Isselstein for offering me the opportunity to conduct research on this interesting and diverse topic. Moreover, I am very grateful for his support, his excellent supervision of my project and for many times of inspiring conversation about my scientific work.

I am grateful to Prof. Dr. Christoph Leuschner for co-reviewing my thesis, and to Prof. Dr. Dr. Matthias Gauly for being a member of my thesis committee and for helpful discussion on my data.

I thank Dr. Bettina Tonn and Prof. Dr. Nicole Wrage-Mönnig for motivating and encouraging discussion on my research and many a topic beyond.

My acknowledgements also go to the technical staff and the student assistants at the department of Crop Sciences for their help in field work and data sampling. In particular, I thank Barbara Wedemeyer-Kremer for her commitment and valuable contribution to the successful realization of this project.

At this point, I would also like to express my gratitude about the joyful time I spent with the Grassland Science group. I thank all of my colleagues for their good company and friendship.

Finally, I wish to thank all the people who are dear to me for the emotional support they provided to me during times of pressure and doubt. You gave me the encouragement and strength I needed to move ahead and accomplish this piece of work. 


\section{Appendix}

Appendix I

Appendix II
Design of field experiment: plots and dates of stocking

Photographic examples of the response of different sward types to stocking with chickens 
Appendix I Design of field experiment

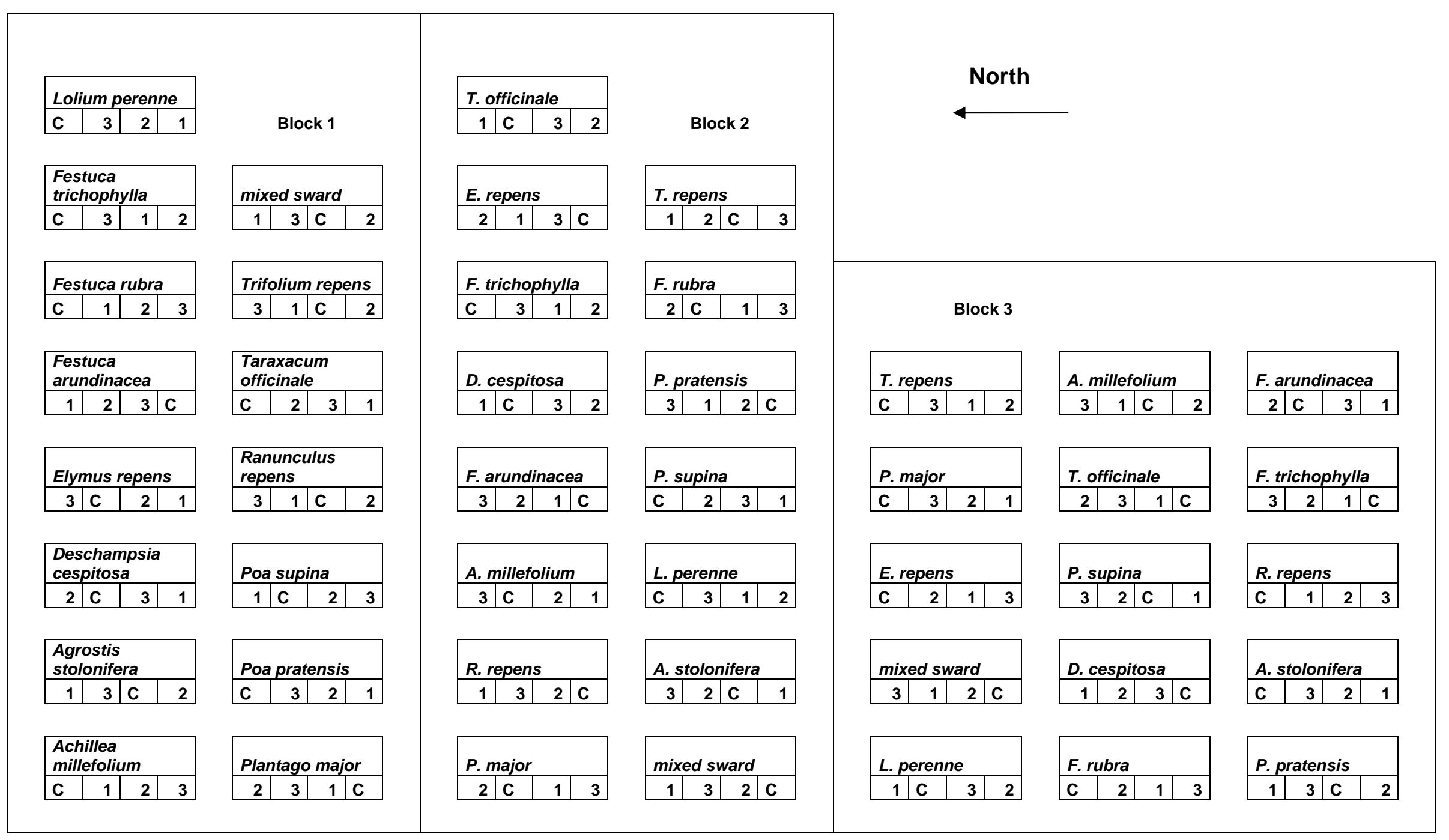

C - non-grazed control; 1 - short stocking duration (1 d); 2 - medium stocking duration (2 d); 3 - long stocking duration (3 d) 
Dates of stocking for the individual subplots in both years of the field experiment

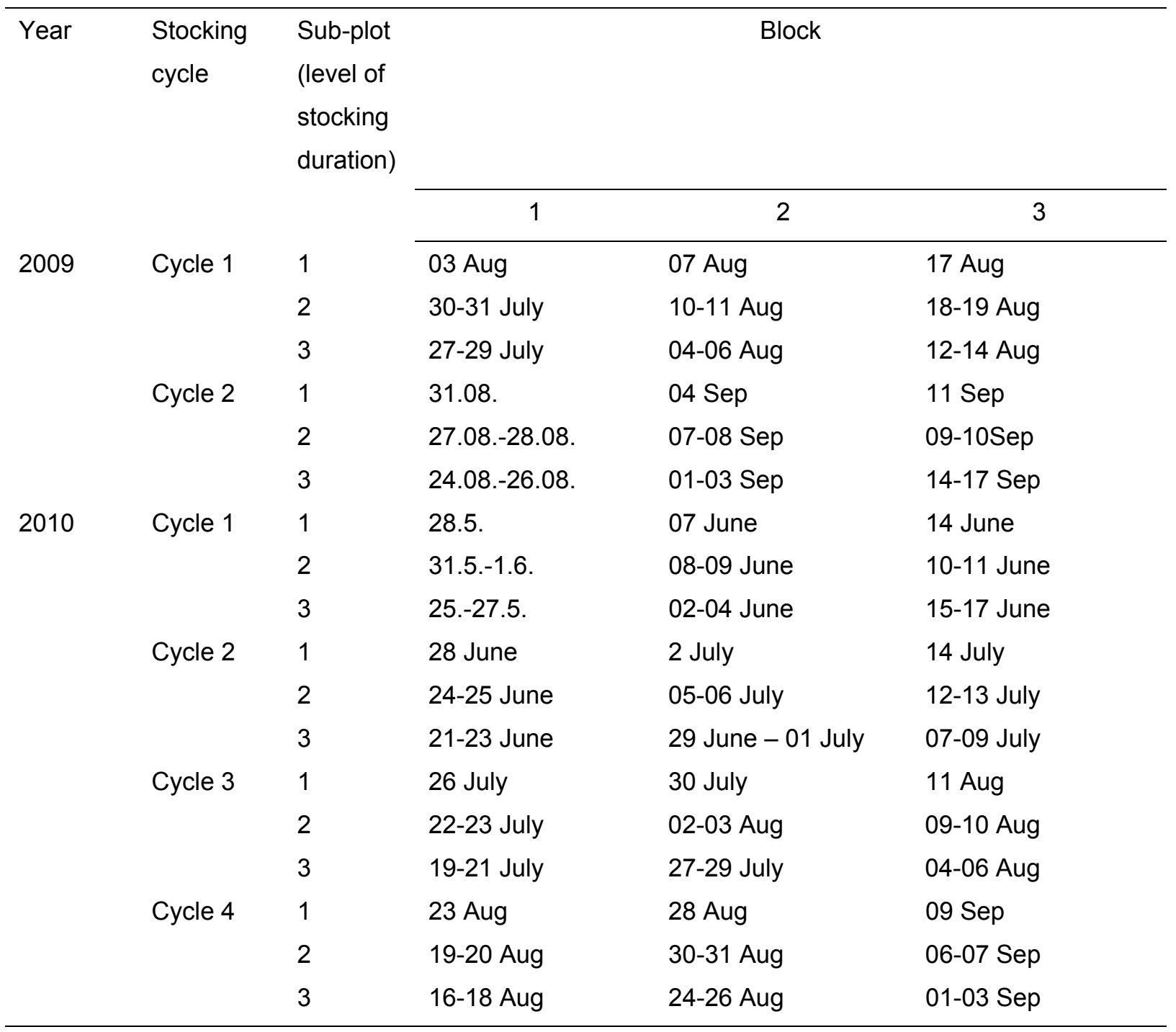


Appendix II

Photographic examples of the response of different sward types to stocking with chickens

a
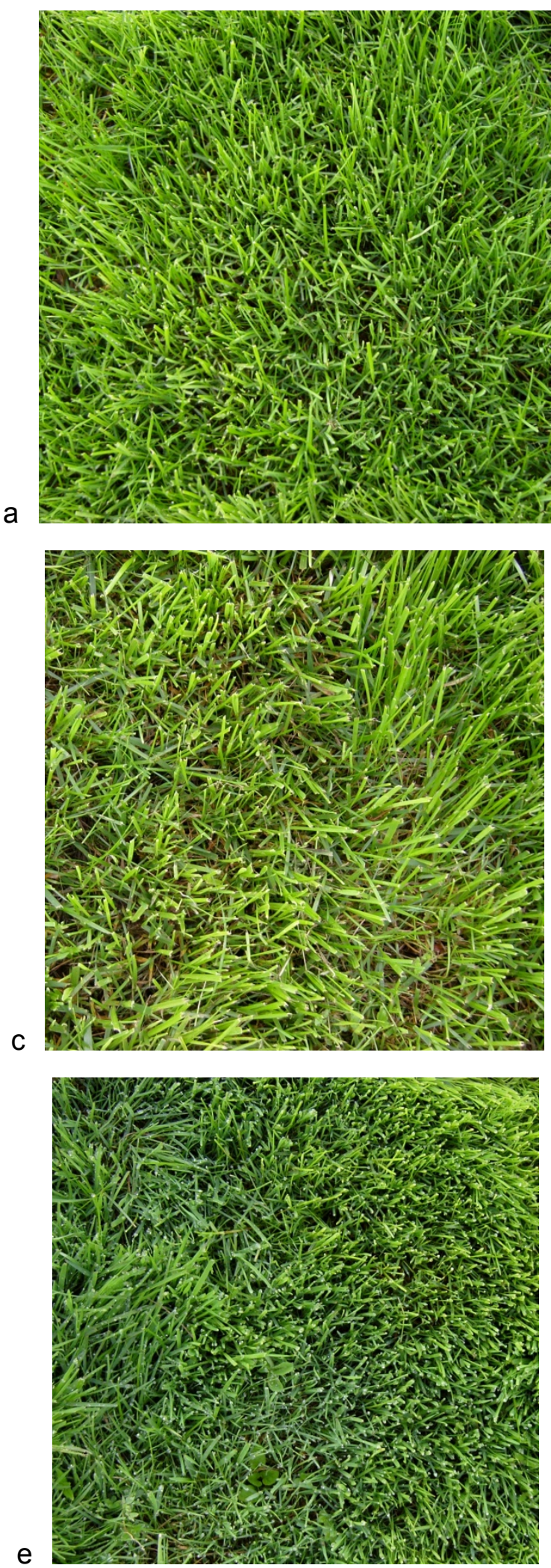

b
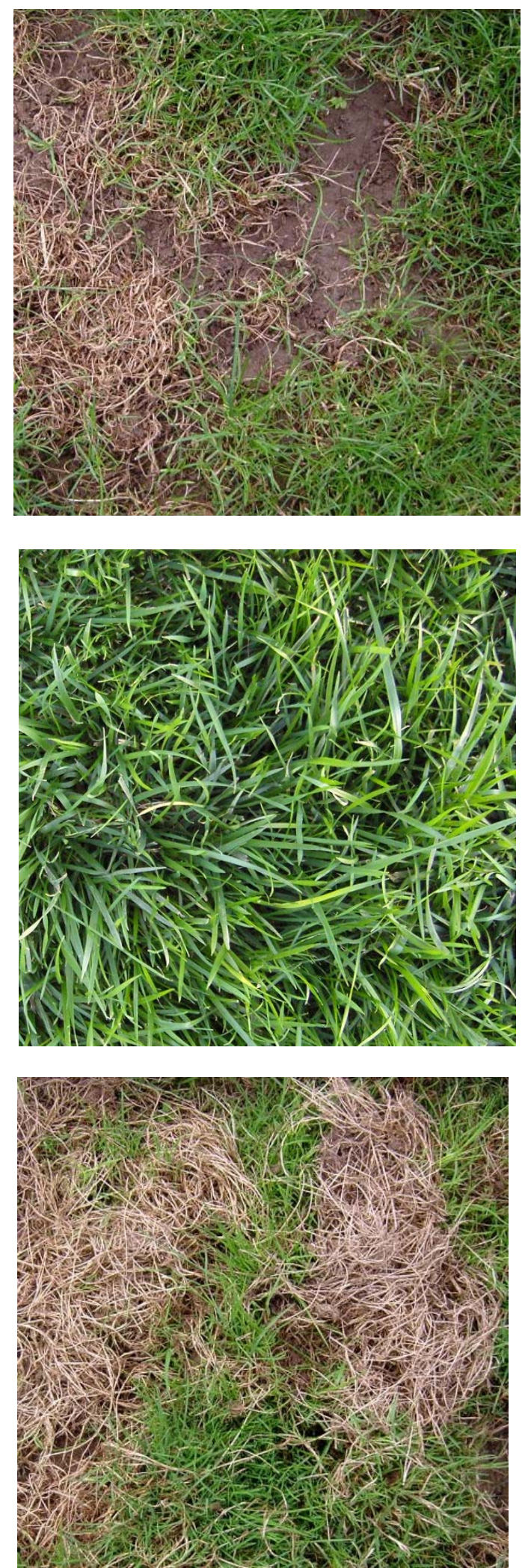

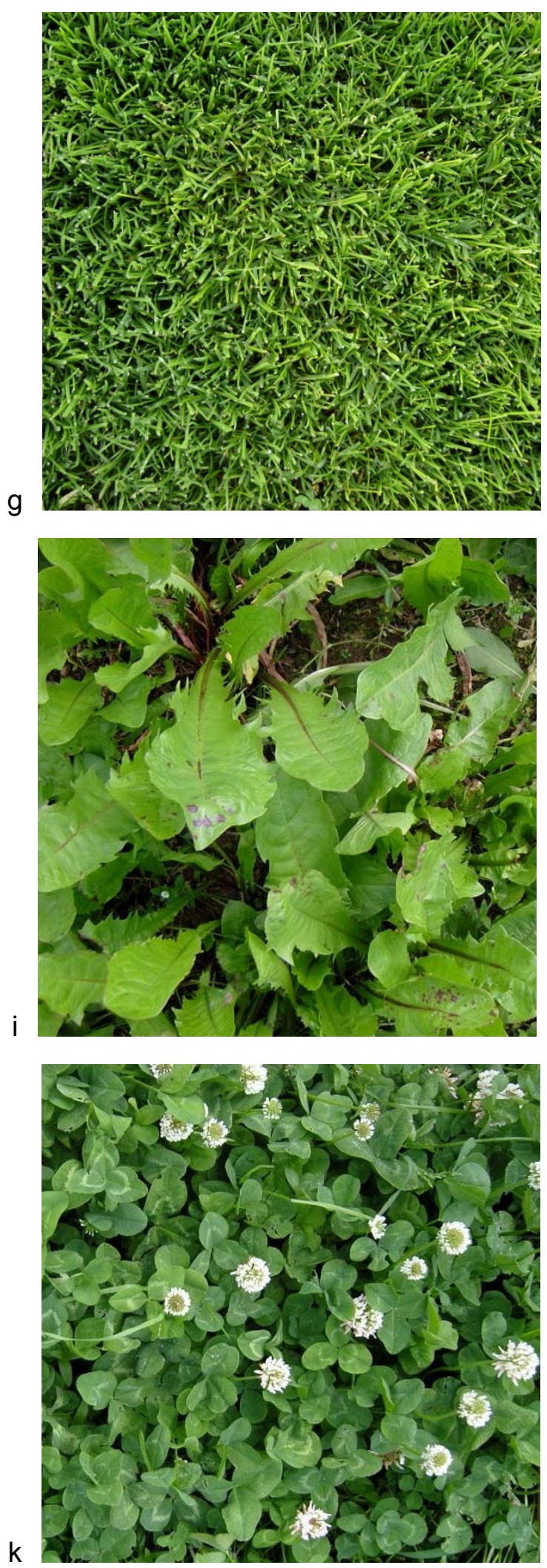

h
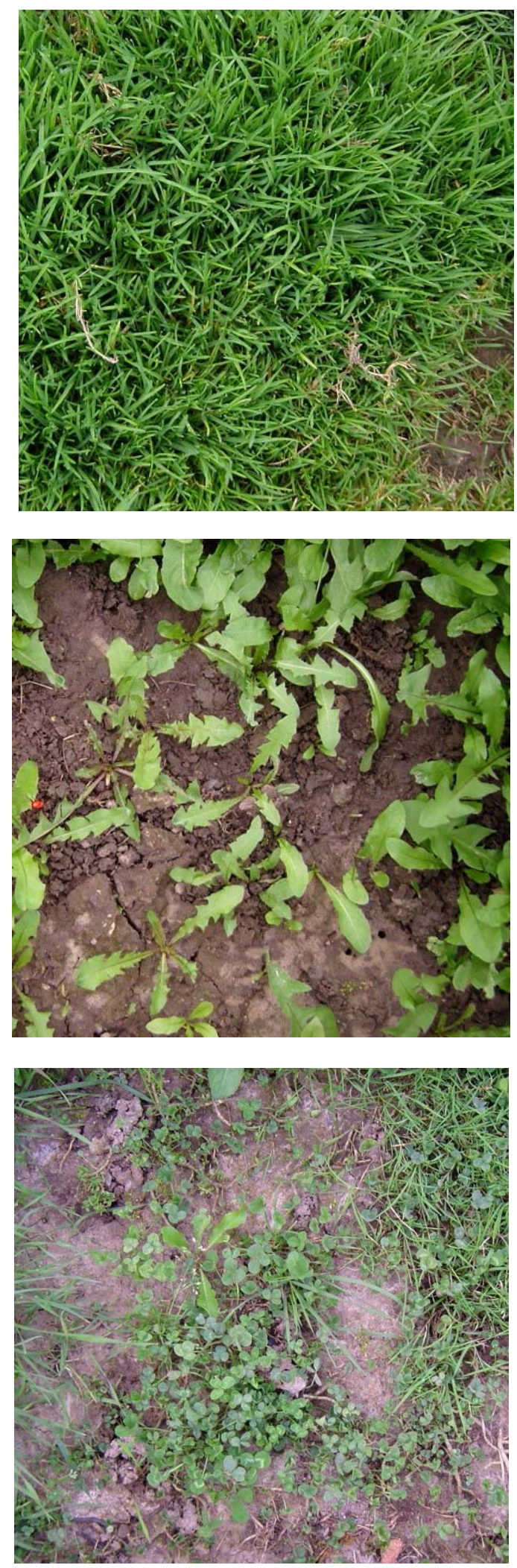

Examples of canopy cover of the swards before the start of stocking in 2010 (pictures left), and after a rest period of four weeks following release from the fourth time of long-duration stocking in 2010 (pictures right). a-b: Lolium perenne 'Bargold'; c-d: Festuca arundinacea 'Mustang'; e-f: Agrostis stolonifera 'Barifera'; g-h: Poa supina 'Supreme'; i-j: Taraxacum officinale; k-l: Trifolium repens 'Rivendel' 